\title{
Policies for Capacity Development
}

\section{Convening Lead Author (CLA)}

Lynn Mytelka (United Nations University-MERIT, the Netherlands)

\section{Lead Authors (LA)}

Ibrahim Abdel Gelil (Arabian Gulf University, Bahrain), Francisco Aguayo (The School of Mexico),

Grant Boyle (McCarthy Tétrault LLP, Canada),

Sylvia Breukers (Energy Research Centre of the Netherlands), Gabriel de Scheemaker (Royal Dutch Shell, the Netherlands), René Kemp (United Nations University-MERIT, the Netherlands), Joachim Monkelbaan (International Centre for Trade and Sustainable Development, Switzerland), Carolina Rossini (Harvard University, USA and University of São Paulo, Brazil), Jim Watson (University of Sussex, UK),

Rosemary Wolson (Council for Scientific and Industrial Research, South Africa)

\section{Contributing Authors (CA)}

Staffan Jacobsson (Chalmers University of Technology, Sweden), Upendra Tripathy (Government of India),

John T. Wilbanks (Creative Commons, Germany)

\section{Review Editor}

Youba Sokona (United Nations Economic Commission for Africa) 


\section{Contents}

$25.1 \quad$ Introduction

25.3 Capacities and Capacity Development for Energy Transitions

25.4.1 Urban Transport. 
25.7.3 Creating Knowledge Networks: South-South, North-South

25.8 Making and Managing Energy Transitions

25.8.1 From Oil to Clean Energy Systems: Policy Learning and Unlearning In Mexico.

25.8.2 Abu Dhabi's Economic Vision for 2030

25.8.3 The Dutch Energy Transition Approach

25.8.4 Moving Towards an Energy Transition

25.9 Enhancing Capacity for Effective Participation at the International Level

25.9.1 Funding Energy Transitions: A Capacity Development Approach.

25.10 Conclusions

25.10.1 Getting There from Here: First Principles.

25.10.2 Making Choices about Energy Transition Pathways.

25.10.3 Policies and Practices in Making and Sustaining Energy Transitions

25.11 Case Studies

25.11.1 Case Study 1: Path Dependence and Lock-in: Decentralized Energy in the United Kingdom

25.11.2 Case Study 2: A Bottom-up Approach for Micro-Hydro in Bhutan.

25.11.3 Case Study 3: How Open Innovation Systems Speed Problem Solving: InnoCentive.

25.11.4 Case Study 4: Creating a Policy Framework for Innovation and Technology Transfer in South Africa

25.1.1 Case Study 5: The Masdar Initiative 


\section{Executive Summary}

This chapter focuses on capacities and capacity development for energy transitions. The transitions put forward in the GEA require a transformation of energy systems that demand significant changes in the way energy is supplied and used today, irrespective of whether the technologies involved are new to the world or to a country, its producers or users.

Energy transitions are, by definition, long-term, socially embedded processes in the course of which capacities at the individual, organizational, and systems levels, as well as the policies for capacity development themselves, will inevitably change. From this perspective, capacity development can no longer be seen as a simple aggregation of individual skills and competences or the introduction of a new "technology." Rather, it is a broad process of change in production and consumption patterns, knowledge, skills, organizational forms, and - most importantly - in the established practices and norms of the actors involved, or what are called informal institutions. In other words, a host of new and enhanced capacities will be needed over time. Informal institutions are reflected in a range of beliefs and boundaries that shape choices about new energy technologies. These can include engineering beliefs about what is feasible or worth attempting and boundaries that shape the processes of choice, such as lines of research to pursue, kinds of products to produce, or practices of consultation and dialogue. They also emerge as "path dependence" in contexts where earlier investments result in high sunk costs, habits and practices are entrenched, and "expert views" are shaped by earlier thinking that narrows the range of choices to established technologies and evaluation techniques.

There is abundant evidence of the slow pace at which new energy technologies are being developed and diffused. Many recent studies have pointed to the continued lack of finance as a serious impediment to the transformation of energy systems in both the North and the South. But finance alone, as this chapter illustrates, does not explain the problems encountered in scaling up projects for energy transitions in developing countries. Nor does it provide a satisfactory answer to the question raised in the GEA as to why, if more energy-efficient and carbon-neutral technologies are available, they are not more widely used. Investments that involve innovative changes are by their nature costly, risky, and likely to deliver returns only in the long term. How, then, might pathways to energy transitions be built today that do not compromise change in the future, especially in poor countries that can ill afford to make the same mistakes that industrialized countries have done and then expend the resources to clean up and rebuild in the next generation? A first step is to better understand the challenges posed by informal institutions because of the way they shape choices in the development of new technologies and affect the speed of technology diffusion in both developing and industrialized countries. A second is to develop the capacities to work with and around existing habits and practices in carrying out energy transitions.

Societies and organizations differ in the extent to which established habits, practices, and norms favor interaction and dialogue or more hierarchical patterns of communication. Until recently, dialogues have not featured centrally in project planning and development. Case studies of the implementation of onshore wind power in Europe and the diffusion of solar home systems in Asia and Africa illustrate that dialogues play an important role in developing and institutionalizing capacities for energy transitions. Dialogues may not "solve" problems, but they do open channels for innovative ways to deal with them.

For dialogues to work, confidence-building measures that recognize the legitimacy of local concerns, interests, and needs, as well as take account of the informal institutions shaping the behavior of actors involved in the change process, are essential in gaining broad societal support for an energy transition. And this is the case whether it concerns the choice of renewable energies, the adoption of smart grids or improved cookstoves, a shift from individual mobility to urban public transport, or the decision to construct energy efficient buildings. At the broader national level, a framework for domestic consensus building that involves the wider community in discussions about key issues and choices and their consequences must be developed. One such approach is to create spaces for dialogue about transition pathways, processes and policies that bring together members of the public and private sector, academics, and civil society in what the Dutch have called "transition platforms." As energy transitions are long term processes, spaces for dialogue at the national level also help to legitimize feedback and facilitate adaptive policymaking overtime. 
The choices made in selecting energy transition pathways and the capacities that will be needed in their pursuit are also inextricably linked to broader development issues and goals. These, too, must become visible as part of a dialogue process and the tradeoffs must be made explicit. The successful implementation of wind power in Germany and Denmark and the targeted bottom-up approaches in the development of small hydro projects in China, Bhutan, Nepal, and Rwanda are examples. The latter illustrate the way mutual interests can be accommodated through dialogues in which local government bodies are brought into the process early in the development of a project and a mechanism for continued dialogue and adaptive policymaking over the life of the project is put in place.

In developing countries, a multi-goal approach can both speed the diffusion of new energy technologies and stimulate the development process. Linking to domestic market building by creating or strengthening capacities for the design, manufacture, distribution, and repair of improved cookstoves and multifunctional energy platforms and the installation of solar home systems have generated multiple benefits such as these. Distributed energy systems based on biofuels are also playing an important role in the broader development process. Developing capacities for making choices about biofuels in technical as well as in economic and financial terms and evaluating these trade-offs are of critical importance in creating such benefits and ensuring their long-term sustainability. Greater attention, for example, needs to be paid to assessing whether, when, and how to scale up the production of biofuels in a given context.

Pursuing a multi-goal approach to energy transitions involves an analysis of local resource availability and the early identification of linkages and support structures that will be needed to build local markets for these new technologies. A multi-goal perspective must then be consciously built into policies, programs, and financing mechanisms. Strengthening the capacities of governments, universities, non-governmental organizations (NGOs), and other organizations in data collection and analysis, research, and problem-solving in the relevant science, engineering and social science disciplines will be essential in supporting such policymaking processes. Developing these capabilities, however, can take many years at a time when decisions about energy transitions that involve biofuels and other clean energy technologies require attention now. This chapter thus explores the role that a variety of different forms of networking for knowledge sharing and collaborative problem solving can play in contributing to the development of domestic capacities for research, analysis, and innovation.

Open innovation practices in industrialized countries are already helping to speed up the pace of problem solving in a growing number of sectors. Users, especially companies, but also government agencies and community organizations, are becoming increasingly aware of these possibilities. The core insight of the open innovation approach is the ability to use the world outside an organization to generate internally useful knowledge in a purposeful manner. This involves the development of networks and the capacities needed to use them. Developing countries are now moving in this direction. In particular, they are strengthening their domestic research sector and linking it to the wider economy through incentives to engage in problem solving, facilitate adaptive changes in the course of energy transitions, and support the process of making choices about energy pathways. Open innovation practices were a critical factor in boosting productivity and reducing costs in the development of ethanol from sugarcane in Brazil, as well as in supporting the growing of jatropha in a multi-cropping environment in Mali and the use of jatropha oil for power and electricity generation.

Designing policies to increase the demand for and supply of clean, energy-efficient technologies, speeding their adoption in sectors such as transport, energy, buildings and building materials, and strengthening their contribution to overall development goals requires the capacity to work from a systems perspective. Bringing key actors together in task forces, panels, and platforms could play an important role here. While not yet widespread, there is evidence that universities in a growing number of countries have created interdisciplinary graduate programs in sustainable engineering that could train a new generation of intermediaries and help change the existing reward structure. But more needs to be done, and more rapidly than in the past, to meet the GEA's goals. 


\section{$25.1 \quad$ Introduction}

"We can't solve problems by using the same kind of thinking we used when we created them." - Albert Einstein

New capacities and new thinking will be needed to take the world to a more sustainable state. This report has outlined the nature and magnitude of the many challenges ahead. Included among these challenges is the need to bring cleaner energy technologies ${ }^{1}$ within the reach of users in the developing world, in terms of both access and price (Chapter 19), and to reduce the negative health impacts of the use of traditional lighting implements, cookstoves and fuels (Chapters 2 and 4). Doing so can create new livelihood opportunities that stimulate growth and reduce poverty, a point we develop in this chapter. From a global perspective, current efforts to reduce greenhouse gas emissions are overwhelmed everywhere by the increasing use of fossil fuels. Thus, worldwide a greater emphasis must be placed on the energy end-use sectors (Chapters 8-10), in order to make use of more energy-efficient technologies and systems, as well as on the supply side, in order to dramatically increase the provision of renewable energies (Chapter 11) while modernizing conventional supply systems (Chapters 12 and 13).

There is abundant evidence of the slow pace at which new energy technologies are being developed and diffused (ESMAP, 2008). Many recent studies have pointed to the continued lack of finance as a serious impediment to the transformation of energy systems in both the North and the South. But finance alone does not explain the problems encountered in scaling-up projects for energy transitions in developing countries. Nor does it provide a satisfactory answer to the question raised in previous chapters as to why, if more energy-efficient technologies are available, they are not more widely used (Chapters $8,9,10,18$, and 22). ${ }^{2}$ In both developing and industrialized countries, lack of knowledge of, and access to - these technologies are major constraints. Meeting the challenges of energy transitions will thus require more comprehensive and integrated approaches to capacity development than those based mainly on building technical and management skills. As one study on capacity and capacity development cautioned, these concepts "are so all-encompassing that practitioners have often found it difficult to make operational sense of them [...] It is [thus] important to begin by asking the question, 'capacity for what?'" (DAC, 2006).

This chapter focuses on capacities and capacity development for energy transitions, with particular emphasis on the pathways explored in Chapter $17 .{ }^{3}$ Capacity is defined here as the ability of individuals, organizations, ${ }^{4}$ societies, and communities to make choices, perform functions,

1 Clean energy technologies are generally defined to include fuels such as natural gas, liquid petroleum gas (LPG), biodiesel, and bioethanol. Some also include carriers such as electricity and end-use devices, e.g., improved cookstoves (Goldemberg et al., 1985; UN AGECC, 2010; see also GEA Chapter 19).

2 This is also the theme of the forthcoming UNIDO Industrial Development Report (UNIDO, 2011). solve problems, and set and achieve objectives in a sustainable manner. Capacity development is understood as the process through which these abilities are obtained, strengthened, adapted, maintained, or changed over time.

Energy transitions are broadly defined as those processes that involve changes to "new," "clean," "sustainable," or "energy-efficient" technologies and the formal and informal institutions required to support them. There is no assumption that energy transitions take place only at the frontier of global knowledge. Moreover, while seemingly very different, energy transitions have much in common. Each involves changes to existing patterns of production and demand that will require new knowledge, skills, organizational forms and habits, practices and norms, whether the process is taking place in a least developed, developing, emerging, or industrialized economy. Because the points of departure for energy transitions are very different across these varied contexts, it is important to develop approaches that enable us to perceive these differences and take them into account in the design of policies, programs, and processes for energy transitions over time.

The transformation of energy systems, irrespective of whether the technologies involved are new to the world or to a country, its producers or users, ${ }^{5}$ is a long-term, socially embedded process that involves a host of other changes that extend beyond merely introducing a new technology. Although capacity development has traditionally been seen as a major concern in developing countries, given the nature and magnitude of the changes needed in energy systems around the world, attention to capacity development is now required globally.

Ultimately, the world must shift to renewable, clean, and green energy sources, zero-energy buildings, and more efficient energy supply systems. This shift will involve multiple interrelated transition processes, each of which will give rise to new capacity issues. As a result, capacity development policies and practices will have to change.

This chapter is structured as follows. Section 25.2 conceptualizes energy transitions. It briefly addresses the theoretical tenets of a transition perspective, as well as how and why it is relevant in helping to understand the levels, processes, mechanisms, actors, and institutions that affect and are affected by technological change. It also introduces the policy dimension in energy transitions. Section 25.3 reviews the capacity development literature and then links the energy transition perspective

3 GEA-Efficiency is a pathway in which energy demand is low and there is a strong emphasis on energy efficiency standards and regulations across all demand sectors. The GEA-Supply pathway focuses on the rapid up-scaling of supply-side options, a necessary condition for achieving a transition where energy demand remains high. New infrastructures and renewables are also important in this pathway. The GEA-Mix pathway is an intermediate transition pathway that emphasizes diversity of the energy supply mix with greater prominence given to local choices and resource endowments and incentives to increase energy efficiency and reduce energy use (see Chapter 17).

4 For example: government agencies, enterprises, universities, farms, and NGOs.

5 This approach to "new" energy technologies is adapted from Ernst et al., 1998 
to the concept of capacity development for energy transitions and the systems-embedded, innovative nature of this process. We argue that models of technology transfer and deployment often fail to appreciate the complexity of change processes, and we introduce the concepts of path dependence ${ }^{6}$ and informal institutions ${ }^{7}$ as analytical tools.

Having thus set out the conceptual framework, subsequent sections discuss specific aspects of capacity development for energy transitions in developed and developing countries. The sections are organized thematically, paying particular attention to a number of capacity issues raised in the three GEA energy transition pathways. These include energy efficiency; the development of new, clean energy technologies and their diffusion; and the choice of energy supply mix and role of local resource endowments in the development of transition strategies. A range of capacities will be needed to develop and implement these strategies in a manner that will contribute to resolving energy access issues and ensure that they make positive contributions to livelihoods and to sustainable development. The six case studies following the conclusions of this chapter amplify the discussions of these challenges.

Section 25.4 addresses the issue of path dependence and informal institutions as impediments to change. Change processes inevitably face challenges that emerge from established interests, habits, practices, and norms. The case studies in this section illustrate these problems in the adoption of energy-efficient technologies and decentralized energy systems. Section 25.5 addresses the importance of dialogue at the local level among relevant stakeholders, illustrated here in the case of wind power. It also stresses local market development and the role of feedback and flexibility at the project level in supporting the diffusion of new energy technologies. Section 25.6 focuses on distributed energy systems and how they can serve multiple goals and bring about multiple benefits at the local level. Examples include the local production of biofuels and the development of small and micro-hydro stations for lighting and stationary power. Access to knowledge and information is critical in the decision-making processes through which choices about the energy supply mix are made. Section 25.7 discusses some of the capacities that are needed to make such choices and new ways of accessing knowledge, including open and distributed innovation processes and the creation of knowledge networks. The latter are also of interest for the role they can play in reducing the brain drain from developing countries.

The "management" of energy transitions is discussed in Section 25.8, which examines the Dutch energy transition approach as an innovative model for creating strategic intelligence for policy and innovation. The Dutch model is of interest to developed and developing countries because of the potential for creative adaptation of three of its core elements: its focus on transformative change, its reliance on bottom-up

6 Path dependence is the tendency for past practices and decisions to shape present choices.

7 Informal institutions include the traditional habits, practices, and norms of actors in the system. processes, and its use of "platforms" to enroll business and other nonstate actors in the energy transition process. This section also looks at how oil producers are adapting to the need for change.

Section 25.9 moves to the international level, which has assumed an important role in energy-related negotiations, particularly with regard to trade and technology transfer. The section focuses on strengthening capacities for effective participation in these negotiations. Section 25.10 draws out a number of "lessons" for capacity development and policies that might stimulate and support capacity development processes for energy transitions. These take the form of pointers and issues for consideration rather than a strict list of what actions to take. Capacity development, as we acknowledge throughout, is a complex process that defies a focus on organizations and a simple management approach.

\subsection{Energy Transitions: Moving Frontiers}

Past energy transitions have been part of broad, systemic processes of change in patterns of production and consumption of goods and services (Smil, 1994; Fouquet and Pearson, 1998; Grubler, 2004). The shift to oil, for example, stemmed from the growing demand for gasoline to power forms of transportation that either did not exist before 1880 (motorized vehicles and airplanes) or relied on the use of wind (ships). The development of automobiles, in turn, owed much to the growing demand for mobility (Geels, 2005). ${ }^{8}$

During each such transition, the old and new energy regimes, based on different technologies, fuels, products, behavior and organizations, co-exist. What is sometimes viewed as a process of technology diffusion is really a more complex transformation process in which a new technological regime grows out of an existing one, with change first occurring in niche markets. The new regime does not emerge in isolation but is connected with the emergence of new technologies, expectations, skills, management systems, supplier-user relationships, ideas, and changes in the regulatory framework (Freeman and Perez, 1988). It sees new fuels and technologies replacing others after a long period of co-existence. Both the technology and social context change in a process that can be seen as co-evolution (Rip and Kemp, 1998). An energy transition thus involves a moving frontier along multiple dimensions. Moreover, these are not deterministic processes, and may fail to emerge or spread, as illustrated in Chapter 19 by the wide gaps in access to modern energy technologies between urban and rural areas of the developing world. Understanding the context in which such transitions occur is critical in bringing about a global energy transformation.

The best theoretical attempt to understand these multilayered processes of systemic change is the transition approach, which is based on a multilevel framework of niches, regimes, and landscapes (Rip and

8 See Chapter 16 for a more extensive discussion of energy transitions in historical perspective. 


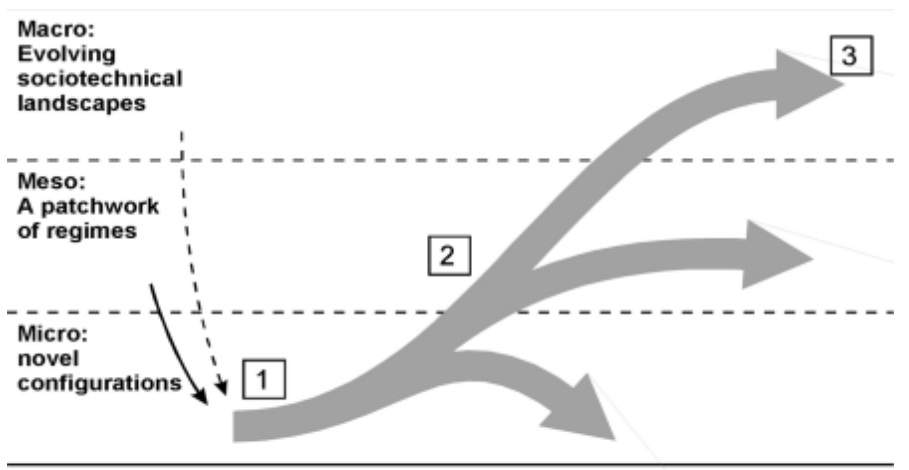

[1] Novelty, shaped by existing regime

[2] Evolves, is taken up, may modify regime

[3] Landscape is transformed

Figure 25.1 | The multilevel transition model. Source: Rip and Kemp, 1996.

Kemp, 1996; 1998; Geels, 2002; 2004; 2005; Geels and Kemp, forthcoming). Central to the transition framework are regimes, i.e., the dominant practices, search heuristics, outlook or paradigm, and the ensuing logic of appropriateness pertaining in a domain - a sector, policy area, or a field of science and technology - that give it stability and orientation and guide decision making (Kemp, 1994). In the case of automobiles, for example, at a high level of aggregation there is a fossil-fuel energy regime, and at a lower level of aggregation there is an internal combustion engine regime for automotive technology. Users are part of a regime that is a component of what Geels (2004) has called the "sociotechnical regime." A regime is an interpretive analytical concept that invites the analyst to investigate the "deep structure" behind activities, e.g., shared beliefs, norms, standardized ways of doing things, heuristics, and rules of thumb (Geels and Kemp, forthcoming). Policy may be involved in promoting or regulating these socio-technical regimes.

Regimes are part of a broader context - the macro landscape of values, infrastructures, settlements, political associations, prices, lifestyles, aspirations, and concerns of people. The landscape may variously sustain a particular regime or put it under pressure. In the case of automobiles, it does both. At the micro level are niches, novelties, and alternative practices (Figure 25.1). Within this scheme, novelties (new products, technologies, or special institutional arrangements) emerge in niches, particular domains of use, constellations of actors, and a geography, all of which are part of a broader world consisting of regimes and landscapes. What happens in each niche is shaped by the external developments with which it interacts. Each of these levels has its own type of dynamics, but developments are interdependent. The diffusion of niche products is constrained by competition from existing, well-developed products and cultural practices.

Transitions are viewed as the outcome of pressures on socio-technical regimes (e.g., cultural criticism, regulations) and the development of alternative products and systems, elements of which are breaking out of niches because of learning economies, support from various actors (including incumbent companies, politicians, civil society) and processes of alignment (Geels, 2002).
The transition perspective has relevance for transitions to energy systems that meet the GEA goals (see Cluster I). Change may occur within an existing regime. For example, carbon reductions may be achieved through technical fixes that leave the logic of the regime intact. Change may also occur through the transformation or replacement of an existing regime with a new regime of energy carriers involving different technologies, practices, paradigms, and institutions. Here, it is important to note that the knowledge and capacity issues involved in adopting technical fixes and creating new regimes are altogether different. The introduction of the catalytic converter as a technical fix to reduce car emissions, for example, required no changes on the demand side or in the powertrain of vehicles. Neither car manufacturers nor users had to acquire special capabilities. In the case of regime-shifting change, however, such as the move to renewables, a wider range of capacity issues are involved in achieving changes in the lifestyles, habits, and practices of users and producers. Society has to create and sustain a capacity for making choices about options and configurations, skills for installation, and knowledge for product development, load management, defining appropriate policies, and adapting policies to changing circumstances.

In order to pursue a path towards an energy transition, a cluster of new technologies will need to be fostered (Jacobsson and Bergek, 2004; Stern, 2006). Energy transitions therefore involve a moving frontier that advances for different technological options at different rates and in different contexts. This has a bearing on both capacities and capacity development processes. When these new technologies come with risks, as they often do in regime-shifting change, the capacities needed to understand the risks, and to contain and manage them, become important. Special government policies and science and technology programs may be needed to stimulate development of the technologies that underpin a new regime, support their diffusion, and guarantee safety, as well as manage transition processes.

Past energy transitions in the industrialized world have included, for example, the transition from wood to coal, from coal to natural gas for power and heating, from gaslight to electric light, the creation of centralized power systems and nuclear technologies, or more recently, the development and diffusion of renewable and clean energy technologies in both developed and developing countries. In many cases, governments have played a role in encouraging transition processes by increasing public investments in science and technology programs, providing market incentives, and introducing regulations and standardization. But governments alone cannot bring about an energy transition. The following section links the energy transition perspective to the capacity development issues that arise from the systems-embedded and innovative nature of the transition process.

\subsection{Capacities and Capacity Development for Energy Transitions}

Capacity building and capacity development have mainly been associated with developing countries in the past, but this is no longer the case. Energy transitions involve a broad set of changes in existing patterns of production 
and consumption, in the knowledge and skills required, the organizational forms, and the business and governance practices, as well as other social habits, practices and norms, whether the process is taking place in a least developed, developing, emerging or industrialized economy. We thus go beyond the traditional development literature to identify a range of capacities that are of increasing relevance in energy transitions. The section begins with a brief review of the early development and "capacity building" literature, its recent evolution, and the challenges it still faces. It then explores issues of capacity development for energy transitions that emerge from the application of an innovation systems approach.

\subsubsection{From Capacity Building to Capacity Development}

The early development literature, as Bouille and McDade (2002) noted, referred to capacities in terms of skills, and the process of creating and/ or strengthening them, as "capacity building." It assumed that relatively few local capacities existed in specific domains and these would need to be transferred ${ }^{9}$ to developing countries mainly through foreign aid and investment. Initially, development agencies focused on providing goods, services, and foreign experts to government ministries in developing countries (UNDP, 2009a), and consequently on ensuring that public sector organizations were capable of managing large public investment programs (Lusthaus et al., 1999).

During the 1990s, a substantial and growing part of the population in developing countries remained without access to energy, although significant investments in energy infrastructure had been realized (WBG, 2003). Donors became increasingly concerned about the effectiveness of foreign aid and this led to major changes in policy, including a rethinking of development assistance practices and the process of capacity building. The policy changes began in 1991, with the publication of a report entitled, Principles for Evaluation of Development Assistance, by the Development Assistance Committee (DAC) of the Paris-based Organisation for Economic Co-operation and Development (OECD). Initially a conversation among donor countries about "the role of aid evaluation in the aid management process," the principles went beyond earlier conceptions of donor-recipient relationships to view development assistance as "a co-operative partnership exercise between donors and recipients" (DAC, 1991). The nature of this partnership was not defined, however, nor were prospective partners included in the discussions. In 2005, this changed when developed and developing countries met in Paris and endorsed the view that capacity development was fundamentally an endogenous process that should be led by the recipient countries, with donors playing a supporting role (OECD, 2005/2008).

9 In the 1950s, development economists such as W. Arthur Lewis and Raul Prebish argued that developing countries were not capturing an adequate share of the gains from technological change. The solution was to industrialize. But the scarcity of capital, skills, and technology made it imperative for these countries to attract foreign investment (Lewis, 1950; Prebisch, 1959). This view subsequently became entrenched in the development literature (see Bell, 1984; Mytelka, 1989; Forbes and Wield, 2002).
The Paris Declaration on Aid Effectiveness sought to address issues of sustainable development that went beyond those of finance. This led to the emergence of a new concept, "capacity development." In contrast with "capacity building," capacity development recognized that some capacities existed everywhere upon which one could build. ${ }^{10}$ The Paris Declaration also took a broader view of the actors involved, moving beyond individuals to include organizations and society (Fukuda-Parr et al., 2002; Bouille and McDade, 2002). The Economic Community of West African States (ECOWAS), in a white paper for a regional policy on access to energy services, agreed, advocating that "capacity-building [should...] be aimed both at private operators (local operators, investors, donors, etc.) and public actors (ministries, regulatory authorities, rural electrification agencies, etc.)" (ECOWAS, 2006). The white paper also stressed the need for linkages across countries within a region (a point to which we return in Section 25.7.3 on knowledge networks).

The capacity development approach understood capacity as an outcome and capacity development as a process. In contrast with standard assessments of individual performance or project outcomes, some of the capacity development literature came to regard participatory monitoring and evaluation at various points in the life of a project as part of a learning process. From this perspective, feedback is a desired outcome that serves not only as a means for measuring progress, but also as an opportunity for "questioning, reflecting, learning and modifying" (IDRC, 2008). More broadly still, tools for evaluative thinking, such as "outcome mapping," adopted by the International Development Research Centre (IDRC), are more attentive to "changes in the behavior, relationships, activities, or actions of the people, groups, and organizations with whom a program works directly" (Earl et al., 2001). This approach has important implications for the kinds of capacities and capacity development processes that are needed for energy transitions (Young, 2008).

The new conceptual insights notwithstanding, "[i]n recent years about a quarter of donor aid, or more than US\$15 billion a year, has gone into technical co-operation, the bulk of which is ostensibly aimed at capacity development. Despite the magnitude of these inputs, evaluation results confirm that development of sustainable capacity remains one of the most difficult areas of international development practice" (DAC, 2006).

The development of sustainable capacity has remained elusive (see Box 25.1), for a number of reasons. One is the persistence of earlier thinking and practices, since "until recently capacity development was viewed mainly as a technical process, involving the simple transfer of knowledge or organizational models from North to South" (DAC, 2006). Such views share with the early development literature a conceptualization of technology as embodied in machinery and equipment, and its transfer and assimilation as automatic and context-free (Bell, 1984; Forbes and Wield, 2002). Development was often seen as a linear process "a sort of race along a fixed track, where catching-up is merely a question of relative speed" (Perez, 1988).

10 Although they differ in their approach to energy transition processes and the capacities needed to support them, the terms capacity building and capacity development are often used interchangeably in the literature. 


\section{Box 25.1 | "We are making progress, but not enough"}

In its 2003 Human Development Report (HDR), the United Nations Development Programme (UNDP) embraced the capacity development approach and stressed the need for initiative and ownership to reside with and in developing countries. This complemented the evolving view of development assistance as a partnership, but it did not resolve the challenges involved in putting such an approach into practice.

Ways to address the many issues of ownership, inclusive partnerships and the effectiveness of aid raised in Paris in 2005 (OECD, 2005/2008) were still being worked out at a follow up meeting in Accra, Ghana, as the Accra Agenda for Action (2008) illustrated. They included the lack of capacities in developing countries to plan, manage, implement, and account for the results of policies and programs; the need to deal with issues of predictability, conditionality of funds, and the untying of aid on the donor side; and the continued difficulties in scaling up for more effective aid.

Source: Accra Agenda for Action, 2008.

During the 1980s and 1990s, researchers in developing countries began questioning the linearity and passive nature of the catch-up process. Effective absorption and diffusion of new technologies, it was found, mainly took place when accompanied by two broad sets of purposive actions:

- innovative practices, such as adapting imported technologies to suit local conditions, adjusting to new sources of inputs, altering the product mix, and resolving bottlenecks in production (Stewart, 1984; Katz, 1985; Mytelka, 1985; Westphal et al., 1985; Lall, 1992); and

- technological learning, by engaging in a process of intensive technological searching and protracted negotiations with prospective sellers or licensers of technology, by adopting a strategy focused on adaptation and upgrading of the original design and by developing in-house research capabilities (Rosenberg and Frischtak, 1985; Katz, 2004; Ernst et al., 1998; Bell, 2009).

Such purposive actions were not easy or cheap, but were often facilitated by a supportive policy environment (Bell, 1984; Kim, 1997; Nelson, 2004). These lessons were soon forgotten, however, and development practice returned to a focus on more passive approaches to technology transfer through development assistance projects and foreign direct investment, rather than on the learning and technological mastery that drove the process of catching up in the "Asian tigers" (Kim, 2004; Mytelka, 2004).

Another factor contributing to the difficulties encountered in capacity development is the continued donor focus on "skills development and individual training" (Baser and Morgan, 2008), with a particular emphasis on upgrading public sector governance (World Bank and IMF, 2004). As those who have adopted "institutional" or "systems" approaches point out, the way public agencies function is shaped as much by the training individuals receive as by their social and political context (Lusthaus et.al. 1999; Baser and Morgan, 2008; DAC, 2006). Inspired by the work of Robert North, they define institutions as the "formal and informal rules of the game," which distinguishes institutions from "organizations" (North, 1994). This approach goes beyond a focus on public agencies to include a wider array of organizations whose involvement in energy transition processes is critical. It also acknowledges that these actors cannot be divorced from the "structures of power and influence," or from the informal "institutions" in which they are embedded (DAC, 2006). From this perspective, training programs can go only so far in bringing about change. Instead, as the business and innovation systems literatures have shown, what often impede change in organizations are the habits, practices, routines, and norms of the actors within the organization and in the wider society (Teece, 1988), ${ }^{11}$ a point developed in the framework presented in Section 25.3.2.

Lastly, an emerging view, more often heard than put into practice, is that the private sector should take on a more prominent role in the design, financing, and delivery of rural and/or renewables-based technologies (van de Vleuten et al., 2007). Public agencies often lack the capacity and motivation to improve rural energy conditions in developing countries and focus quasi-exclusively on urban energy needs, while expecting private actors to address rural conditions. Private firms, local or international, often lack the in-country capacity to deliver the necessary energy carriers or technologies, in part also because policies and regulation do not favor this type of solution.

\subsubsection{An Innovation Systems Approach}

The definition of capacity as the ability of individuals, organizations, society, and communities to make choices, perform functions, solve problems and set and achieve objectives, and of capacity development as an endogenous learning process through which these abilities are obtained, strengthened, adapted, maintained, or changed over time, owes much to the work of UNDP (2008a; 2008b; 2009d). It differs from the UNDP definition, however,

11 An example of how these informal institutions can slow the process of change can be found in Section 25.11, Case Study 1, on the introduction of smart grids in the UK. 
in three important ways. First, as in the broader institutional and systems literature, this definition distinguishes between organizations, such as industries, farms, government ministries, hospitals, universities, non-governmental organizations (NGOs), and informal institutions. Second, it is rooted in an understanding of energy transitions as processes of innovative change that take place interactively across the multiple levels shown in Figure 25.1. Third, it relates to the growing importance of learning and innovation in the processes of development and change.

During the 1980s and 1990s, changes in production and competition in the industrialized countries drew attention to the role of knowledge and innovation in the competitiveness of firms and, by extension, of nations (OECD, 1992). Over time, the knowledge intensity of production extended beyond the high technology sectors to reshape a broad spectrum of traditional and new industries in both developed and developing countries (Mytelka, 2000). In the developing world, this change placed a premium on learning, capacity development, and innovation in the process of catch-up and keep-up, as case studies in Asia, Latin America, and Africa have shown (Ernst et al., 1998; Muchie et al., 2003; Pietrobelli and Rabellotti, 2006). This would lead to a growing interest in innovation systems thinking as a useful approach to contextualizing learning and innovation processes, first in the industrialized countries and, more recently, in the developing world. ${ }^{12}$

As a set of conceptual tools and frameworks, the innovation system approach is still evolving. Since its appearance in the 1980s, the approach has provided comprehensive and integrated analyses of the processes of learning and innovation in various societies and economies. It is particularly relevant to energy transitions, which are broad processes of innovation and change.

An innovation system can be seen as a network of firms and other economic agents that, together with the institutions and policies that influence their innovative behavior and performance, bring new products, new processes, and new forms of organization into economic use (Lundvall, 1992; Nelson, 1993). ${ }^{13}$ The strength of the innovation systems approach lies in its focus on the interactions among these actors and their embeddedness in an institutional and policy context that influences their behavior and performance. Institutions in this sense are not organizations, but "sets of common habits, routines, norms, rules and established practices that regulate the relations and interactions between individuals and groups" (Edquist, 1997) and prescribe behavioral roles, constrain activity and shape expectations, or what we call here informal institutions (Hall and Taylor, 1996; Edquist, 1997; Scharpf, 1997; Storper, 1998; Hukkinen, 1999). These habits and practices are learned behavior patterns marked by the historical specificities of a particular system and

12 In Brazil and South Africa, an innovation systems approach has been applied in research, in industrial surveys, and in policymaking. It has also been adopted by the European Union, by individual Asian countries, and by New Partnership for Africa's Development (NEPAD) for their innovation surveys.

13 The innovation system approach is introduced in Chapter 24. moment in time. As such, their relevance may diminish as conditions change. This is particularly likely during the course of energy transitions, which are, by definition, dynamic processes.

From a policy perspective, the strength of the innovation systems approach lies in the attention it draws to policy dynamics and the way these emerge from the interaction between policies and the habits and practices of the actors whose behavior is targeted by policy (Mytelka, 2000). Policies can be designed to reinforce desirable habits and practices, or to induce change, provided that there is some understanding of the habits and practices of local actors, and that a continuous process of feedback provides the inputs for adaptive policymaking. Learning and unlearning on the part of firms, policymakers, and other actors in an emerging or established innovation system are thus at the heart of its ability to respond to new challenges. Continuous flows of knowledge and information provide critical inputs into this process.

These insights have particular relevance for energy transitions that are long-term processes and will require adaptive policymaking to successfully carry out the broad range of interrelated changes, negotiate the multiple pathways, and manage the risks and uncertainties involved. Capacities at the actor and systems levels can be expected to differ both across socioeconomic contexts and over time in energy transition processes. By conceptualizing energy systems as socially embedded and historically shaped by the habits and practices of the actors within them, the innovation systems approach draws attention to the importance of addressing issues that arise out of these informal institutions, in the design of capacity development policies and processes. Among these are the challenges posed by path dependence, ${ }^{14}$ i.e., the tendency for past practices and decisions to shape present choices, and lock-in, where complementary technologies or products can very quickly gain dominance in a market even if they are inferior. ${ }^{15}$

Path dependence in energy transitions is reflected in a range of beliefs and boundaries that shape choices about new energy technologies. These can include engineering "beliefs about what is feasible or at least worth attempting," and boundaries that shape processes of choice such as lines of research to pursue, kinds of products to produce, organizational routines and development trajectories (Teece, 1988; Mytelka, 2008). ${ }^{16}$ Path dependence also emerges in contexts where earlier investments result in high sunk costs, habits and practices are entrenched (see Box 25.2), and "expert views" are shaped by earlier thinking that narrows the range of choices to established technologies and evaluation techniques.

14 For more on the concepts of path dependence and lock-in, see Chapter 17.

15 The classic example of lock-in is the QWERTY keyboard used in typewriters and maintained in computers, even though the placement of keys makes it inefficient (David, 1985). For further lock-in examples, see Chapter 19.

16 The business literature has recently begun to focus on "taking the bias out of meeting" and strategic plans by "gathering data, discussing analogies, and stimulating debate that together can diminish the impact of cognitive biases on critical decisions" (Lovallo and Sibony, 2010). However, they do not seem to be aware of the way in which past practices can also affect the selection of data and analogies. 


\section{Box 25.2 | Path dependence}

In 2008, the World Bank's International Finance Corporation approved a US\$450 million loan for the Tata Mundra project, designed to build five coal-fired power plants in the Indian state of Gujarat. This illustrates the challenge that path dependence can pose for energy transitions. In this case, traditional norms and practices that oppose the use of subsidies and employ short-term, static cost comparisons to evaluate alternative options, provided the rationale for an energy choice that will have negative implications for India's $\mathrm{CO}_{2}$ emissions in the long term.

The first of the Tata Mundra power plants will be commissioned in mid-2011. It is expected to emit $40 \%$ less $\mathrm{CO}_{2}$ than existing coal-fired power plants in India, but given the lifespan of the new plants, it will contribute "23.4 million tons of $\mathrm{CO}_{2}$ per year" to the environment for the next 2-0 years (IFC, 2009).

IFC vice-president Rashad Kaldany justified this decision on the grounds that, in comparison with other alternatives, "[t]his is by far the least expensive and to try to do something like either wind or solar would cost huge amounts in terms of subsidies" (Wroughton, 2008). While this may be true in the short term, taking longer-term considerations into account, such as the future costs of retrofitting a plant with carbon capture and sequestration technology, or the imposition of a carbon tax on coal-fired power plants, might have altered the choice matrix.

In 2010, the World Bank approved yet another loan for the construction of a coal-fired power plant, this time in South Africa. Once fully operational in 2015, the Medupi power station will emit 26 million tonnes of $\mathrm{CO}_{2} /$ year (Duffy, 2010). Decisions such as these, to support old, polluting technology and to promote new and renewable forms of energy only when they are commercially viable, create further disincentives to change energy demand and supply patterns and make it even more difficult to move down a cleaner energy pathway.

Investments that involve innovative changes are, however, by their nature costly, risky, and likely to deliver returns only in the long term. How, then, might pathways be built today that do not compromise change in the future, especially in poor countries that can ill afford to make the same mistakes that industrialized countries have done and then expend the resources to clean up and rebuild in the next generation? To address this challenge, two complementary approaches are discussed.

One approach involves rethinking the standard economic calculations that have so far failed to take account of social, economic, and environmental costs and their cumulative impacts over time. ${ }^{17}$ The other approach recognizes the long time horizons required to develop industrial production capacity in new energy technologies and to build the necessary infrastructure and markets. It therefore favors developing a portfolio of new technologies and associated industries in parallel, and not in sequence (Jacobsson and Bergek, 2004). From this perspective, the most appropriate policy would be not to select the current "best," "off-the-shelf" technology, as neoclassical economists would prefer, but simultaneously to foster a broad range of technologies and associated industries (Sandén and Azar, 2005)..$^{18}$ Thiswould apply

17 Daniel M. Kammen, the World Bank's new "clean-energy czar," reiterated this point in a recent interview (Broydo Vestel, 2010). not only to traditional leaders in technology, but also to newcomers such as Brazil, China, and India, and to other countries that today only import their capital goods. In the latter cases, the time needed to build up production capacity would, of course, be shorter than developing entirely new industries. As a major Latin American research program in the 1980s demonstrated, even importing, successfully operating, and reproducing technology requires substantial engineering efforts and may take decades rather than years to develop (Katz, 1983)..$^{19}$

A better understanding of informal institutions is also needed because of the way they shape choices in the development of new technologies and affect the speed of technology diffusion in both developing and industrialized countries. Diffusion, as we saw in the previous section, is associated with innovation in organizational routines, new mindsets, practices, and supplier-user relationships. It is thus a context-specific process involving elements of innovation (Kline and Rosenberg, 1986). Much of the literature on energy transformations, especially in

18 For example, F-i-T is an instrument for a broad range, while green certificate markets always select the best off the shelf.

19 The introduction, use, and diffusion of imported solar cells, for example, would require the capacities of local engineering firms to design and deliver whole systems; roof and façade manufacturers, electricians, and architects to incorporate the new technology and extend its applications; and changes in formal and informal institutions to align with the new technology. See the cases of Bangladesh and Senegal in Section 25.5.2. 
developing countries, retains an earlier language - that of technology transfer - or has adopted a new language - that of "technology deployment" - both of which conceive of the process in contextually neutral and linear terms. In most developing countries, for example, technology transfer through donor-supported projects has been one of the principal ways in which "new" energy technologies have been deployed. But they have rarely led to rapid and sustainable diffusion a problem that is widely acknowledged and most often attributed to the general lack of absorptive capacity in developing countries. ${ }^{20}$ Absorptive capacity is only part of the problem, however. The availability of affordable energy technologies, especially for lighting and power, is important, and the habits, practices, norms, and interests of local actors play a major role.

A recent study of capacity development initiatives based on an analysis of 18 case studies, ${ }^{21}$ suggests that donor practices also tend to reinforce path dependence in the project design and implementation phases (Baser and Morgan, 2008), and thus are likely to contribute to the slow diffusion of new energy technologies in developing countries in several ways. Current approaches to capacity analysis are overly focused "on the macro and the aggregate levels such as state building, improved governance and democratization." At the operational level, the experience of managing projects and programs has given rise to an emphasis on "prediction, targeting, control, results and accountability," and an interest primarily in "ideas that are simple, make immediate sense and can be easily integrated into what they are already doing" (Baser and Morgan, 2008).

This section has moved beyond the development literature in its understanding of the range of capacities and the types of capacity development processes that impact on energy transitions. While finance and governance remain major challenges, capacities that will strengthen the flexibility of existing systems to respond to change are critically important in undertaking and sustaining an energy transition. Among these, building the capacity for long-term, dynamic, multi-goal strategic programming and policymaking will be needed. This will not be an easy task in developing countries. It will require vastly increased access to and capacity for the analysis of a continuous stream of domestic and international information and knowledge as inputs to the policy process.

Within the policy process, capacities for individual and organizational learning must be strengthened. In both developing and developed countries, a broader definition for the identification of capacities and capacity development processes to include the learning and

20 For discussions of technology transfer processes and specific cases, see Mytelka, 1985; 1986; Bell and Pavitt, 1997; Kim, 1997; 2003; and Mytelka. 2004.

21 Although the study does not deal specifically with new energy technologies, the cases on education, environmental action, local government support, and NGOs are relevant for issues raised in this chapter. unlearning of habits and practices by all actors in the "innovation" system will be needed. "Institutional" capacity development in this sense refers not only to changes in formal rules, legislation, or standards. It also calls for innovation in organizational routines, mindsets, and feedback mechanisms, as well as the creation and strengthening of new networks that enhance interactions and enable learning processes. ${ }^{22}$ From this perspective, capacity development for energy transitions aims to embed new practices and the technologies that are part of these practices, within existing social contexts. The next section explores this process in the context of energy efficiency in diverse environments.

\subsection{Path Dependence and Informal Institutions}

Path dependence and informal institutions have been important contributing factors to the limited acceptance and slow diffusion of a wide variety of new energy and energy-saving technologies. This section illustrates these challenges with reference to the adoption of new and potentially more efficient energy-related practices and energy technologies in urban transport, energy services, buildings, and construction materials. While energy efficiency is often simply a palliative practice within an existing regime, ${ }^{23}$ it can - and should - become a pathway towards a regime-altering energy transition. We therefore look at where and how this is being done, and what lessons might be drawn from these experiences for the kinds of capacities and capacity development processes that are needed.

\subsubsection{Urban Transport}

In the 1960s, major cities in Europe and North America began to develop and implement urban transport policies. These policies were sometimes implemented in collaboration with national governments and the private sector, and then followed decades of fluctuating oil prices and increased traffic congestion and pollution. These policies were not particularly regime-altering. They focused on the creation or extension of metro systems, the reintroduction of the electric trolley, and the development of light rail systems and, more recently, of bus rapid transit (BRT) lanes. ${ }^{24}$ To a lesser extent, they have also included partnerships that could significantly alter urban transport technologies by accelerating the adoption of electric and hydrogen fuel-cell

22 See the discussions on open innovation systems and knowledge networking in Section 25.7.

23 A contemporary example is the introduction of energy efficiency standards for automobile engines, not to discourage their use but as a means to deal with energy security issues by reducing consumption of imported gasoline.

24 For an overview of these systems, see Chapter 9. 
vehicles, notably in urban bus networks. ${ }^{25}$ There are also experiments that might lead to substantial changes in personal mobility practices, such as the Velib self-service, subscription-based, bicycle hire system launched in Paris in 2007 (C40 São Paulo Summit, 2011) and, more recently, the development of similar programs for automobiles. All of these approaches aim to reduce the use of cars in urban environments by working with existing habits of personal mobility, but around the practice of doing so through personal vehicles that clog city streets and collectively generate far more $\mathrm{CO}_{2}$. European cities are at the forefront of these initiatives.

The first decade of the $21^{\text {st }}$ century also marked an important watershed in human history when, for the first time, more than $50 \%$ of the global population are urban dwellers (see Chapter 18). Many of the world's mega-cities are located in developing countries where energy and transport policy and planning are weak and public transport systems do not meet emerging needs. The situation is particularly problematic in Africa (Davison and Sokona, 2001), but it has emerged in the new millennium as a major challenge in cities across the developing world, largely as a result of the continued growth in urban populations and in the use of automobiles. ${ }^{26}$

A number of strategies have been developed to deal with this problem and to attract automobile users to switch to public transport systems. Some of these strategies have emphasized energy efficiency and linked it to a process of ensuring the survival of the public bus systems. In the case of the Bangalore Metropolitan Transport Corporation (BMTC), this required significant changes in government policies and in the management of the corporation (see Box 25.3).

\section{Box 25.3 | Bangalore Metropolitan Transport Corporation}

Until August 1997, when it became an independent state-owned corporation, the Bangalore Metropolitan Transport Corporation (BMTC) was typical of India's public bus companies. Its revenues failed to cover costs, and buses were old and inefficient in their use of fuel and polluting. Morale and discipline among workers was low, strikes were frequent, a lack of managerial skills contributed to poor operational efficiency, and there was little scope for introducing changes from the bottom up.

When financial support from the Karnataka State government was not forthcoming and transport services were threatened with privatization, BMTC's management needed to develop a new strategy. They began by bringing the workforce on board. Training, more transparent management practices, and innovative labor welfare measures encouraged workers to be more attentive to maintaining their buses and ensuring compliance with pollution norms. Increasing the number of bus depots from 13 to 29 made it possible to monitor fuel consumption more closely and improve maintenance practices and operational efficiency. As revenues grew, BMTC was able to retire 1700 aged vehicles and purchase 2974 new ones that met European standards.

BMTC also worked hard to change traditional practices in its relationship with the Karnataka government, and in 2003 set up a cell to create an environmental plan for the company and develop closer working relationships with the Karnataka State Pollution Control Board. By 2007, in comparison with Mumbai, Delhi, Chennai, and Ahmedabad, the BMTC had the highest bus to population ratio, the youngest bus fleet, and the best fuel economy ratio. It was also India's only large profit-making state transport corporation. The BMTC has received many awards in the field of affordable public transport, and fuel efficiency in urban services. Perhaps the most important impact, however, was the federal government's decision to diffuse the BMTC model across India's cities.

Source: Torres-Montoya, 2007; Tripathy et al., 2008.

25 These began with the California Fuel Cell Partnership, launched in 1999, and a series of EU programs designed to test hydrogen fuel cell (HFC) buses and refueling stations in some member states (e.g., the CUTE and ECTOS programs). These programs have expanded through collaboration with municipalities, regional governments, and industry in the building of hydrogen refueling infrastructure across Europe and the introduction of HFC and electric HFC buses and other vehicles into commercial use. See the Hydrogen Bus Alliance (www.hydrogenbusalliance.org) and HyRaMP, the European Regions and Municipalities Partnership for Hydrogen and Fuel Cells (www.hy-ramp.eu).
26 The challenge presented by urban population growth and increased automobile use has been particularly acute in Beijing (since the Olympic Games in 2010), in New Delhi (despite the conversion of bus and taxi fleets to less polluting compressed natural gas), Bogota, and Mexico City. Over the past few years, in each of these countries, city and national governments have combined forces to develop transport, urbanization, and related strategies to overcome this problem, sometimes with external funding from, for example, the Clean Development Mechanism in the case of Bogota, and the Clean Technology Fund in the case of Mexico City. 
Other strategies have focused on the issue of access to transportation and the role it can play in achieving broader development goals. Several of these initiatives have been supported by local mayors. Curitiba, capital of Brazil's Paraná state, was a pioneer in that respect. Driven by population growth, the city moved away from earlier urban planning efforts based on the automobile, to the design of a master plan, adopted in 1965, for integrated transport and urban planning. As it evolved, the plan focused on the development of a public transport system that was unique at the time - the BRT system (Lindau et al., 2010).

There are now 47 BRT systems worldwide, and more are under construction (see Chapter 9). Among developing countries, 16 cities in Latin America have built BRT systems, and the model has spread to Asia. Africa, however, lags far behind. In sub-Saharan Africa, only Johannesburg, South Africa's largest city, has thus far built the first line of its BRT system, Rea Vaya. ${ }^{27}$ Focused on the need to overcome the legacy of apartheid, Rea Vaya links Soweto residents to Johannesburg and is interconnected with the city's other transport networks, Metrorail and the Gautrain. Rea Vaya buses are powered by fuel-efficient diesel engines that meet stringent Euro 4 emissions standards. ${ }^{28}$ To the extent that it induces the anticipated $15 \%$ of car users to shift to public transport, Rea Vaya is expected to substantially reduce $\mathrm{CO}_{2}$ emissions. ${ }^{29}$

Despite the attractiveness of these transport systems - more frequent bus services, low fares - the use of private cars continues to grow (see Chapter 9). While access to cleaner and more efficient transport systems potentially influence the behavior of urban and peri-urban residents, more is needed to change established habits and practices with respect to the choice between personal and public transport. On the whole, BRT systems, moreover, have not moved away from standard bus technology and imported petroleum-based diesel fuel. There is some tentative movement in this direction in a few larger cities - for example, in the production of biodiesel and its use in some delivery vans in Cape Town, South Africa, and the development of biodiesel in Brazil. ${ }^{30}$ But, of more interest is the spontaneous development in the production and use of biodiesel for the more traditional minibus/ matatu/tuk-tuk sector, which plays an important role in urban transport in many developing countries.

\section{Box 25.4 | Biodiesel initiative in Tanzania}

After years in business in the United States, a Tanzanian national returned to his home country and established Mafuta Sasa Biodiesel in 2008. Tanzania consumes over two million liters of petroleum diesel daily, all of which was imported when the company was founded. Mafuta Sasa is positioning itself to replace $2 \%$ of Dar es Salaam's diesel market with biodiesel from used cooking oil that has been chemically transformed into biodiesel suitable for use in diesel engines or generators. Matatu owners, the company's principal customers, can now purchase biodiesel at a price $20 \%$ lower than that of imported petroleum diesel.

Source: Mwakilasa, 2008; Mafuta Sasa, 2011.

These two examples notwithstanding, given the continued rise in automobile use in growing urban areas, greater efforts will be needed to integrate urban planning and energy policy with other policies that affect the habits and practices of actors on both the demand and the production side (Sinha, 2003; Mutizwa-Mangiza, 2009). Only then can we move away from the car culture of the past and towards more energy-efficient and environmentally sustainable transport systems of the future.

\subsubsection{Smart Grids}

Problems of path dependence and informal institutions also impact on the speed with which new energy-related technologies diffuse in

27 Accra, the capital of Ghana, is beginning construction on its future system, an elevated monorail that will allow maximum use of existing streets and walkways. the industrialized world. Sunk costs in centralized grid systems and the engineering skills that maintain them or, as we show in the next section, traditional cement plants that cannot easily be converted to the production of low-energy/low-carbon cement, for example, explain some of the reluctance in adopting these technologies. In other cases, the costs of conversion and "cost-sharing" formulas may be controversial, also

28 The first European emissions standards date from a 1970 directive. Each amendment to this directive is numbered consecutively: Euro 1, Euro 2, and so on. Euro 4 dates from 2005 .

29 Estimates of expected $\mathrm{CO}_{2}$ savings from Rea Vaya can be found on the City of Johannesburg website (City of Johannesburg, 2011). Similar estimates exist for Bogota's TransMilenio (ESMAP, 2009) and Mexico City's new BRT lines.

30 In the city of Sao Paulo, a new project is now underway to replace diesel in buses by ethanol from sugarcane and an additive (cenbio.iee.usp.br/projetos/best.htm). The project is funded by the European Union. The city has also launched a hydrogen fuel cell demonstration project. 
slowing the process of change. In the United Kingdom, for example, the regulatory formulas that governed distribution network companies until recently did not allow companies to recover the costs of investment in RD\&D for network innovation (Sauter and Bauknecht, 2009). What makes these issues so intractable is the way existing habits, practices, and norms interact with the above factors.

A deeper understanding of traditional habits and practices will be required to overcome the problems associated with path dependence and lock-in that slow the processes of change towards low-carbon energy systems. Two types of lock-in are particularly relevant here. First, most energy systems are locked into a high-carbon pathway and are heavily dependent on fossil fuels (Unruh, 2000). Second, in some countries, there has been an historical lock-in to centralized energy supplies and policymaking. This second form of lock-in has its roots in the search for economies of scale in electricity generation (Foresight, 2008). However, this can be problematic if the transition to more sustainable low-carbon energy systems requires some measure of decentralization. As Chapter 15 pointed out, optimized interconnected networks making use of real time information and modern communications technology linking energy supply sub-systems provides redundancy, robustness and flexibility, that can lower overall costs. Critical elements in the new system include distributed generation and microgrids, integrated in digital smart grids that can monitor and heal themselves. Public-private partnerships are important in achieving this vision. Changes such as these will require the development of new habits, as well as interactive practices and skills.

The United Kingdom's energy system provides an apt illustration of these tensions, since it has both a highly centralized architecture and structure, and is subject to ambitious plans for a transition to a low-carbon economy. Two-thirds of the UK heating demand is met by natural gas from a centralized network (DTI, 2007). Less than $10 \%$ of heat demand is met by off-grid heat generation - i.e., by sources other than gas or electricity. Furthermore, less than $10 \%$ of the United Kingdom's electricity is supplied from renewable energy or combined heat and power (CHP) plants connected to the electricity distribution network. These levels of decentralization are much lower than those in most other northern European countries (WADE, 2006). This centralization of the United Kingdom's energy infrastructure is mirrored in policy frameworks and energy market rules. Local and regional institutions have little say in the shape of energy investment and decision making, except with respect to planning decisions (Foresight, 2008). Only very recently has a legal restriction on the ability of local authorities to sell electricity been lifted (DECC, 2010b).

This centralized approach to energy provision is not necessarily problematic in industrialized countries. ${ }^{31} \mathrm{An}$ analysis by the UK government

31 The centralized approach to energy provision may be more problematic in a number of developing countries, particularly where low population densities and large distances between cities and villages prevent the rolling out of a low-cost infrastructure through the extension of urban energy systems. We discuss a number of alternatives to deal with this problem in Section 25.5.2 on solar home services. shows that there are many ways to meet the United Kingdom's ambitious target of cutting carbon emissions by $80 \%$ by 2050 (DECC, 2009). Some of these are technically possible while relying mostly on centralized electricity generation. However, many of the government's policies and plans rely on significant decentralization - including the strategy to meet the UK share of the renewable energy target, the plans for new economic incentives for local renewable heat, and the desire to have smarter grids that balance electricity supply and demand in more complex ways (DECC, 2010a). To facilitate this, some new policies and regulations have been developed and implemented. Grants for householders to install "micro-generation" in their homes, feed-in tariffs for smaller renewable energy installations, and new incentives for electricity distribution companies are just some of these.

It is too early to tell what impact these schemes will have. The experiences of the household micro-generation grants have been mixed. Frequent rule changes and adjustments created significant uncertainty for householders and installers (Bergman and Jardine, 2009). A key aim of many of them is to build new capacity. In the case of micro-generation, the installers, plumbers, and electricians who work in households need new skills, while distribution network companies need to build up capacity and skills in innovation to complement their business-asusual system maintenance skills (see Case Study 1, Section 25.11 for more details).

\subsubsection{Passive Buildings and Building Materials}

Similar challenges related to path-dependent choices also confront the speed with which new energy-saving materials and the technologies for passive- or even positive-energy buildings ${ }^{32}$ are being taken up, whether in refitting the old or building the new (see Chapter 10). "Novel cements" that use less energy and produce less $\mathrm{CO}_{2}$ during manufacture have been given tepid reviews in industry fact sheets (Taylor and Collins, 2006). The testing of new building materials, moreover, does not figure prominently on the agenda of voluntary initiatives such as the World Business Council for Sustainable Development's Cement Sustainability Initiative, "Getting the Numbers Right," which focuses on the development of sector-specific $\mathrm{CO}_{2}$ accounting and reporting protocols (WBCSD, 2009). In 2009, MIT researchers announced that the basic molecular structure of cement has now been decoded, opening up new opportunities for working around entrenched habits and practices. As pointed out by MIT Professor Franz-Josef Ulm, a "validated molecular model" will make it possible to manipulate the chemical structure and design new cement and concrete products for both strength and environmental qualities (Brehm, 2009). To speed these new low-carbon products to market, however, will still require funding for $2-3$ years of development and testing to overcome earlier uncertainties among users and producers in the industry. Policies introducing $\mathrm{CO}_{2}$ as a factor in pricing cement,

32 Positive-energy buildings could, for example, supply excess energy to the grid. 
such as carbon taxes or caps on carbon, as well as new building codes and other energy- and environment-related legislation, would widen the market for low-carbon/low-energy materials.

The building sector has also been slow to encourage the demand for such products, and in many countries has found scant regulatory support for doing so, although a few high-profile positive-energy buildings have been built in the last few years, such as the Elithis Tower in France and the Masdar headquarters building under construction in Abu Dhabi. This is now beginning to change.

Progress is now being made in some niche areas that might point to ways of working around and with existing habits and practices in the building sector. C40 Cities, a voluntary group of mayors from among the world's largest cities, is encouraging the emergence of Mayors as champions in energy-efficient and eco-friendly buildings and urban transportation systems. Since the Mayor of Seoul made a commitment to retrofitting in 2007, 87 buildings - 45 public and 42 private - have been designated for retrofitting, and 62 of these had been completed by the end of 2009 (Oh, 2009). Holistic retrofits "can achieve 50-90\% final energy savings in thermal energy use in existing buildings with cost savings typically exceeding investments," but GEA scenario work demonstrates a significant lock-in risk. If building codes are introduced universally and energy retrofits accelerate, but policies do not mandate state-of-the-art efficiency levels, substantial energy use and corresponding greenhouse gas (GHG) emissions will be locked in for many decades (see Chapter 10).

Elsewhere, innovative builders and developers are experimenting with the integration of multiple energy-saving technologies in new building construction. In the United States, with support from federal, state and municipal governments, new housing is being built that combines geothermal heat pumps, energy recovery ventilation systems, and innovative wall insulation technology using solar panels and autoclaved aerated concrete (Colaneri, 2010; McDonough,2008).

The Leadership in Energy and Environmental Design (LEED), an internationally recognized green building certification system launched in 1998, grew out of the environmental NGO movement in the United States. ${ }^{33}$ Hosted by the US Green Building Council in Washington, DC, LEED has brought together a broad coalition of actors including lawyers, scientists, environmentalists, NGOs, business firms, and government agencies, to define green buildings and to establish common, measurable standards. By 2010, some 400 buildings in the United States and 37 in other countries ${ }^{34}$ had been awarded LEED certification at the

33 This discussion of LEEDS is drawn from the websites of the US Green Building Council (www.usgbc.org), the Natural Resources Defense Council (www.nrdc.org), an environmental NGO whose chief scientist, Robert Watson, was one of the pioneers in the green building movement and founding chairman of the LEED rating system, and M. Landman's list of "LEED Platinum Certified Buildings" based on the database of certified projects (Landman, 2010).

34 These countries include Australia, Brazil, Canada, China, Germany, India, Saudi Arabia, South Korea, Sri Lanka, the United Arab Emirates, and the United Kingdom. platinum level, which assigns points based on criteria such as sustainable site development, water saving, energy efficiency, ${ }^{35}$ materials selection, and indoor environmental quality. LEED certification, especially at the platinum level, is becoming recognized as a mark of quality in green building design, construction, and retrofitting, and is helping to bring about changes in existing norms and practices in the building industry. Developing an appropriate policy and regulatory environment could further encourage this process.

In designing policies to increase interest in energy efficiency solutions on both demand and supply sides of the transport, energy, buildings, and building materials sectors, the capacity to work from a systems perspective is critical. New approaches are required to overcome the reluctance of architects, builders, and engineers to work with new materials or, as we saw in the case of smart grids, to accelerate the introduction of new distributed energy systems. Bringing key actors together on task forces, panels, and platforms ${ }^{36}$ could play an important role here. While not yet widespread, there is evidence that universities in a growing number of countries have created interdisciplinary graduate programs in sustainable engineering that could train a new generation of users ${ }^{37}$ and potentially help to change existing reward structures in the building profession. But more needs to be done, and more rapidly, in order to develop the capacity to integrate knowledge in new ways by, for example, establishing sustainability certificate programs that will attract current building and materials professionals, bring them up to date, and encourage the processes of networking and knowledge exchange.

Strengthening local capacities to design regulatory policies, support programs, and financial stimulus packages that correspond to domestic conditions will also be needed to accelerate the introduction and rapid diffusion of new energy technologies, as we saw in the case of smart grids. But in a long-term process such as an energy transition, developing capacities for and practices of adaptive policymaking will be essential over time as conditions change. Such adjustments may require legislation introducing mandatory review processes or sunset clauses that provide for the automatic phase-out of existing legislation.

\subsection{Dialogue, Market Building, and Diffusion}

Societies and organizations differ in the extent to which established habits, practices, and norms favor either interaction and dialogue or more hierarchical patterns of communication. They may be based on

35 A reading of their on-line literature does not make it clear whether certification at the platinum level implies a passive plus building (www.green-buildings.com/ content/781911-leed-certification-conspiracy).

36 Platforms are discussed in the Dutch transition approach (Section 25.8.3).

37 These include prestigious institutions such as Kyoto University in Japan; KTH Royal Institute of Technology in Sweden; the Indian Institute of Technology in Mumbai; the University of Cambridge in the United Kingdom; and Stanford, the University of Michigan, and MIT in the United States. 
intense interactions or go-it-alone practices, accepting of criticism and the need for change, or see all criticism as negative and build little feedback and few mechanisms for introducing corrective action into project design and implementation. This section explores the importance of dialogue in developing and institutionalizing capacities for energy transitions. It illustrates this with regard to the role of dialogues in the implementation of onshore wind power in Europe and in the diffusion of solar home systems in Asia and Africa. In these cases, links to market building were particularly relevant. Finally, the section reviews the slow pace of diffusion of multifunctional energy platforms and improved cookstoves, and assesses the contributions that dialogue and market building might play in the development of sustainable solutions to these challenges. Understanding dialogues is a first step in this process.

Until recently, dialogues have not featured centrally in project planning and development. Instead, in both developed and developing countries, a common approach has involved a top-down, linear process, in which the flows of information and knowledge are driven by governments or the research or business sectors. Communication consists in the transfer of information and knowledge through the distribution of printed materials, awareness-raising campaigns, the internet, and formal training programs. As the literature now stresses, experts must recognize that they have access to only one of many "forms of knowing and valuing," and often lack sufficient knowledge of the qualities of places, problems, potential solutions, and how to make policies work effectively (Gibbons et al., 1994; Healey, 1998; Renn, 1999; DAC, 2006). Consultations involving focus groups, village-level discussions, and stakeholder meetings can give the impression of being two-way processes, but the boundaries of such consultations are pre-established and often provide limited opportunities for those consulted to express interests, needs, and preferences other than those already on the agenda (Gibbs,1997). The process often fails to reach a broad enough range of potential users to stimulate the adoption of flexible processes at the project design stage, and thus few opportunities for adaptive change are built in once a project is under way. Interpreting the results of consultation processes is also problematic if, as the German physicist Werner Heisenberg noted in relation to his work on quantum mechanics, "what we observe is not nature in itself, but nature exposed to our method of questioning" (Heisenberg, 1962).

An interactive dialogue process, in contrast, offers room for the articulation of a broad range of views, interests, preferences, and needs. Preparing for such a dialogue process involves dealing up front with issues of how to proceed, the content, where the information will come from, the form and frequency of interactions, channels of knowledge and information, and the expected outputs and outcomes of the process. Establishing the legitimacy of interactive dialogue processes also extends to the concepts of "monitoring and evaluation," and the need to transform these somewhat punitive sounding - and thus often ignored - activities so that they provide feedback and flexibility in the course of project implementation (IDRC, 2008).

\subsubsection{Dialogue at the Local Level: Wind Turbines}

The deployment of onshore wind farms is shaped by a broad array of national policies, but often involves relatively small-scale, decentralized, and location-dependent applications that need planning consent from local authorities. Successful implementation therefore requires numerous local decisions and investments in the wind farm siting process.

In many countries, national policies favoring wind power have come to signify a top-down imposed development model that takes little note of local land-use planning and environmental issues. They often do not encourage project developers to involve local stakeholders in the design and planning of wind projects. In the Netherlands, ${ }^{38}$ for example, most project developers are accustomed to building large power stations and have little interaction with local stakeholders. They have failed to recognize local planning concerns, sparking opposition to wind farm project from municipalities and other local stakeholders. Dutch energy companies faced difficulties in getting wind projects built in the 1990s and this contributed to the demise of the turbine manufacturing industry. ${ }^{39}$

In the United Kingdom, the limited development of wind power during the 1990s was due to the lack of experience with small-scale, decentralized, and location-dependent technologies, and the dominance of large, established utilities in wind projects. Some of the first large projects were planned in windy areas, which were ecologically sensitive hilly areas where there was no industrial activity. Public concerns and reluctance among local planning authorities resulted. The tradition of grassroots initiatives to protect the landscape subsequently made local opposition to wind projects very effective.

In Germany, in contrast, national policies were more favorable, enabling the grassroots environmental movement to propose locally based wind projects in collaboration with local communities. In the state of North Rhine-Westphalia, for example, federal and state governments responded to the grassroots movement, and in the early 1990s policy support was tailored to the needs of grassroots wind project initiatives. The German feed-in tariff system guaranteed access to the grid and did not discriminate against small, independent initiatives. Thus a diverse range of actors was able to become involved in both turbine manufacturing and project development. ${ }^{40}$ Local ownership has been helpful in mobilizing support from the local level upwards, while the involvement

38 The case studies in Germany, the Netherlands, and the United Kingdom summarized here are drawn from the work of Breukers and Wolsink, 2008; Agterbosch and Breukers, 2009; and Toke et al., 2008.

39 A very different type of project developer, the Dutch wind power cooperatives, adopted a much more collaborative approach, but their impact has remained marginal.

40 In the early 1990s, Denmark also introduced feed-in tariffs. These were not only stable over long periods, allowing investors to plan their projects with confidence, but were also set quite high for the first years. Although the level of subsidies was later reduced, by 2002 almost 2,900 MW of generating power had been installed and a strong industry built. Denmark's main focus in the mid-2000s is on re-powering existing onshore wind farms and on developing offshore projects (UNDP/GEF, 2008). 
of diverse actors at local, regional, state, and federal levels precluded early resistance, as in the United Kingdom and the Netherlands. The institutionalization of environmental concerns in society and in politics also contributed to the successful development of wind projects as a form of local energy activism. Later, when the turbine and related industries were booming, the support for wind power became broader based - wind power represented not only environmental, but also economic (e.g., employment) and industrial (manufacturing and related services) interests.

Habits and practices are not immutable, but are embedded in the broader social context. In Germany, with the rapid growth of the wind energy sector in the late 1990s and the early 2000s, locally based projects have become less evident, and projects are increasingly developed by outsiders. Although local support has waned and resistance has increased, implementation began to decline when an impressive level of capacity had already been installed. North Rhine-Westphalia has achieved more in a generally less conflicting environment than has been the case in either the United Kingdom or the Netherlands.

While some "unlearning" took place in the German context, there seems to have been some "learning" in the Dutch and British contexts. In the late 1990s, Dutch policies no longer favored energy companies over other project developers. Farmers with access to financial support were responsible for a steady rise in the implementation of locally owned projects. These farmer-led projects provide clear local economic benefits and are developed by people who are part of the local political and social contexts. A further advantage is that the farmers own the land on which the turbines can be sited. Moreover, the farmers are well organized at several levels and so have been able to enter into collective negotiations with national energy distributors, local and provincial authorities, etc.

In the United Kingdom, there have been efforts to reinvigorate a "cooperative" tradition for wind power, stemming from the acknowledgement that the projects proposed and planned by "outside" companies are not always successful in gaining local support. In addition to such "community project initiatives," some commercial project developers have adopted a strategy encouraging the early involvement of local stakeholders. ${ }^{41}$ Although there have been successes, the majority of wind turbine projects still meet with opposition from the firmly rooted and increasingly well-organized movement to protect the landscape.

As the case of onshore wind power shows, attempts to speed up implementation of new energy projects without sufficiently addressing local concerns are unlikely to engender societal commitment and acceptance. They may result in stalemate situations where further developments

41 In line with this UK experience, but related to micro-hydro power development in developing countries, Rwanda has encouraged dialogues between beneficiary communities and local entrepreneurs in the development of plans for micro-hydro. See Section 25.6.2. are blocked in a context of conflict and polarization. ${ }^{42}$ One lesson is that energy transitions involving decentralized and location-dependent applications need support from the bottom up from a diversity of actors and networks. Such applications need to "fit" into the contexts for which they are proposed. This is not just a matter of compliance with formal procedures, permits and technical standards, but is very much a social-political process involving local stakeholders.

\subsubsection{Market Building and the Diffusion of Solar Home Services Systems}

For decades, technology transfer through donor-supported projects has been one of the main ways in which new energy technologies have been deployed in developing countries. Although many of these projects were designed to provide energy access for the poor, especially those in rural areas with no access to energy grids, widespread diffusion of these technologies has not followed. This section discusses the problems encountered in the introduction of solar home systems (SHSs) in developing countries, and how they have been addressed.

As early as the 1970s, SHSs were envisaged as off-grid energy services, but the costs and time needed to improve the technology and to build local capacity to produce spare parts and repair the systems drove many away. Although petroleum price hikes temporarily increased interest, efforts to develop SHS technology were not supported by government policies and SHSs were largely abandoned until the mid-1990s.

By this point, the technical performance of SHSs had improved, but producers still faced the challenge of ensuring consistent quality. The absence of quality standards contributed to customer dissatisfaction. Whether treadle pumps, solar water heaters or SHSs, standards and certification are needed "to increase customer confidence [...] and reduce the negative perception arising from low equipment quality, unsatisfactory installation and incorrect operation and maintenance procedures" (GNESD, 2007). The prices of these systems had not come down sufficiently for most rural households, as studies in South Africa and elsewhere have shown (ERC, 2007; GNESD, 2007).

With the exception of Kenya, which has one of the most "dynamic commercial photovoltaic markets in Africa with a non-subsidized demand of 1-1.3 MWp per year that has been growing at an annual rate of $15 \%$ since the mid-90s" (GTZ, 2009), the diffusion of this technology has remained relatively slow in Africa (Hankins, 2011). Ho (2011) notes, "[i]n 2005, Kenya was home to just over 150,000 solar systems with a median size of 25 watts; coverage has since reached some 300,000

42 This point is not limited to onshore wind power, as is shown by a recent example of the long-term process of litigation that characterized the offshore deployment of wind turbines in the US state of Massachusetts. 
households." ${ }^{43}$ Sustained market growth in Kenya has been fuelled by a number of factors. On the demand side, these include the "(r)elatively high incomes among farmers (coffee, tea, horticulture), rural teachers, civil servants and businesses with a strong demand for consumer electronics (TVs, radios, cell phones)" (Ho, 2011) and support from NGOs and missions that provide medical and other services in remote areas that require off-grid power. On the supply side, it has been supported by the availability of photovoltaic (PV) modules in a range of sizes, local battery manufacture, an active entrepreneur class with strong connections between Nairobi and rural areas, and growing government interest. The latter was reflected in the Rural Electrification Program which, working with two foreign companies, installed PV systems in over 150 schools in remote offgrid areas between 2005 and 2009 (GTZ, 2009). With regard to capacity development, however, "(o)utside the solar companies themselves, Kenya has no organized solar energy training programs for artisans or engineers. It does have some university-level courses in alternative energy, but these are fairly basic and do not prepare 'solar engineers' per se" (GTZ, 2009).

With a view to removing barriers to the delivery and financing of SHS, the World Bank and the Global Environment Facility (GEF) initiated a series of pilot projects to provide off-grid solar energy services to rural households in 12 developing countries (Martinot et al., 2001). ${ }^{44}$ The project tested two approaches for the delivery of SHSs - a dealer-sales approach and an energy service company (ESCO) approach - but it left open the possibility of switching from one to the other, or modifying the chosen approach once the project was underway. This flexibility was critical in developing the capacities for learning and adaptation at the project management and local levels that later proved essential in the diffusion of SHSs in a number of countries.

The range of countries in which these approaches were tested lends robustness to the findings and are supported by evidence from other projects introducing SHSs in Kenya, South Africa, Nepal (Brew-Hammond et al., 2008), and Ethiopia (ERC, 2007; UNDP, 2007). Among the main findings of these studies, three in particular stand out.

First, demonstration projects such as these need to be turned into experiments in learning for all partners, including donors, supplier firms, and clients. From the choice of approach for the delivery of SHSs to the type of financing and the focus on capacity building activities aimed at market development, learning through feedback and continuous dialogue were critical in moving the project ahead. This is particularly relevant where there are small market players who are frequently overlooked when the need for scale or minimum quality prevails. Without learning through feedback, opportunities for upgrading can also be lost as local

43 In addition, observations in Kenya also show that a larger number of rural households obtain electricity from car batteries and small PV systems than from the national grid (Jacobson, 2004). This resembles the early automobile industry, where American farmers and rural dwellers used their Model T Fords not only for transport but to run corn shellers, grinders, wood saws, water pumps, and fodder and ensilage cutters (Kline and Pinch, 1996).

44 The 12 pilot projects were implemented in Argentina, Bangladesh, Cape Verde, China, Dominican Republic, India, Indonesia, Kenya, Lao PDR, Morocco, Sri Lanka, and Vietnam. residents and businesses, which initially adopted solutions that were far from ideal, acquired the means to purchase a better system.

Second, the decision to build flexibility into the project design is critical. This recognizes that different habits, practices, norms, and experiences of government staff, suppliers, and users may require adaptive changes along the way. The Sri Lanka project, for example, adopted both dealersales and ESCO models. Early in the project, one dealer decided to shift to the ESCO model but soon found that "the costs of monthly collections among dispersed and remote rural population [were too] high. The firm did not have sufficient rural infrastructure and standing in rural communities to handle collections effectively and efficiently," and so switched back to direct sales, this time facilitated by credit from a microfinance organization (Martinot et al., 2001). The flexibility built into the project design legitimized a process of adaptation that could take place once it became clear that rural practices and norms were hampering the firm's ability to function. Since the communities' experiences with microfinance made this other option possible, the ESCO model has largely been abandoned.

Third, the emphasis on creating and building a market means that projects must focus on those capacities needed to encourage the diffusion of SHS technologies (Martinot and Birner, 2005) even after a project has ended (Martinot et al., 2005). Taking a broad systems perspective, these include strengthening the capacities of dealers to engage in community outreach and tailor systems to local needs, developing novel financing mechanisms, and encouraging the emergence of local installation, maintenance and repair services. In Ethiopia, for example, the Solar Energy Foundation, which won an Ashden Award in 2009, created a school for young people to train as solar technicians in Rema, Ethiopia, where 2,100 SHSs were installed between 2006 and 2008. Graduates of this school have opened Solar Centers in four other areas in Ethiopia, thus stimulating the diffusion of SHS systems across the country (Ashden, 2009). In the World Bank/GEF project, working with standard-setting bodies to ensure product quality and with regulatory bodies to review pricing policies was also important. ${ }^{45}$

Since 1997, Sri Lanka has benefited from three energy projects funded by the World Bank, International Development Association, and the GEF. By 2008, these projects had "created a vibrant local industry of suppliers, developers, financiers, consultants, and trainers," and "some 120,000 households were using solar home systems, with 750 new installations occurring monthly. Nearly 6,000 households... [were] obtaining electricity from micro-hydro minigrids that communities own, operate and manage" (World Bank, 2008). It thus appears that Sri Lanka has developed the capacities to sustain the diffusion of SHSs in the near term.

The Bangladesh case shows, perhaps more clearly, how creating a market can drive the diffusion process, as well as promote the development of local manufacturing and value chains. Initially, the government's Rural Electrification and Renewable Energy Development

45 Examples of this can be found in Martinot et al. (2001). 


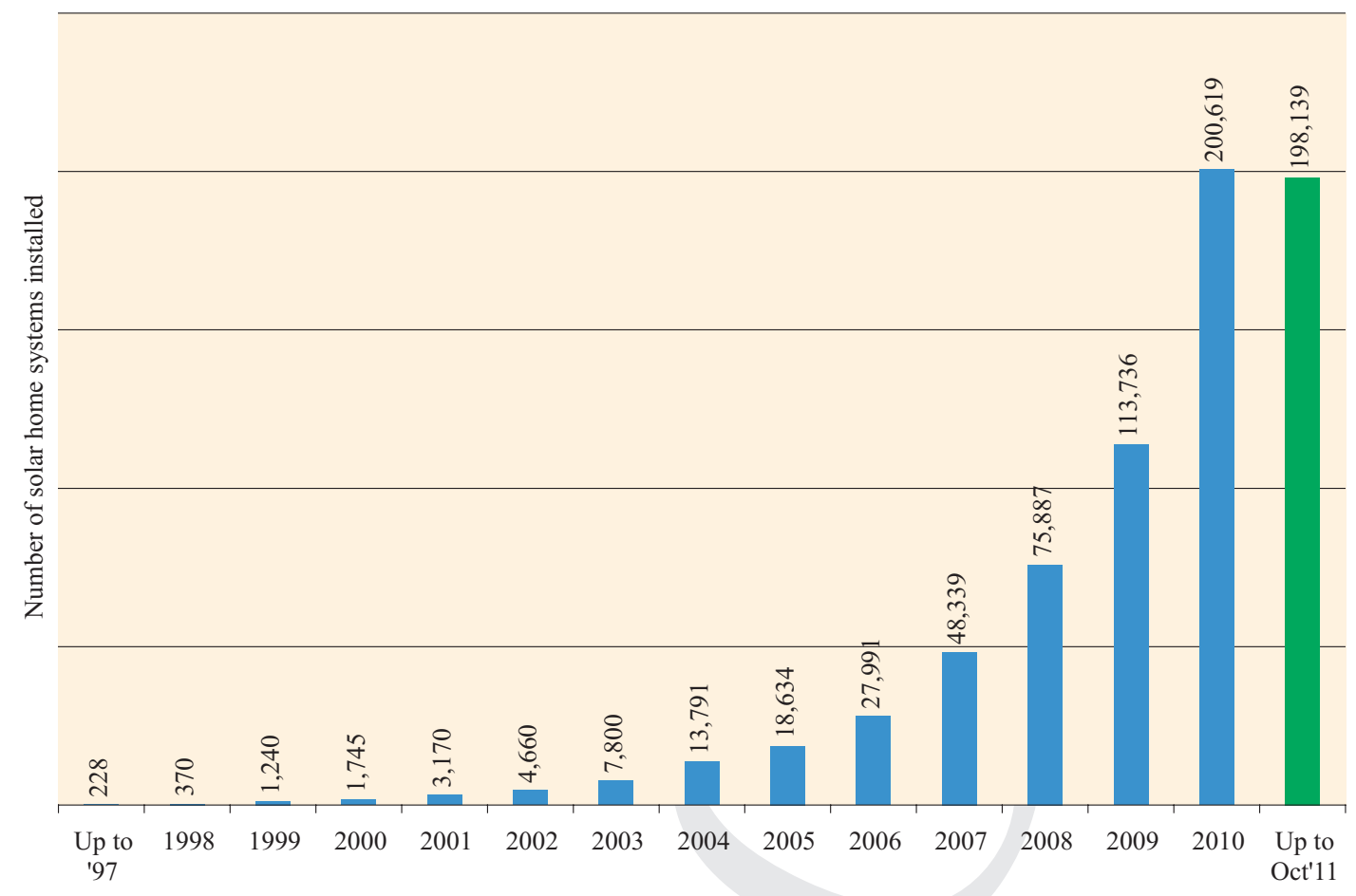

Figure $\mathbf{2 5 . 2}$ | Yearwise installation of solar home systems (SHS). Source: based on Grameen Shakti, 2011.

Project, funded by the World Bank and GEF and managed by the Infrastructure Development Company Limited (IDCOL), expected the installation of 50,000 systems by the end of 2007 , but by then over 150,000 households had installed solar systems, and 7000 more were being added each month (REN21, 2008).

Three factors were important in the rapid diffusion of SHSs in Bangladesh. One was the availability of subsides from IDCOL to participating organizations that acted as distributors. This enabled these organizations to extend credit to buyers. The second was the creation in 1996 of Grameen Shakti, a not-for-profit company under the Grameen Bank that focused on bringing energy to rural areas. By 2007, it employed 1500 field staff, had trained 1000 engineers and 1000 local technicians, of which most were women, and had established a network of 390 village unit offices in Bangladesh's 64 districts. It was through these village unit offices that Grameen Shakti promoted SHSs. Soft credit through installments, which made SHSs affordable, community involvement in planning, which led to social acceptance, and effective after-sales service contributed to the rapid development of the SHS market in Bangladesh. ${ }^{46}$ By the end of 2010, Grameen Shakti technicians had installed 518,220 Solar Home Systems and the number installed per year had risen dramatically as the capacities needed

46 Grameen Shakti was awarded the European Solar Award in 2003, the Ashden Award for Sustainable energy in 2006, and the Right Livelihood Award "for outstanding vision and work on behalf of our planet and its people" in 2007 (Right Livelihood Award, 2011). to put these systems into place developed (Grameen Shakti, 2011; see also Figure 25.2). The third factor was the role of Rahimafrooz Batteries Ltd., a local company that turned its experience in battery manufacture to the production of rechargeable batteries for PV systems. The company has since diversified into the design of charge controllers and fluorescent lamps for local manufacture. It has supplied 25,000 complete systems to distributors and provides training and technical support. In 2006, Rahimafrooz Batteries Ltd. was awarded an Ashden Award for sustainable energy (Ashden, 2006).

In addition to the "for-profit" sector, many foundations, NGOs, and social enterprises are now playing a role in developing local capacities for the diffusion of clean energy technologies, and in stimulating the development of supportive manufacturing and repair capabilities in developing countries. In Africa, for example, the African Rural Energy Enterprise Development (AREED) network, ${ }^{47}$ funded by UNEP, GEF, and other donors, works through NGOs in Botswana, Zambia, Tanzania, Mali, Senegal, and Ghana (Agbemabiese, 2008) to simulate and support energy transitions in rural and urban areas by providing advisory services to small- and medium-sized enterprises (SMEs) and linking these to local sources of seed financing development of energy demand-side services (Brew-Hammond and Kemausuor, 2008).

47 The "REED" model has been implemented in Africa (AREED), Brazil (BREED) and China (CREED); see AREED, undated. 


\section{Box 25.5 | African Rural Energy Enterprise Development (AREED)}

AREED's underlying philosophy and its innovative, networked approach makes it unique. Both of these characteristics encourage dialogue and the search for innovative solutions. AREED is, in its own words, based on the powerful idea that "impoverished people can transform their lives and break out of the vicious circle of poverty when they are empowered from the ground up" with proven, powerful, practical energy technologies. At the same time, collective experience from a variety of energy initiatives is driving renewed interest in alternative delivery models. This trend is manifested in the growing support for SMEs as versatile energy service providers capable of extending access to energy, while promoting poverty reduction and development through bioenergy systems such as the production and use of plant-based oils to power multifunctional platforms and village electrification schemes.

AREED also seeks to penetrate rural markets that would otherwise be unattractive to entities motivated solely by profit. Its focus is on "social enterprises" - defined as business organizations whose surpluses are reinvested in the business or in the community to achieve social objectives.

Source: AREED, undated.

In Senegal, AREED is working through Environment and Development Action in the Third World, an NGO, to develop a multifaceted market for solar energy technology that brings together local entrepreneurs, NGOs, government agencies, and financial service providers. With rising oil prices, the interest in solar energy has increased in Senegal, encouraged by government support for SMEs and solar technology. The agency for Rural Electrification through Local Initiatives "is responsible for the development of small energy business delivery through the use of solar technology" (Drame, 2008). Nonetheless, companies dealing in solar heaters went bankrupt (Drame, 2008). When the AREED program started, several of the bankrupt companies came together to form Africaine de Maintenance et d'Équipement (AME), a company that installs and maintains solar water heating systems. AME received a loan from AREED in 2001, which was repaid in full as the company's management capacity improved. A second loan went to Prosoleil, which manufactures solar water heating systems, and a third to Motagrisol, a producer of solar-powered milling machines (Drame, 2008). Working through the AREED network, a broader base for solar energy services is being built in Senegal.

\subsubsection{Diffusion: "Scaling Up" and "Scaling Out" at the Project Level}

Both the "scaling up" and "scaling out" of pilot projects are important in the diffusion of new energy technologies to users in rural, off-grid areas or to the urban poor. Scaling up involves moving from small-scale demonstration projects to larger, commercially viable enterprises that might benefit from economies of scale to reduce prices and thus increase sales. This process was discussed in Section 25.4.1 in connection with a series of European programs that demonstrated, tested, and are now moving towards the commercialization of electric and hydrogen fuel-cell buses. Scaling up can also be achieved through collaboration between research and users (see Sections 25.6 and 25.7).
Scaling out involves the diffusion of new technologies to new users. This section focuses on two energy technologies that are important in rural, off-grid areas and to the urban poor: multifunctional energy platforms (MFPs) ${ }^{48}$ and improved cookstoves. The diffusion of these technologies to micro and small enterprises, households, and communities has proven challenging. The focus of this section is on how adaptive learning and the development of local capabilities for market-building can stimulate, support, and sustain a scaling out process.

\subsubsection{The Multifunctional Platform}

MFPs provide access to mechanical power for income generation in off-grid areas. UNDP's MFP Program was built on an earlier project by International Fund for Agricultural Development and UNIDO. Launched by UNDP in Mali in 1994, ${ }^{49}$ it has since been extended to Burkina Faso, Ghana, Senegal, ${ }_{10}^{50}$ and other West African countries with the financial assistance of a growing number of donors. Its 16-year history offers many insights into the challenges still facing the diffusion of new energy technologies in developing countries.

48 An MFP is a source of mechanical and electrical energy meant to reduce the need for repetitive manual labor, especially that of women in rural Africa. Typically, an MFP consists of a diesel engine (8-12 hp) mounted on a chassis that can power equipment such as grinding mills, de-huskers, de-hullers, oil press equipment, water pumps, and battery chargers.

49 The launch was followed by a preparatory phase and then the full pilot phase.

50 Due to conflicting figures and the absence of reference dates in a number of UNDP publications and other reports, only the first four West African countries in which the MFP program operated are discussed here, but this covers a 13-year period in the life of the program. In addition, recent independent initiatives to set up MFPs will also be mentioned. 
One of the program's main objectives was the inclusion of village women in an income-generating activity. Women, through their village associations, would thus be the owners, managers and operators of the platforms and were trained in the necessary skills. They were also responsible for mobilizing a portion of the funds needed for the MFP's housing and tools. Although in some cases, men were employed to operate an MFP, it was not until the Ghana MFP project was launched in 2005 that ownership by individuals, both men and women, became a possibility. Another objective was sustainability, often the Achilles heel of such projects once donors are no longer involved, which was achieved by training and building up a network of mechanics and providing them with motorcycles so that they could repair the platforms whenever necessary.

MFP country projects proceeded in two phases. The project began in Mali with a three year pilot phase (1996-1999), during which 48 MFPs were installed. ${ }^{51}$ This was followed by a first scaling out phase (2000-2004), at the end of which a total of 576 MFPs had been installed in Malian villages (UNDP, undated). The pace was somewhat slower in Burkina Faso, where 25 MFPs were installed during the pilot phase (2000-2003). A lack of consistent data makes it difficult to determine how many MFPs were installed in the national diffusion phase (2005-2009). ${ }^{52} \mathrm{~A}$ recent UNDP press release, however, reported that MFPs have been installed in 441 localities in that country (UNDP, 2010). In Senegal, 44 MFPs were installed during the pilot phase (2002-2005) (UNDP, undated). The diffusion phase did not begin until two years later, with the support of the Bill and Melinda Gates Foundation and other funding sources. The additional funding also made possible the extension of the MFP programs in Mali and Burkina Faso. The Ghana MFP project began with a pilot phase (2005-2007), during which only 32 of the 40 platforms anticipated were actually installed because the budget "did not adequately capture potential issues of commodity inflation and change-orders" (Brew-Hammond and Crole-Rees, 2004; UNDP and UNOPS, 2008). This also slowed the start of the scaling out process, for which negotiations were only completed in 2009.

Unlike the emphasis on building local markets and the adaptive changes that were introduced during the pilot phase of the Solar Home Services project (Section 25.5.2), the design and implementation of the MFP project was marked by established routines and practices that slowed the diffusion process. The early MFP projects, for example, did not support the development of independent initiatives to establish MFPs. A duly registered women's association had to request a platform. Nonetheless, such initiatives began to emerge in Mali, where "19 platforms were installed without any subsidies from the project. In these cases, the villages directly contacted private artisans who had been trained by the

51 The MFP program targeted villages with between 800 and 2000 people. This meant 2300 villages in Mali, 3200 villages in Burkina Faso, and 1400 villages in Senegal.

52 One UNDP source states that "[t]o-date 120 MFPs have been installed," but the document itself has no date (UNDP, undated). project, and procured and installed the multifunctional platform on a commercial basis. These [...] are not monitored by the project and no information has been gathered" (UNDP, 2004).

In contrast to the capacity development practices in the SHS cases, the MFP program also spent heavily on literacy training in addition to training in the management and operation of the MFPs. ${ }^{53}$ This was costly but necessary in a program designed to enable rural women to assume ownership and management control of the MFP and to operate it. In its earlier phases, however, it might have contributed to a relatively narrow range of operations, such as milling and grinding, when a wider scope for income-generating activities through the operation of the platform including sawing, welding, and water pumping - would have been possible but required a much higher financial outlay. This was noted in a review of the MFP project in Mali, which recommended measures such as increases in subsidies and help from other members of the community, such as men's associations (UNDP, 2004). The issue was raised again, however, in the Evaluation of the Ghana MFP pilot phase where the report recognized that " $[t]$ here is a clear demand for other mechanized services at all MFPs visited during the evaluation [...] More flexibility is needed here" (UNDP and UNOPS, 2008). Greater flexibility in adjusting to new interests, in accommodating the need for diversity in delivery models and in nurturing village-to-village learning and networking processes could have made a difference in the speed with which MFPs diffused. ${ }^{54}$ This is particularly relevant where independent initiatives, such as the decision to replace imported diesel with jatropha oil, ${ }^{55}$ have taken place with positive results in contexts as different as Maurolo, a small village in Mali, or Garalo, a much larger town in that country. ${ }^{56}$

Although the diffusion of multifunctional platforms has so far been slow, this is now changing. Feedback, flexibility, and adaptive learning are evident in the expansion of new services offered by MFPs in Mali, Burkina Faso, and Ghana, and the diversity of operational model approaches. In Ghana, of the 32 platforms installed, 11 are owned by individual women, 11 by groups and cooperatives (mostly women), nine by individual men, and one is run as a partnership (UNDP and UNOPS, 2008). Using MFPs as part of an expanding number of energy services such as water pumping and electricity provision is accelerating, and the capacities in engineering, finance, decision-making, and

53 A small number of men - five out of 30 trainees per literacy class and per MFP village - were also trained.

54 Deployment of energy platforms was based on a donor/government selection process and was not supportive of independent initiatives to redesign or install platforms. Recent research has shown that farmer-to-farmer learning processes can speed up the diffusion of new technologies in developing countries. They provide a tool for small-scale farmers that enables them to gain insight into their own performance in farm management, and to learn by comparing their performance with that of colleague farmers (Sinja et al., 2004; Taweekul et al., 2009).

55 Jatropha oil is a vegetable oil from the Jatropha curcas plant. When the plant's seeds are crushed, it produces a high-quality biodiesel.

56 Maurolo uses jatropha oil in its MFP; Garalo is using it for the generation of electricity (see Section 25.6.1; KITE, 2004). 
monitoring are being developed. The diffusion process is also moving beyond the established MFP Programs in West Africa to East Africa, where discussions on the need for MFPs is underway in Tanzania (Caniels and Romijn, 2010) and two MFPs have been installed in Uganda (EPA, 2010a; 2010b). Changes are also taking place as the program opens to newcomer initiatives in the development of jatropha as a replacement for diesel by commercial enterprises such as Mali biocarbonate (Mali Biocarburant, 2010). Columbia University, working with Engineers without Boarders (USA), has developed and tested an engine modification kit and are working with a local NGO to test it further in Uganda (EPA, 2008).

\subsubsection{Cookstoves}

Improved cookstoves are another important addition to the portfolio of "new" energy technologies that serve multiple purposes (see also Chapters 4,10 , and 19). They can raise the level of energy efficiency and save on the amount and cost of wood and charcoal. Their design, production, repair, and use can also stimulate local learning and innovation and contribute to market creation and income-generating activities, as well as reduce damage to the environment and to the health of the women who are the primary users. The many possible benefits from this one "new" technology have made it the focus of donor attention for decades.

During the 1970s and early 1980s, international donor agencies introduced nearly 100 stove projects and programs. A review of these efforts by the Canadian International Development Research Centre (IDRC), however, showed that widespread diffusion was not taking place (Krugmann, 1988). The Energy Sector Management Assistance Program also reported on this in more detail in the mid-1990s, after which several World Bank projects were reoriented (Barnes et al., 1994). Nonetheless, this problem has persisted into the new millennium. Chapter 19 provides a table of 52 "improved" cookstoves that were developed from the mid1980s to 2009 and distributed in Africa, Asia, and Latin America. Only three of these models - two in India and one in Africa - succeeded in achieving a distribution of over one million stoves. In the following section, we look briefly at some of the factors that contributed to the past failure and the emerging success of these models.

Two of the most important factors contributing to the failure of improved cookstove projects stem from the fact that they were designed in the North and transferred to the South. The former led to a choice of materials and associated production costs that tended to raise the price of stoves beyond local household income possibilities. It also led to inappropriate designs for users, mainly women, whose inputs were rarely sought. It also limited income-generating opportunities from the growth of local production and the development of skilled artisans for maintenance and repair.

Among the exceptions to this practice was the Kenyan jiko, a charcoal stove that was built and sold through conventional artisanal market channels. But even more important in understanding the speed and extent of the diffusion of jikos, in the absence of subsidies or special programs, were a number of design features that helped to build the market, provide opportunities for the development of local supply chains that supported the diffusion process, keep costs of the jiko low and prices within an affordable range for rural households. The stoves, for example, were made by local artisans and the insulation provided by ceramic liners was manufactured in local factories. When the liners wear out, artisans can either replace them or take the old jiko as part of the purchase price for a new one. The artisan then replaces the liner, refurbishes the stove, and resells it. Ceramic jikos are also much more energy efficient, and their cost varies with size and quality and can be bought for prices as low as US\$2. According to a study by the German organization GTZ, between 1997 and 2001 about 1.6 million Kenyan ceramic jikos were sold, and "it became a model for a number of other stoves like the Lakech stove in Ethiopia" (Brew-Hammond et al., 2008).

Local design, manufacture, and repair were also important in the development and diffusion of improved mud chulhas with a chimney in India and a major factor in the reduction of smoke pollution in the homes of users. As many as 28 million improved chulhas, including replacement stoves, were sold from 1983-1998. While the chulhas have been praised for their positive impact on health, questions have been raised about their efficiency, particularly when the chimneys are replaced by the women themselves or by untrained artisans, with considerable loss in energy efficiency (Kishore and Ramana, 2002). Further research to upgrade the chulhas by lengthening the time between rebuilding mud walls and chimney and training programs for local artisans in repair and upgrading of the stoves would have improved their overall energy impact as well as contributing to local livelihoods.

More recently, the emergence of social entrepreneurship and microfinance in the Indian energy sector has led to the development of lower cost, more efficient stoves that emit little smoke and are able to reach the bottom-of-the-pyramid markets. These new start-ups, however, are struggling to fund additional research and larger-scale production that would help to reduce costs and prices (GVEP, 2009). They also face new competitors entering the market with "high-tech" wood and agricultural residue stoves designed in the North with the financial support of international foundations.

In the past few years, new stakeholders have become interested in stoves, including commercial European and US firms, with a view to capture carbon funds and reduce deforestation at the same time. Some completely different stove models ("second generation") were the result. These included scientifically designed models, such as those developed by Envirofit. These stoves look modern and guarantee good performance in terms of fuel efficiency and emissions. They are also not cheap and can be several times more expensive than traditional stoves. Contrary to traditionally improved stoves, second-generation stoves are 
produced on a large scale in China ${ }^{57}$ or in the industrialized world and imported into the developing countries. The role of traditional stove makers, as we shall see below, is minimal.

Envirofit, a nonprofit organization based in the United States, received donations and institutional support from the Shell Foundation that helped "to fund product development and early stage product commercialization" (Envirofit, 2010). The company was able to work closely with Colorado State University's Engines and Energy Conversion Laboratory to develop improved cookstoves based on new materials and processes for which patents are pending. Like the jiko, these cookstoves burn wood and residues, as opposed to new fuels such as liquid petroleum gas (LPG), but are more energy efficient than traditional stoves. Envirofit's business plan is based on high-volume, centralized manufacturing and global supply chain management that is expected to generate "strong margins" through their sales channels in developing countries (Envirofit, 2010). With a price tag of US\$35, the diffusion of such stoves would require significant subsidies from international donors. In May 2008, Envirofit launched their cookstove business in India. Since then, the Shell Foundation "has helped them to develop market strategies which focus on rural villages across southwest India ... One of the challenges was to make the stoves affordable to users" (Gomes, 2009)..$^{58}$

However, stoves from Envirofit are designed to use firewood and residues, and not charcoal, whereas the main urban market for cooking energy, particularly in Africa, is for charcoal. Charcoal is an efficient and convenient fuel for the end-user, but if production efficiencies are taken into account, it is no longer a very efficient fuel. Charcoal-using households use $30-100 \%$ more energy for cooking than firewood-using households, depending on the efficiencies of the stoves used (GTZ 2010). Unless trees for charcoal making come from farmers' fields or plantations, deforestation may accelerate. Charcoal is a quickly growing commodity in urban areas, and it is also a lower cost cooking fuel than any of the modern alternatives such as kerosene, LPG, and electricity. Since towns are expanding rapidly across the developing world, its consumption is increasing rapidly. To meet broader development goals, strengthening capacities for the design and manufacture of improved cookstoves for charcoal and the development of the sustainable production of charcoal in developing countries could be of importance. E\&CO, Inc. is doing just this.

A not-for-profit investment corporation founded in 1994, E\&CO supports small and medium-sized enterprises involved in supplying clean energy technologies. It works closely with these local entrepreneurs and with local partners to support research, development, and production in developing countries. In collaboration with AREED, which provides key business support services as well as seed funding to local enterprises in the

57 Aprovecho Research Center, located in Cottage Grove, Oregon, is the designer and developer of improved "Rocket Cook Stoves," which it disseminates through its "not-just-for-profit entity" StoveTec, created in 2008. The stoves are mass produced in Shengzhou, China (ARC, 2011).

58 Richard Gomes is communications and business manager, Shell Foundation UK. energy sector, E\&CO provided a first loan of US\$70,000 to Toyola Energy, a small start-up company making improved cookstoves in Ghana. Having trained in energy-efficient stove manufacturing under the Ghana household energy project in 2003, the proprietor, Suraj Wahab, was making a small number of charcoal stoves that "reduce the amount of charcoal needed for cooking by around 35\% resulting in significant household savings" (EnergyAccess, 2010). By 2010, Toyola had produced and sold more than 50,000 stoves to households across Ghana and was the recipient of two further loans from E\&CO, each in the amount of US\$100,000.

This section took the discussion of informal institutions a step further in its identification of capacities needed for the development and diffusion of "new" renewable energy technologies such as wind, solar power, and woodfuels. These have an important role to play in meeting the energy needs, sustainable development goals, and economic and environmental objectives of communities in developed and developing countries. Critical factors in the success of such ventures are dialogue in the initial phases of project development and the inclusion of mechanisms for feedback and flexibility in project design. Dialogue between users and producers also contributes to the kind of signaling that creates awareness of opportunities for widening local markets and speeding up the process of technology diffusion.

For local entrepreneurs in developing countries to take advantage of these new flows of information, however, there will be a need to strengthen capacities for the local design, manufacture, repair, and distribution of new energy-related technologies, such as improved SHSs, cookstoves, and MFPs. As these cases have illustrated, however, the creation of new types of funding and the capacities to access these funds through stronger business support systems are also needed to make such potential benefits a reality.

\subsection{Distributed Energy Systems and Development: A Multi-Goal Perspective}

This section expands on the discussion above by looking at a variety of biofuels and the capacities and capacity development processes that could enable their local production and use in the generation of electricity and in building an evolving portfolio of clean energy technologies for the transport sector. It also explores the development of small and village-level hydro for on- and off-grid applications. Decentralized production of biofuels and distributed energy systems could contribute to the realization of development goals, while simultaneously moving towards an energy transition that includes smallholders and the poor.

\subsubsection{Energy Access, Income Generation and Inclusion: Making Choices about Biofuels}

Biofuels have had a checkered history. They are alternatively praised as a means to provide energy access, energy security, and reduced 
greenhouse gas emissions, and criticized as contributing to the destruction of tropical forests and competing with food crops for the use of agricultural land. As the world's population grows and climate change affects agricultural production, making choices about biofuels will require new skills, information, and capacities to analyze trade-offs and design, monitor, manage, and enforce policies that ensure sustainability (see Chapter 20).

By 2005, with oil prices again rising, interest worldwide has been attracted to liquid biofuels for the transport sector (ESMAP, 2005b; see ESMAP 2005b; 2010 for further information). ${ }^{59}$ Although electric vehicles are also making a comeback in urban environments, levels of electricity output are insufficient to meet their widespread use in Europe in the near term ${ }^{60}$ and are likely to be a niche or longer-term option, particularly in the developing world. Biofuels are also being developed for energy generation, thus creating new options for distributed energy in off-grid environments. ${ }^{61}$ From an even broader, but longer-term development perspective, biofuels can open up opportunities in developing countries for what the $O E C D$, in a recent study, has termed the "bioeconomy" 62 (OECD, 2009). Strengthening local research capacities, participating in collaborative research and development (R\&D) efforts, and coordinating policies across government ministries are key elements in laying the foundation for the long-term development of the bioeconomy and the multiple options it will offer in the future (ESMAP, 2005a; $O E C D, 2009)$. In the past, this would have been dismissed as unrealistic, even as a long-term goal for developing countries. However, the recent development of biofuels from sugarcane, jatropha, and algae suggest that building a bioeconomy in the developing world is not an altogether unrealistic proposition, as the following examples illustrate. Evidence of the role that local $R \& D$ capacities can play in stimulating the growth of the bioeconomy in the developing world is already emerging.

In Brazil, for example, sugarcane-based ethanol was the first biofuel to be commercialized successfully in a developing country and perhaps

59 In 2010, the US Department of Energy awarded US\$78 million to the National Alliance for Advanced Biofuels and Bioproducts and the National Advanced Biofuels Consortium.

60 See McKinsey and Company, 2010, a study prepared for 28 companies from the automobile, oil and gas, utilities, industrial gas, equipment car manufacturers, wind and electrolyser companies, one NGO and two government organizations. The report emphasizes the importance of developing a range of technologies that will ensure the long-term sustainability of mobility in Europe and in this connection, stresses the need to reassess the role of fuel-cell electric vehicles in the light of recent technological breakthroughs

61 Taking advantage of their experience with flex-fuel engines in the transport sector, Brazil's Petrobras, in collaboration with General Electric, has upgraded an 87 MW power plant to operate using either natural gas or ethanol. General Electric was interested in this research project because in other countries it has some 770 turbines similar to those in the Brazilian plant that could be converted to run on ethanol. Both companies are members of the Model Fuels Consortium, whose goal is to accelerate adoptions of Green Fuels (GE, 2010; Petrobras, 2011).

62 The "bioeconomy" spans an array of sectors, including agriculture, health, environment, and industry. in the world. ${ }^{63} \mathrm{~A}$ long-term research effort that brought government, growers, and ethanol producers into the process was a major factor in bringing down prices and eliminating subsidies. It is important to emphasize here that land-use issues were not of major importance in Brazil, where sugar plantations were already in place and options for sugar exports were in decline. ${ }^{64}$ The use of sugarcane as the feedstock for ethanol in Brazil has contributed to its overall positive climate benefit (UNEP, 2009). Most sugarcane plantations, however, were concentrated initially in the north-east and south-east regions of the country ${ }^{65}$ and the need to transport ethanol around the country resulted in some negative effects on net $\mathrm{CO}_{2}$ benefits. The plantation system, moreover, largely excluded smallholders from the biofuels sector.

In the development of biodiesel production the Brazilian government sought to include smallholders and the poor. A variety of inputs were identified for biodiesel and several of these are available in most regions of Brazil. They can be grown by smallholders and processed and distributed locally. Government policies have been put in place to encourage the purchase of feedstock for biodiesel from smallholders (Teixera et al., 2008). In keeping with earlier successful practices in the development of higher-yielding sugarcane varieties for ethanol production, the research that has made possible the development of crop varieties and production techniques for biodiesel was subsidized by the government and has been supported by both the public and private sectors.

Biodiesel from palm oil is an example of how this new approach is leading to a rethinking of the role that decentralization can play in strengthening smallholder production and in generating externalities. In the Amazon region of Brazil, oil palm trees are long-lived and abundant. Producing biodiesel from the palm oil of existing trees is an option with multiple benefits in areas where choices are few and the damage to forests is already great. ${ }^{66}$ Palm oil biodiesel production would help resolve the problem of electrification in the Amazon region, which has the lowest electrification rate in the country (Coelho et al., 2005). Since 2002, the Brazilian Reference Center on Biomass (CENBIO), in collaboration with other research institutes, has been working to develop and test a rural electrification model for the Amazon based on the use of local palm oil (Coelho et al., 2003). This could result in "a quite significant improvement in [greenhouse gas] emissions compared to conventional

63 For a case study of this process, see Chapter 24. Additional discussion is available in Chapter 11.

64 This resulted from a combination of the special trading arrangements concluded between the European Economic Community and its associated African, Caribbean, and Pacific states, and between the former Soviet Union and Cuba, and the production of sugar from beetroots in Europe and the development of corn syrup for use in prepared food and beverages in the United States.

65 Nowadays $80 \%$ of the alcohol production is from states in southeast (São Paulo, Parana, and Minas Gerais) and mideast states (Goias, Mato Grosso do Sul, Mato Grosso, and Tocantinhs). In Parana State sugarcane is produced by smallholders organized in cooperatives.

66 In a number of African countries, palm oil has also traditionally been used for lighting. 
diesel. On the other hand, if areas that were not previously cultivated are converted to palm oil production, the net resulting balance can be dramatically negative" (UNEP, 2009).

On May 6, 2010, former President Lula da Silva announced the Program for Sustainable Production of Palm Oil on abandoned and degraded agricultural lands in the Amazon region. The program, designed to support poor farmers in the region, specifically prohibits the expansion of oil palm at the expense of native forests (Butler, 2010), although whether this can be enforced is debatable. Estimates of the production of biodiesel from harvesting palm nuts and processing the oil locally in the Amazon region put the cost of the biodiesel below that of the petroleum-based fuels currently transported to the region over land. In addition to this saving in fuel costs, the harvests and processing can provide local populations with income and potentially forestall further destruction of the rainforest to plant soybean destined for export as part of the animal feed chain.

Jatropha has been praised as a feedstock for biofuels because of its ability to grow on marginal land and in arid environments unsuitable for food crops. It is a particularly good substitute for petroleum-based diesel and kerosene, and can be used as a transport fuel or as a replacement for off-grid stationary power. Small-scale production of jatropha can also help to restore the productivity of degraded land (UNEP, 2009) and open new income-generating opportunities.

In Mali, for example, jatropha is now being grown on "marginal" and unused land to provide fuel for a local $300 \mathrm{~kW}$ power plant (UNEP, 2009; ACCESS SARL, 2010). In early 2007, rather than rely on imported diesel for a future off-grid generator, villagers from the commune of Garalo in Mali chose to plant jatropha. ${ }^{67}$ Of the 440 hectares (ha) planted with jatropha, two ha were prepared as a nursery and $95 \%$ of the fields were planted by individual farmers, ${ }^{68}$ of which $6 \%$ ( $25 \mathrm{ha}$ ) were for women (Burrel, 2008). The main purpose of the plant is to provide access to electricity for a range of energy services that include lighting, refrigeration, the use of welding equipment and agricultural processing machinery by businesses and workshops. It was also designed to reduce the cost of the village water pumping system by replacing the diesel genset then in use with electricity from the local mini-grid (Rijssenbeek and Togola, 2007).

Research and advisory services are playing an important role in the development of smallholder jatropha farms. In 2008, to assess the condition of the jatropha plants, a sample of 118 ha comprised of 100 fields in 21 of the villages, were surveyed by a local agronomist working with the International Crop Research Institute for the Semi-Arid Tropics. The capacity to form such linkages between farmers and research is critical for learning, problem solving, and the sustainability of projects that

67 The village worked closely with the Mali Folk Centre, a Malian NGO that is a member of the AREED network.

68 The remaining $5 \%$ were collective fields. involve new technologies. Feedback from this survey, for example, has contributed to strengthening the positive outcomes of the project in two ways. First, the survey indicated that $71 \%$ of the farmers intercropped jatropha with food crops such as maize, sorghum, millet, peanut, sesame, and beans. These farmers had thus dealt with the assumed need to choose between food and fuel by developing a system that produced both. Second, the survey alerted farmers unfamiliar with jatropha cultivation to the need for wider spacing between plants if intercropping were to continue as the jatropha plants grew (Burrell, 2008).

In 2008, the power station in the Garalo township provided electricity to 230 clients, of which 198 are households, 19 are shops, restaurants, workshops, and mills, two are healthcare providers, seven are local government buildings, and four are places of worship. ${ }^{69}$ This had increased to 251 consumers in 2010, according to ACCESS SARL, a Malian energy service provider that has been selected by the municipality to manage its power station and grid (ACCESS SARL, 2010). It is expected that the number of users will more than double over the next two or three years as the jatropha plants mature and the yields and incomes of smallholders increase. Local oil transformation is also contributing to income generation, economic growth, and poverty reduction in the broader community as access to and costs of energy services decline (Burrell, 2008).

Much of the success of this project can be attributed to strong community participation nurtured by a continuous dialogue and the availability of information and technical support from local agencies such as the Mali Folk Centre (Goertz, 2006; Burrell, 2008). This has led to considerable follow-up, experimentation, and local learning, for example, in shifting from the costly process of using plastic bags for seedlings in the nursery to the use of direct seeding in the fields. Improving methods of intercropping is another area that has benefited from local research and is serving to increase farmers' incomes. ${ }^{70}$

The problem with using jatropha oil for fuel arises when it is reconceptualized as an export commodity. Upscaling the smallholder model for the large-scale production of biodiesel fuel for the domestic market, and even more so for export, requires considerable rethinking.

First, the assumption that jatropha is a low-cost, low-input crop that grows virtually by itself is problematic in this new context. Recent research in India, for example, has shown that the price of jatropha oil depends upon increasing the yields, and that this in turn requires improved seeds that reach their potential when well watered and often when fertilized (Altenburg et al., 2008). The failure to reach anticipated yield levels has led to the abandonment of a number of joint ventures in India (Dogbevi, 2009a; 2009b).

69 The data come from billing records. In addition to the clients, 45 public lights have been installed. Every client pays 500 CFA (approximately US\$1) extra for these lights (Burrell, 2008).

70 Changes in billing practices are also under consideration to reduce the financial burden on customers. 
Second, a larger volume of feedstock is needed. Regrouping land parcels into large-scale farms and increasing mechanization are new practices introduced as a means to increase yields. But these practices require substantial amounts of capital. They also lead to changes in the organizational model away from smallholder farming to cooperatives, in some cases, but more frequently into contract farming with multinational corporations as partners. These practices also result in the outright sale of land to local or foreign firms, resulting in the potential alienation of smallholder lands and requiring considerable attention to regulatory and other policies that currently do not exist.

Algae are yet another entrant into the biofuel chain that could contribute to clean energy technologies, the growth of the bioeconomy, and the broader process of sustainable development. In a popular (non-technical) classification for liquid fuels made from biomass, such fuels are discussed in terms of first, second, and third generations where the "different generations are distinguished primarily by the feedstocks from which they are derived and the extent to which they are (or are not) commercially developed" (Chapter 11). Algae are currently placed among third-generation biofuel fuels. However, "land use constraints, competition with food and demand for biomass with high caloric value have made marine based biomass an attractive alternative supply option over the past years [...] Promising concepts for aquatic biomass include (1) land-based open ponds for microalgae, (2) horizontal lines between off shore infrastructure, e.g., wind farms for macroalgae (seaweed), and (3) vertical lines near shore in densely used areas and nutrient-rich areas for macroalgae" (Chapter 7). Marine algae use saline water, $\mathrm{CO}_{2}$, and non-arable land. Located near point-sources of $\mathrm{CO}_{2}$, such as factories and coal-fired power plants, hybrid production systems ${ }^{71}$ open opportunities for clean-up, ${ }^{72}$ while optimizing the system cost and contamination of production (Huntley and Redalje, 2006).

Algae technologies can also provide bio-based inputs or end products for a wide array of markets. Algae biomass, for example, can be converted to end applications such as biofuels and animal feed. Hydrotreated algal oil can be mixed in any ratio with conventional diesel or aviation fuel, and can then make use of the existing infrastructure. Of the algal biomass, approximately one-third can be converted into biofuels. Dried whole algae or the remaining dried defatted algal mass can be used as a source of high-quality protein in animal feed (Kiron et al., 2009) and in food products. Although the market for protein is likely to expand rapidly due to population growth, the supply of highquality, algae-based protein may become greater than the growth in demand (Balagopal et al., 2010). A high supply could lower feed and

\footnotetext{
71 Hybrid systems combine (expensive) photo bioreactors with (contamination-prone) open ponds.

72 The closer, the more concentrated, and the purer the $\mathrm{CO}_{2}$, the cheaper the cost of production will be.
}

food prices and change the structure of the animal feed and food industries. ${ }^{73}$

Microalgae are single-cell organisms that convert $\mathrm{CO}_{2}$ and sunlight into biomass through photosynthesis. Compared with terrestrial alternatives, marine algae do this very efficiently. They have the potential to produce substantially more biomass per $\mathrm{m}^{2}$ per day than conventional biofuel feedstocks, such as palm oil or rapeseed oil, but without the need for fresh water and minimizing the need for land, phosphates, and nitrates. Because the production of the end product can take place in a liquid medium, advanced industrial processing techniques are available that have the potential to reduce processing costs and allow scaling up to very large volumes. ${ }^{74}$

Production yields are directly dependent on the amount of light reaching the growing algae, so that the most efficient algae facilities will be located between latitudes $23.5^{\circ} \mathrm{N}$ and $23.5^{\circ} \mathrm{S}$. Most development of know-how, however, is currently taking place in the infrastructure-rich United States. This opens opportunities to build capacities outside the US, particularly as the most effective, non-genetically engineered algae strains for any given commercial open pond facility are likely to be found locally. Expertise is rare anywhere at the moment, which necessitates global cooperation and the use of virtual teams that include researchers and other experts based in different locations. Developing countries could play an important role if domestic knowledge capabilities in these domains are strengthened. There are also interesting research, development, and testing opportunities in closed bio-reactor processes in developing countries, as current collaborative research between a German and a South African university illustrates. ${ }^{75}$

Solving the many engineering problems and market issues that new industries face requires bringing people together from different disciplines and different industries, as well as patience. This goes beyond earlier practices of consulting with researchers from different firms or industries. Instead, it opens a dialogue between disciplines that speak different languages, have different points of view, and may display different logic based on different value systems. As the discussion of open innovation systems in Section 25.7.1 shows, networks of this sort have already been put in place to speed up the process of problem solving

73 An algal industry with a capacity of $450 \mathrm{kbd}(1 \mathrm{kbd}=1000$ barrels/day) of algal oil could supply up to $15 \%$ of the crude protein needed in the compound animal feed market by 2030, thus enriching crops such as protein-poor cassava for use as animal feed and reducing the damage to land and forests from soybean monocropping.

74 Biofuels must be both profitable and sustainable. Algae do not yet meet both criteria simultaneously. An important element of cost reduction is to maximize the biomass and/or algal oil produced per $\mathrm{m}^{2}$ per day, which would minimize the physical footprint of a facility for a given plant capacity.

75 In 2009, Jacobs University (Germany) partnered with Nelson Mandela Metropolitan University (South Africa) to expand the testing of its photobioreactor, which currently uses marine microalgae to convert $\mathrm{CO}_{2}$ from a coal-fired power plant, breweries, refineries, and cement factories in the Eastern Cape region into organic compounds through photosynthesis (Guetali SADC, 2009). 
in a variety of new technologies. This form of cooperation should be stimulated and encouraged. Corporations that are the first to master this will be more successful in executing the associated complex integrated projects and create more value.

\subsubsection{Small and Micro-Hydro: Bottom-up Solutions}

Hydropower is the main source of renewably generated electricity in the world today and there is still considerable potential for exploitation, in particular in rural areas of developing countries (see Chapter 7, Section 7.6 and Chapter 11, Section 11.3). Many developing countries have tried to build small and micro hydro projects, ${ }^{76}$ some for connection to grids and others for off-grid use. Where many projects failed is through a lack of local ownership: plants are designed and constructed by foreign firms with minimal input from local stakeholders. Once commissioned, plants are transferred to the local community, which then must assume operation and maintenance responsibilities as well as costs. This has had negative consequence for sustainability. We take a closer look at the experiences of China, Bhutan, and Rwanda here.

By the end of 2007, after 30 years of unremitting efforts, China had built more than 45,000 small hydropower (SHP) stations with a total installed capacity of about 50 gigawatts. Together, they generate $150 \mathrm{TWh} / \mathrm{year}$ and account for one-third of the total hydropower nationwide. By developing small hydropower, half of the territory of China, one-third of the counties, and over 300 million people had access to electricity in 2009 (REN21, 2009).

The large number of SHP plants in China is directly related to transmission system needs, government tax policies, and feed-in power rates. The Ministry of Water and Power also played an important role in this process by providing interest-free loans to China's rural utilities and technical assistance to ensure that locally developed plans conformed to national standards. Although large hydro plants can generate huge amounts of energy, the existing grid system prevented the efficient transmission of electricity to rural villages. By providing policy support and financial incentives, funding for renovating rural grids, especially through the Clean Development Mechanism (CDM) since 2004, and technical training, the state built pilot counties of primary rural electrification infrastructure and encouraged local governments and farmers to develop small hydropower to solve the problem of local access to electricity. This environment encouraged private companies to invest in the

76 Definitions of small, micro-, and mini-hydropower vary across countries and can even include systems with a capacity of just a few megawatts. The United States of America, India, and Brazil define microhydro as $<100 \mathrm{~kW}$ and mini hydro as 100 1000 kW (Moreira and Poole, 1993). In China, small hydropower refers to plants with an installed capacity of up to 50 MW (Zhou et al., 2009). In Nepal, small, micro-, and mini-hydropower systems are defined respectively as plants with 1-15 MW (usually feeding into a grid), $100 \mathrm{~kW}-1 \mathrm{MW}$, sometimes stand-alone, but more often feeding into a grid. Micro installations with capacities of 5-100 kW usually provide power for a small community off-grid (AEPC and UNDP, 2009). construction of small hydro plants, and up to $85 \%$ of the funding now comes from private sources (Zhao and Zhu, 2004). Zhejiang province is a case in point.

Severe power shortages in Zhejiang province necessitated reforms. Due to preferential government policies (a guaranteed power price, macro planning, and a standardized bidding process) and stable and high profits, the Zhejiang water resources industry has attracted the highest national amount of private investment in this sector. The national fund for grid construction was used to build the connecting infrastructure, while private funds were tapped to develop the small hydropower sources. Private investment covers $80 \%$ of installed small hydro capacity.

A wide range of investors have been involved in this process. Water resources enterprises, power corporations, individuals, overseas Chinese and shareholding corporations have cooperated in establishing corporations and limited companies. Shareholding SHP corporations, originally located in villages or counties, became provincial group corporations. This not only quickened the exploitation of hydropower resources, but also fostered water conservation, developed a wide range of local capabilities, and raised living standards.

Village-scale power, however, continues to be one of China's biggest challenges for isolated villages. Early project experience suggests that village power applications will require government assistance for some time due to economics, the challenges of management arrangements, and the need for local regulators and tariff frameworks. Most villagescale power systems managed by traditional utilities have not been successful in China. Other operating and management models are clearly needed. Even collecting tariffs high enough to cover operating and maintenance costs can be a challenge - about $1 \mathrm{RMB} / \mathrm{kWh}$ (or about US\$0.10/kWh) seems to be about the maximum.

SHP development in China is decentralized and managed by local governments and people. The state encourages the development of local small hydro power resources - based on the principle of "self-construction, self-management, and self-consumption" and the policy of "those who invest should enjoy the revenue and ownership." The results have been impressive. The bottom-up development of village power schemes undertaken by local village organizations and business firms, seems to show a greater chance of success by coordinating mutual interests at the earliest stage of development, generating commitment through face-to-face communications with working people, and following a rigorous process for clarifying the interests, roles, and responsibilities of all parties. ${ }^{77}$

\footnotetext{
77 A bottom-up approach to rural electrification in Nepal also appears promising, although its lessons "are not being adopted and upscaled at a desired pace," despite the passage of a Local Self-Governance Act in 1999, and evidence that "local government bodies are dissatisfied with central agencies, which are perceived to be indifferent to local proposals including local program needs, objectives and modalities" (Nepal, 2007).
} 
The Kingdom of Bhutan faced similar problems in its efforts to develop off-grid micro-hydro projects. Due to their lack of financial viability, the Bhutan Power Corporation has been reluctant to take over the management of the new micro-hydro plants (MHP) being built. When the Chendebji micro-hydro was commissioned in October 2005, an alternative model involving the community had to be developed. This communitybased management model is being piloted in Chendebji and is expected to be refined and used for similar projects in the future. To ensure sustainability and diffusion of micro-hydropower in the rural areas, such projects should be coupled with the development of income-generating opportunities and a program of continuous training to maintain the skills of local plant operators (see Case Study 2, Section 25.11).

The situation in Rwanda differs from that in both Bhutan and China. A small, densely populated country, Rwanda had an available national electricity generation capacity of 71 MW in 2010 (Bensch et al., 2010). This provides access to about $10 \%$ of its 10 million people. Some 270 MHP sites have been identified, of which about 20 have been developed or are under development. ${ }^{78} \mathrm{Grid}$ expansion is rapid and sites that even five years ago were expected to remain more than $15 \mathrm{~km}$ from the national transmission grid are now close enough to be grid-connected. As a result, most MHP plants have a choice between connecting to the grid or not, based on a trade-off between incremental investments for transmission lines and incremental income from being able to sell $100 \%$ of the produced electricity.

Public funds were used to develop most of the MHP plants and operational responsibilities were, until recently, given to local communities. These were not able to manage the plants in a sustainable manner (GTZ, 2010). The national electricity company is not interested in managing these plants even when grid connected, as they are too small and associated management costs are too high compared to its larger plants. Over the past several years, a number of privately owned MHPs became operational and more are under construction. These are funded by a private sector participation program for the development of micro-hydro in Rwanda (Pigaht and van der Plas, 2009). Under this program, local entrepreneurs develop the plan for these plants jointly with beneficiary communities, secure commercial loans from local banks, and are financially supported by a government subsidy. Since plant owners have taken loans to finance part of the investment costs, they have every incentive to ensure that the plants continue to function properly. The government has now decided that management of all public MHP plants will be auctioned off to the private sector, and future MHP plants will only be established with contributions from the private sector. Although the cost of electricity from these plants is slightly higher than from $100 \%$ publicly financed plants to cover private financing costs, more funds are available for immediate development of village power systems. In addition, the sustainability of privately financed plants is likely to be higher, and plants are developed around locations with the highest interest among the local population (Pigaht and van der Plas, 2009).

78 This involves about $17 \mathrm{MW}$ in plants with capacity of between $100 \mathrm{~kW}$ and $5 \mathrm{MW}$.
Overall, there is great potential for the further development of hydropower, especially in rural areas of developing countries and with the participation of local communities and private sector players. But the successful development of this potential requires comprehensive government policies at the local, regional, and national levels. Such polices include financial support through taxes, feed-in tariffs, and soft loans; the creation of programs for technical assistance and capacity development in the design, maintenance, and management of small and micro-hydro; and changes in regulatory policies that make conditions more favorable for private sector investment in village-based micro-hydro projects. The success of targeted bottom-up approaches in China, Bhutan, Nepal and Rwanda illustrates the need for mutual interests to be accommodated through dialogues in which local government bodies are brought into the process early in the development of a project and a mechanism for continued dialogue over the life of the project is put in place.

This section has also illustrated that, in addition to enabling energy access, distributed energy systems based on biofuels could have an important role to play in the broader development process. The need to develop capacities for making choices about biofuels in technical, as well as economic and financial, terms, and in evaluating trade-offs is of critical importance in creating such benefits and ensuring their longterm sustainability. Greater attention, for example, should be paid to assessing whether, when, and how to scale up the production of biofuels in a given context. Strengthening the research and problem-solving capabilities of local universities and research institutes in agro-, bio-, and social sciences will be essential in supporting such policymaking processes. Developing these capabilities, however, can take many years at a time when decisions about energy transitions that involve biofuels require attention now. The next section explores the role that a variety of different forms of networking can play in contributing to the development of domestic capabilities for research, analysis, and innovation.

\subsection{Strengthening and Sustaining Capacities for Networking and Innovation}

In the last quarter of the $20^{\text {th }}$ century, open and distributed innovation emerged as a response to new needs for knowledge sharing in the information technology and biopharmaceutical industries that were not being met by the existing patent system (Harhoff et al., 2007; Dechezlepretre et al., 2009). The networks and knowledge-sharing approaches that were developed helped to deal with the diversity of knowledge inputs that characterized these new technologies, enabled enterprises in developed countries to catch up with the technological frontier, ${ }^{79}$ and contributed to more rapid problem solving that accelerated the diffusion of new technologies. Networks for knowledge sharing and collaborative research are now emerging in the field of new energy technologies.

79 See the case studies of the international collaborative ventures of US firms in the telecommunications equipment industry, pharmaceuticals, biotechnology, aircraft, robotics, and automobiles (Mowery, 1988) and of European firms (Mytelka, 2001). 
This section discusses the special features of open and distributed innovation approaches as they have emerged in the developed countries. It then focuses on the application of these approaches in developing countries, notably in the strengthening of university-industry linkages and in a variety of new knowledge networks that support research, analysis, and problem solving in new energy technologies, and thus speed their development and diffusion. From a multi-goal perspective, networks such as these are now also being designed to support broader development goals by reducing the brain drain from developing countries.

\subsubsection{Networks for Open and Distributed Innovation}

Open innovation explores the potential of an organization, i.e., a firm or university, in a networked environment (Chesbrough, 2006). A network culture provides an opportunity to connect more people, who embody a wider knowledge base, to an organization's mission. ${ }^{80}$ The core insight of open innovation is the ability to use the world outside an institution to generate internally useful knowledge - and the core dependency of open innovation, in turn, is the need to make the flow of knowledge in and out of an institution a purposeful thing, not a random process.

A world of purposeful information flow is at odds with many of the business structures of the last 50 years, especially intellectual property rights. The idea of leveraging the sharing of knowledge as a key business strategy, rather than using intellectual property exclusively as a measure to prevent or exclude competition, is thus a novel one that has not yet resulted in the widespread adoption of models such as business-tobusiness networks or the collaborative research programs that are now common in the European Union. ${ }^{81}$ There is, however, movement in this direction. The BIOS Project in Australia, for example, began with a single core patented technology for transferring genes in plants. It was developed specifically to avoid encumbrance from existing patents, so that users could develop plants without any fear of "reach through" claims affecting things that were as yet undiscovered. Now called the Initiative for Open Innovation, it offers a range of legal tools that allow the possibility for many classes of contracts other than patent licenses. These tools encourage new improvements to the underlying technology, ${ }^{82}$ as well as improve the potential for profit-making into the covenant.

80 For example, to contribute to internal projects from the outside, to take a project that fails to gather internal support forward using outside funding, to generate novel projects outside and "spin into" new internal projects.

81 These date back to the European Strategic Programme for Research and Development on Information Technologies (ESPRIT) in 1983. Funded in part by the European Union, each project must be cross-national and bring together at least one enterprise with other actors (universities, users) for collaborative research and technology development (RTD). Annual competitions are held to select projects for funding and all partners have full access to knowledge and technology developed within the project (Mytelka, 2001)

82 A plant created would be freely available, but if a licensee improved the gene transfer tool itself and patented the improvement, then the improvement would have to be made available back to all other licensees of the tool (IOI, 2011).
Other projects aim to go even further towards the creation of infrastructure for open innovation by specifically encouraging patent holders to make their patent portfolio available for licensing through public license offers that are open to everyone on reasonable terms, while retaining the defensive benefits of patents. This goal is based on the understanding that many patent holders have patented inventions that could have broad or new applications in areas that they did not anticipate, but they may not have a strategy to actively license them or offer them for such uses. By making public license offers on reasonable terms, patent holders can encourage others to seek out novel uses that could have important economic or environmental benefits (see Science Commons, 2011).

Capacity development in this area involves the creation and use of standard licenses for most uses of patents outside a company's core business space. It also creates open and widespread patent "landscapes" in key areas so that risks and opportunities are well understood and public-private partnerships to ensure that vendors are in place to provide services to entrepreneurs, large companies, and universities, each of which plays a key role in the innovation ecosystem under open innovation.

The second approach, generally called distributed innovation, is most closely associated with the open source software culture reflected in the development of Linux (Feller et al., 2005). Distributed innovation is less a modification of existing practices than a truly disruptive aspect of the network culture. In terms of innovation power, it consists of a collected set of individuals whose individual actions "snap together" into a coherent group through standard technical systems and digital networks. Distributed innovation has now spread from information and communications technologies to the biosciences, pharmaceuticals, environment, agriculture, and related energy technologies. Recent studies have provided evidence that this approach is able to speed problem solving in technologies that span multiple knowledge bases and have relevance to multiple disciplines involved in new energy technologies (Lakhani et al., 2007; Lakhani and Pannetta, 2007). InnoCentive, an online network that puts "seekers" in touch with "solvers" of technology and policy problems, for example, has begun to include energy-related problems on its list (see Case Study 3, Section 25.11).

A related development is the recent emergence of informal Internet discussion groups on subjects of importance to developing countries. Their purpose is to exchange information on a certain technology or process, use the collective experience of network members to solve problems posed by network participants and to advance knowledge and understanding of these technologies to a wider audience of commercial firms, researchers, government officials, and students. Among these, two well-known examples are the Stoves Discussion Group (Stoves, 2011) and the Microhydropower Discussion Group (microhydropower.net, 2011).

Scientific publications are also playing an important role in knowledge dissemination and network creation. The push to share knowledge has 
increased tremendously since the Internet became commonplace. "Open Source" publications ${ }^{83}$ co-exist with for-fee publications, and numerous government organizations, donor organizations, UN Agencies, NGOs, and universities provide open access to reports and papers prepared by their staff or consultants.

\subsubsection{University-Industry Linkages}

Brazil has a long history of government support for domestic research, as the development of ethanol and biodiesel illustrates (see Section 25.6.1). The technology transfer offices in Brazilian universities and the development of collaborative relationships between universities/ public research institutes and the enterprise sector trace their origins to the transition from a "top-down" system to one that operates at multiple levels - municipal, regional, national, and multinational. This transition allowed for the emergence of new initiatives by new actors, especially universities and industrial associations (Lahorgue et al., 2005). Technology parks, technology transfer offices (TTOs), science parks, and incubators have proliferated since the 1990s (Coutinho, 2001). But, despite these initiatives, Brazilian manufacturing firms have relatively low innovation capacity. Their spending on innovation is mainly related to the purchase of machinery and equipment and, to a lesser extent, on research and the development of new products and processes. In contrast with other countries, moreover, Brazilian companies do not receive significant public financing for these activities (BRASIL, 1996; BRASIL, 2004; BRASIL, 2007), and about $60 \%$ of $R \& D$ activities in Brazil are funded and carried out by the government (Cruz and Mello, 2006). But this includes major research institutes in state-controlled companies such as the Brazilian oil company, Petrobras, and the research and reference centers located in a number of Brazilian universities.

Petrobras was a pioneer in the creation of knowledge networks as a vehicle for the development of offshore oil technology at a time when low oil prices created a disincentive for major companies to invest in this technology. Between the late 1960s and the early 2000s, "Petrobras massively transformed its offshore technology networks [...] from a passive learning network to an active learning network" and developed in-house research capabilities that later enabled them to engage in strategic networks that involved two-way flows of knowledge and collaborative research activities" 84 (Dantas and Bell, 2009). The reform of the power sector in the mid-1990s opened yet more opportunities for networking and collaborative research. From the start of the energy privatization process, and as a condition within the concession agreements, companies were obliged to invest $1 \%$ of

83 Such as www.ashden.com, www.scidev.net, and www.scirp.org/journal//ce.

84 The concept of two-way knowledge flows in collaborative research was developed and extensively applied to analyze strategic partnerships and networks in the European Union (Mytelka, 2001). annual net revenues in energy efficiency and R\&D. ${ }^{85}$ This was complemented in 2000 by the creation of "CT-Energy," a fund to support public interest research, ${ }^{86}$ which specifically included energy $R \& D$ and energy efficiency among its "social benefit investments."

In 2002, the Brazilian government's White Book on Science, Technology and Innovation (see Portal do Ministério da Sciência e Technologia, 2002) focused on creating "an effective science, technology and innovation national system" in Brazil. This was followed by Brazil's current policy framework, the industrial, technological, and foreign trade policy, launched in 2003, the 2004 Innovation Law (10.973/2004), and the expansion of sectoral funds, including those earmarked for renewable energy technologies that encourage and financially support a broad range of energy-related networks.

Brazil currently has a substantial network of research groups, or reference centers. They serve as recognized regional or national centers of excellence in a specific domain and are also open information networks in the field of energy technology. Among the research groups and networked centers is the award-winning GreenSolar research group, whose multidisciplinary research on solar thermal energy technologies draws together university departments of civil and mechanical engineering, electronics, control and automation, architecture, computer science, and management. ${ }^{87}$ GreenSolar also works closely with companies such as Electrobras and the main business association in this field, and ABRAVA, the Brazilian branch of the Global Solar Thermal Energy Council. Among the reference centers are CENBIO, which undertook the research on palm oil production in the Amazon (see Section 25.6.1), ${ }^{88}$ and the Brazilian Reference Centre on Biofuels (CERBIO), which works in collaboration with the Paraná Technology Institute to undertake research, development, and innovation on biofuels. It also evaluates the technical feasibility and social and environmental impacts of these biofuels. CERBIO was chosen by the federal government to support the national biodiesel program, which brings together some 30 institutions including universities and enterprises. In this latter capacity, CERBIO is also part of the "Brazilian Service for Technical Answers," through which specialists address technical questions in various fields.

85 This measure was intended "to avoid the risk that the new companies, mostly owned by foreign investors, would transfer all their R\&D efforts elsewhere, a trend already noted by [...] Bourgeois and Jacquier-Roux, 2001" (Jannuzzi, 2005). See also www. annel.gov.br.

86 CT-Energy does not substitute for the obligation to invest, present in the concession contracts. The fund supports energy efficiency programs and initiatives that would not be considered by utilities or market agents, such as the development of energy efficiency standards, consumer training courses, promotion of events, scholarships or research grants directed to projects that will contribute to improvements in energy supply and use. The fund supports regional initiatives to develop local capacity and projects (Jannuzzi, 2005).

87 GreenSolar is based at the Pontificia Universidade Católica in Minas Gerais, Brazil.

88 Information on Brazilian zoning for sugarcane at both federal and state levels is presented in Chapter 20 
Like Brazil, South Africa issued a white paper on science and technology in 1996 outlining the concept of a national innovation system (DST, 1996). Three years later, it had become evident that, in the context of South Africa's complex socioeconomic challenges, more would need to be done to raise investment in science and technology. This led to the development of the South African research and development strategy, which provided funding for a range of technology missions that were central to innovation and to the promotion of economic and social development (Mehlomakulu, 2008). The strategy also recommended interventions to improve the efficiency and effectiveness of the national innovation system, including the establishment of a national agency to stimulate innovation and the introduction of legislation to encourage technology transfer from public research institutions to industry. After declining for much of the 1990s, gross expenditure on R\&D has been rising steadily, approaching a level of $1 \%$ of GDP, ${ }^{89}$ more than half of which is undertaken by industry and not government, as in Brazil.

In most of the "research-intensive" universities and science councils, TTOs were set up during the late 1990s and early 2000s at the initiative of the institutions themselves, who recognized the need for and were willing to devote some resources to this activity, as occurred in Brazil. Active government involvement in promoting technology transfer from public research organizations began shortly thereafter, leading to more TTOs.

While the newer TTOs are still in the process of institutionalizing the relevant policies, procedures, and practices, the more established TTOs have now accumulated some degree of experience and expertise. Patenting and licensing, nonetheless, remain low. Various factors have contributed to this (Wolson, 2008; Sibanda, 2009). The pipeline of invention disclosures is thin. Since the number of potential disclosures is related to institutional R\&D expenditure (Heher, 2005), a smaller system is likely to yield fewer disclosures. Furthermore, researchers are often reluctant to make disclosures, whether due to a lack of interest or incentive or skepticism about the academic technology transfer endeavor. A relatively small pool of researchers with interest and experience in the technology transfer process also affects the quality of disclosures and, as a consequence, they are often not ideal subject matter for commercialization. The costs of patenting are high, and many institutions do not have adequate budgets to pursue international filings. Although the number of technology transfer practitioners is increasing, capacity remains limited, as do capacity-building opportunities. Finally, local licensing opportunities are scarce, with South African technology-led companies typically accessing their technology from abroad, in the belief that local institutions are, for the most part, not a valuable source of innovation, according to a 2005 Innovation Survey (DST, 2007) or are undertaking their own research. Both the South African Technology Innovation Agency and the new Intellectual Property Act provide for financial support and

89 Gross expenditures on R\&D rose from $0.6 \%$ of GDP in 1997 to $0.95 \%$ of GDP in 2006 (DST, 2006/2007). capacity-building activities, which are welcomed, and are expected to assist in overcoming some of the identified problems once they are up and running (see Case Study 4, Section 25.11).

There has also been some concern that South Africa is not capturing the benefits of its own R\&D. However, while examples exist of technologies developed in South Africa that have been commercialized abroad, a recent study investigated some of these cases, but the data failed to identify any technologies that had been transferred overseas and successfully commercialized to the point that they were generating income to their current owners, without benefit to the original inventors (Pouris, 2008).

One example from the field of renewable energy clearly illustrates that commercialization outside the country is by no means synonymous with denying South Africa and South African inventors the optimal benefit of their innovations. The technology for cheap, thin-film, silicone-free photovoltaic cells was developed at the University of Johannesburg with support from the Innovation Fund, a government agency that promotes technological innovation. The university and the inventor set up a company in South Africa to commercialize the technology. The company's decision to license the technology to a German firm attracted strong criticism, on the basis that this was "unpatriotic" and with the implication that the technology was being "lost" to South Africa. But while the first plant was set up in Germany, plans are now afoot to build a South African manufacturing plant that will generate substantial investment and employment and essentially kick-start a new local industry. This is a collaboration between the German licensee and various local investors, including the company owned by the university and inventor. The local partners have also invested in the German firm, resulting in a cross-shareholding that has facilitated access to relevant expertise, know-how, suppliers, and finance that were not available within the country. Arguably, had efforts to set up a local plant been confined to South Africa, it would have taken far longer to build the necessary capacity and attract the funding required (Planting, 2006; Pouris, 2008; Reuters, 2009). While few would argue against licensing new technologies to new spin-out or start-up or existing domestic companies, this case shows that this is by no means the only way to capture value from a technology for the country.

\subsubsection{Creating Knowledge Networks: South-South, North-South}

Knowledge networks for joint research and problem solving, knowledge sharing, analysis, and long-term planning can contribute positively to the development and diffusion of new energy technologies in a number of ways. Such networks, for example, can potentially create confidence that attracts greater funding and might strengthen the sense of local ownership within the context of donor-supported projects. Participation in knowledge networks that strengthens local research capacities, moreover, can create incentives that reduce brain drain, thus contributing to 
the provision of context-specific inputs that are needed for policymaking, for problem solving, and for the design, development, and diffusion of new energy technologies. These benefits are, of course, potential. In this section, we explore some of the ways in which knowledge networks that provide such benefits have emerged and evolved. The focus is on developing and least developed countries where, until recently, such opportunities have been rare.

There is much concern in the developing world about the problem of brain drain. The challenges that this presents are exacerbated by the growing need for access to a continuous stream of knowledge and information in order to make choices about energy technologies and pathways towards energy transitions. Some efforts are being made through networks of centers of excellence, such as the Global Network on Energy for Sustainable Development (see GNESD, 2009), to provide inputs for policymaking in developing countries.

One of several partnerships in the field of energy that were launched at the World Summit on Sustainable Development (WSSD) in September 2002, Global Network on Energy for Sustainable Development (GNESD) became operational in 2004. GNESD received core funding from Germany and Denmark. It has also received initial support from France, Italy, the United Kingdom, the UN Foundation, UNDP, REEEP, and UNEP. It was originally composed of 21 public and private research centers and NGOs engaged in research, with a variety of different strengths in the energy area and situated in both developed and developing countries. However, over the years GNESD has evolved into a South-South knowledge network consisting of 10 centers of excellence. Current membership spans a number of subregions, focusing on policy-oriented research that addresses different aspects of energy access and Millennium Development Goals achievement. Some members have worked together before in other networks. ${ }^{90} \mathrm{~A}$ number of the members are themselves networks; consequently, GNESD's reach is quite wide.

GNESD's work focuses on energy access, energy security, renewables and bioenergy for the poor - notably those in urban and peri-urban areas - and energy policy issues facing governments in the developing world. Within this framework, a steering committee, currently composed of representatives from eight member organizations in the developing world, three from OECD countries, and two from donor organizations, meet annually to decide on the network's thematic programs. The first of these focused on energy access issues. It reviewed existing energy policies in Africa, Asia, and Latin America to identify the effects of reforms that have been carried out in the past and to recommend policy measures that can increase the possibility of bringing energy to those currently without access. One of its outcomes was a publication on how to overcome barriers and unlock potentials in renewable energy technologies (GNESD, 2007) tailored to the needs

90 Interview with Daniel Bouille, Bariloche Foundation, Argentina, center representative. of users, which was followed up by workshops in developing countries organized by member centers to disseminate their findings. ${ }^{91}$ GNESD also undertakes research at the request of developing country governments. In 2010, the UN Secretary-General's Advisory Group on Energy and Climate Change recommended that "[e]xisting knowledge networks should be mobilized and new ones built [...] to accelerate the transfer of best practices (with respect to modern energy system policies and regulations)," and specifically cited GNESD as "a good example of knowledge creation and sharing on energy policy analysis" (UN AGECC, 2010).

In the sciences, the challenges of the brain drain remain acute, and the benefits derived from earlier efforts to build North-South networks in the areas of health and biosciences have not relieved this. In July 2009, the Wellcome Trust ${ }^{92}$ announced a grant of $£ 30$ million (US\$47.9 million) over five years to support seven newly created research consortia based in Africa. The grant is renewable after an independent review. The approach is new in several ways. First, the objective is to strengthen research capacities in Africa itself. The seven consortia are thus based in Africa, each one headed by an African researcher, and their research will be conducted mainly in Africa. As Dr. Alex Ezeh, executive director at the African Population and Health Research Center in Kenya, who is leading the Consortium for Advanced Research Training in Africa, noted, " (n)otwithstanding the attention it has historically received, research capacity remains very weak in Africa. Existing research capacity-strengthening programs and collaborative partnerships in Africa are largely driven by Northern academic and research institutions" (Wellcome Trust, 2009). To this, Dr. Margaret Gyapong, director of the Dodowa Health Research Center of the Ghana Health Service and head of the new Research Institute for Infectious Diseases of Poverty, one of the seven consortia, added, "Africa is losing many of its best scientists to the brain drain, partly because of the absence of coordinated institutional strategies and national research environments [...] poor integration of knowledge across disciplines, and a lack of consistent engagement with policymakers, users and community beneficiaries" (Looi, 2009). The seven consortia include 52 African institutions in 18 African countries, and have linkages to research centers in Australia, Denmark, Norway, Switzerland, the United Kingdom, and the United States. While it is still too early to evaluate its contribution to the development of research capacity in Africa; if successful, it might constitute a new approach to consortia development for energy transitions.

91 Its second theme, renewable energy technologies, was launched in early 2005 and completed during 2006 and 2007. Two other themes were launched thereafter, one on urban and peri-urban access to energy, and the other on energy security. The former has already produced case studies of India, Senegal, Argentina, Thailand, and Kenya, and dissemination workshops have been held to discuss lessons from the needs assessment and the analysis for policies and programs for capacity building.

92 The Wellcome Trust is the United Kingdom's largest charity. 


\section{Box 25.6 | UNU Geothermal Training Programme}

The United Nations University Geothermal Training Programme (UNU-GTP) is aimed at professionals employed by local organizations, public or private, in which geothermal work is already underway or starting up. Potential participants are nominated by their organizations and the selection process emphasizes direct insertion upon return (see UNU, 2011).

The GTP offers courses in nine fields related to geothermal technology and good environmental practice. The programs of individual participants are tailored to these fields so that, over time, teams are built up with the capacity to support local research, exploration, production energy, and environmental planning. This strengthens the "ownership" of geothermal resource planning in projects funded through development assistance and strengthens the set of capabilities needed for research, development, and planning in these countries.

The adoption of a regional approach in areas with large reserves of untapped geothermal potential has encouraged the development of knowledge networks that support local learning and have helped to attract investment in geothermal exploration and energy supply. The Rift Valley in East Africa illustrates this approach. It began with a gradual expansion in the number of participants from Rift Valley countries in the six-month training and research program. This was followed by the first "short course" in Africa, which brought together 33 participants from Kenya, Djibouti, Eritrea, Ethiopia, Tanzania, and Uganda, the six member countries of the African Rift Geothermal Energy Development Facility (ARGeo), a program supported by GEF, UNEP, and $\mathrm{KfW}$, a German development bank (Hamlin, 2004). After successfully testing advanced seismic and drilling techniques in Kenya that will substantially reduce costs (UNEP, 2008), a five-year program of exploratory drilling in the ARGeo countries has been developed and funded (ARGeo, 2010).

A similar approach is being pursued in Central America (Fridleifsson, 2006).

In the field of new energy technologies, the role that training programs can play in supporting research, development, and diffusion of geothermal energy in developing countries has been already demonstrated by the United Nations University Geothermal Training Programme (UNU-GTP). Established in 1978 and located in Iceland, the program was designed to assist in establishing groups of specialists in selected organizations - research institutes, municipal energy utilities, and universities - in developing countries with significant geothermal potential. These groups, in turn, would create local capacity for the exploration, development, and use of geothermal energy in these countries (see UNU, 2010). Initially, the vehicle for capacity development was a six-month specialized training program that brought scientists and engineers from developing countries to Iceland. In 2005, this was complemented by "short courses" on thermal energy topics open to both specialists and decision makers from the public and private sectors. These workshops are held in the developing countries. Co-sponsored by local energy agencies, they include graduates of the UNU-GTP in their teaching staff (Georgsson, 2008).

In terms of standard assessments of project outputs and outcomes, the UNU-GTP has been very successful. Over the period 1979-2010, 452 scientists and engineers from 47 countries completed the program, including more than 75 from China, 53 from Kenya, 31 from the Philippines, 30 from El Salvador, and 27 from Ethiopia and Indonesia. Today, China is a world leader in the direct use of geothermal energy. Kenya, the Philippines, and El Salvador obtain 10-22\% of their total electricity from geothermal energy, and Ethiopia has started its first geothermal power plant (see UNU, 2010)..$^{93}$ What is unique about this program, however, is its many spillovers - some intended from the outset and others the product of iterative learning and adaptation processes. ${ }^{94}$ These innovative practices have created incentives for trained personnel to return home and to stay in jobs for which they have been trained. This helps to meet the challenges of the brain drain, as well as contributing to the sustainability of geothermal research and local production once donor funding ends.

As the variety of new initiatives reviewed in this section illustrates, networking and open and distributed innovation can play an important role in providing the continuous flow of information, "research-based

93 Since its introduction in 2000, 25 have also graduated from the MSc program.

94 See Sections 25.3.1 and 25.3.2 for a discussion of these differences. 
evidence," and analysis that governments need to make informed choices about energy technologies and pathways. However, as Simon Maxwell, director of the United Kingdom's Overseas Development Institute (ODI) points out, "engaging with policy requires more than just research skills" (Young, 2008). Researchers will need to work closely with policymakers throughout the research process, from identifying the problem to undertaking the research itself and drawing out the recommendations for policy and practice. These capabilities are not inherent in the research task, nor is collaboration of this sort the norm in policymaking practice. Working closely with researchers, bilateral and multilateral development organizations, and NGOs, ODI has developed an iterative approach to "engaging with policy" that draws on the concepts of complexity, on the tools of outcome mapping developed by the IDRC (see Section 25.3.1), and policy engagement tools developed by the ODI itself. The process of learning to work in partnership begins by mapping the political context around the policy issue, identifying the key participants and the desired changes in behavior. Developing an engagement strategy, analyzing internal capacities to effect change, and establishing the assessment tools and learning frameworks will then be needed to make alignment and learning in partnership happen (Young, 2008). As this list reveals, many new capacities, in the sense of habits, practices, norms, and values, will be developed in this process.

Participation in networks also strengthens the capacity of governments, local industry, research, and NGOs to innovate and speed up the processes of change. For this to benefit developing countries, however, a concerted effort must be made to strengthen local research capacity, foster a better understanding of open licensing practices in relation to intellectual property rights, and develop and implement policies that support networking and innovation. Innovation, as we have stressed from the outset, must be broadly conceptualized to include both the uptake of knowledge at the frontier and knowledge that is new to the user, community, or country, if not to the world. Problem-solving networks, especially in developing countries, are thus as important as those that lead to patented products and processes.

As the case studies in this section also illustrate, participation in networks and the capacities to innovate are not limited to South Africa and Brazil, but provide opportunities for a wide range of developing countries to move more rapidly towards an energy transition, as the example of geothermal energy showed. ${ }^{95} \mathrm{~A}$ cobenefit of this process is that it can create the positive environment that encourages researchers to remain at home, thus reducing the brain drain.

95 Some of the smaller developing countries, of which Kenya (jikos, geothermal energy) and Cuba (modernization of thermoelectric plants, natural gas [Saenz, 2008]) are interesting examples, have forged ahead in specific energy-related areas, linking problem solving to the needs of local users.

\subsection{Making and Managing Energy Transitions}

This section focuses on the way capacities in the energy sector - notably skills, habits, practices, legal and other norms, and policies - have been built up. But, it also explores the extent to which they have been maintained over time, transferred to new applications, or progressively unlearned as they became less relevant in the course of an energy transition. We look at three very different cases from established oil and gas producers and exporters. In the first two, we focus on the build-up and erosion of R\&D capabilities in Mexico's oil industry and its slow start in moving towards renewable energies and on the Abu Dhabi Economic Vision 2030, which is designed to turn the emirate into a knowledgebased leader in new and renewable energy technologies. The third case examines the approach to an energy transition process taken by the Netherlands.

\subsubsection{From Oil to Clean Energy Systems: Policy Learning and Unlearning In Mexico}

The discovery of giant oil deposits in Mexico during the late 1960s and early 1970s led to a production boom that turned Mexico into a major oil exporter. Over the next two decades, the Instituto Mexicano del Petróleo (IMP), the research arm of PEMEX, Mexico's National Petroleum Company, emerged as a major R\&D center, with strong capabilities in exploration, development, and engineering projects, as well as flexible production planning. The IMP undertook basic and applied $R \& D$, the training of researchers and personnel, and detailed engineering projects. ${ }^{96}$ This would change as Mexico entered a period of economic instability.

With oil prices rising, interest rates at historically low levels, and importsubstitution-led growth slowing down, the Mexican government yielded to the temptation to fuel economic growth by relying on oil revenues and external debt. This mode of development financing collapsed with the crisis of 1982. The "hands-off" model of economic liberalization that followed reoriented growth towards export-oriented industries, substantially reducing the share of oil revenues in total exports, but it did not bring about macroeconomic stability or sustained growth. The accumulation of reserves became negative in this period and after the Mexican financial crisis of 1995, a second surge in oil exports would again push annual production higher.

Since then, accelerated oil exploitation has been driven by a new investment model in which the burden of activity has been shifted to the private sector, leveraging these investments with internal debt. The adoption of these new financial schemes has had a strong negative impact on capacity building. During the crisis years, IMP's

96 "By the late 1970s, about $90 \%$ of the detail engineering of Pemex projects was developed in Mexico" (Guajardo, 2007). 
capacities were not renewed, as PEMEX abandoned efforts to attract new investment and relied increasingly on technological outsourcing. The new investment model was based on build-operate-lease and build-operate-transfer operations carried out by foreign firms. In these turnkey projects, all $R \& D$, licensing, design, engineering, and sometime operation is undertaken by the contracting firms. The buyer acquires a ready-to-use plant (or the final product). By "buying" these capacities, this investment model eliminates the demand for local engineering and R\&D skills, and therefore the learning space needed for local capacity building and the development of new enterprises and organizations.By the early 2000s, the output of Mexico's major oil fields, particularly the Cantarell field, had entered a period of decline, slightly ahead of other giant oil fields in the world (Höök et al., 2009). Nevertheless, production for export continued. Growing certainty about the nature and volume of deep-water reserves in the Gulf of Mexico convinced PEMEX officials that the company must rapidly engage in deep-water drilling and development in order to maintain the pace of extraction. This led to a relaxation of the legal constraints on subcontracting to private partners, on the grounds that PEMEX lacked technical and operational experience to exploit these offshore resources (see SENER, 2007).

Indeed, oil exploration, development, and production in deep waters require a different set of technologies and capacities. Drilling below 500 meters in the sea demands floating platforms, special drilling ships, and satellite guided systems, as well as robotized and other remote-controlled equipment and installations, all equipped to operate under extreme climatic and pressure conditions. Naturally, using these systems also requires specialized capabilities in project design and development that PEMEX clearly lacks. But this is what other firms at similar stages of technological development, such as Petrobras in Brazil, have done (Ballarin, 2002). Moreover, it is precisely what PEMEX did in the past.

The challenge goes beyond the difficulties of building efficient (and safe) deep-sea drilling platforms. Electricity generation in Mexico was opened to independent producers in 1993 , and by 2008 , the private share in generation had grown to $40 \%$. The lack of incentives and a lowest-cost policy for new installed capacity meant that most capacity growth in combined-cycle gas turbines was also constructed via turnkey investment schemes. In addition to its negative impact on the development of local engineering and research capacities, this policy framework has blocked the adoption of renewable energy sources. A similar situation prevails in the development of wind energy (Borja et al., 2005), where turnkey investments are the rule. The Mexican government has since committed itself to exploiting existing, and developing new, renewable energy sources (SENER, 2006), and has recognized the role of technology R\&D in this process (SENER, 2002). But in the absence of a coherent policy framework for capacity building beyond some support to basic research and market deregulation, there is little demand for detailed engineering, design, and R\&D services from local institutes and firms. In the solar energy sector, for example, despite the accumulation of important capabilities in the Instituto de Investigaciones Eléctricas (IIE), ${ }^{97}$ the lack of an industrial incentive framework has prevented spinoffs and transfers of knowledge and technology from the public to the private sector. Moreover, no local industry supplying photovoltaic components has developed. Movement towards an energy transition will thus require a rethinking of current practices and policies that shape incentives, innovation, and the diffusion of new energy technologies.

\subsubsection{Abu Dhabi's Economic Vision for 2030}

In contrast with Mexico, which "unlearned" earlier positive habits of capacity development, Abu Dhabi illustrates movement towards the learning of new habits and practices as it seeks to overcome its dependence on oil and gas, and to develop domestic capacities for an energy transition. Since the discovery of petroleum in 1958, Abu Dhabi's energy sector has been the primary driver of both economic development and environmental degradation. Industrial growth in the emirate, as in much of the Arab Gulf region, has involved the construction of thermal electric power plants, aluminum smelters, cement plants, oil refineries and platforms, and petrochemical and fertilizer plants. According to the World Resources Institute, the United Arab Emirates (UAE), of which Abu Dhabi is a member and the capital, is the world's second largest $\mathrm{CO}_{2}$ emitter on a per capita basis (WRI, 2010).

In view of its small population, the transition to an oil and gas economy also brought with it a heavy reliance on foreign technology and on foreign labor and expertise to operate it. Efforts have been made to reduce the reliance on oil by diversifying into agriculture, manufacturing, tourism, and aviation; by re-exporting commerce; and by establishing freezone facilities and telecommunications. And yet these have tended to exacerbate the problem. The region's member states face a growing challenge in maintaining the demographic balance between nationals and expatriates. In an interview in 2008, a human resource specialist from the Dubai Municipal Government reported that expatriates occupied $99 \%$ of jobs in the private sector and $91 \%$ in the public sector out of a total 3.1 million employees in the UAE: "Going by the trend, [...] UAE nationals will account for less than four per cent" by 2020 (Ashfaq Ahmed, 2008).

Arab states have begun to implement a variety of schemes to encourage nationals into employment and to force private companies to hire more of them. So far, these efforts have been largely unsuccessful in reducing the reliance on expatriates and integrating nationals into the economy.

97 These include capabilities in resource assessment, project development, and plant and prototype design. IIE also defined the technical requirements for design and installation of PV systems with a nominal capacity of up to $30 \mathrm{kWp}$ connected in parallel to the low-tension distribution network. Also, in collaboration with the Federal Electricity Commission and the Rural Development Program, the IIE provided engineering services that enabled the installation of over 40,000 solar panels (IIE, 2006). 
The solution to this challenge lies primarily in the education system, which needs to prepare and equip students with not only the right skills and qualifications but also the work ethic to make them competitive in the job market. Education reforms and training initiatives are being put in place to address the skills gap and to ensure that the supply of suitably qualified employees meets the market's growing requirements, yet the outcomes of these efforts remain to be seen.

One encouraging development is the Abu Dhabi Economic Vision $2030,{ }^{98}$ launched in 2006, which identifies nine pillars that will form the architecture of the emirate's social, political, and economic future. These include the creation of a sustainable knowledge-based economy, for which the above education reforms and the Masdar initiative (see Case Study 5, Section 25.11) will be critical. Unlike Mexico, using the financial resources generated by the "energy-oil and gas" sector is a central element in the energy transition process envisaged in Abu Dhabi's vision of the future and its application in the Masdar initiative. To support the latter, the government has announced that renewable resources will meet $7 \%$ of the emirate's total power-generating capacity by 2020 . It is estimated that this will create a market valued at US\$ 6-8 billion, and will reduce $\mathrm{CO}_{2}$ emissions by 2.4 million tonnes/year. ${ }^{99}$

Despite the progress made, the Masdar Initiative has not been without its problems. In October 2010, Abu Dhabi announced its intention to reduce the costs of the Masdar initiative by $15 \%$ and push the completion date from 2016 to between 2020 and 2025. As Sultan al Jaber, the chief executive of Masdar, emphasized, "The vision as a whole remains intact. No scale-back, no scale-down. There isn't a model or example anywhere around the world today that we can use. We have to come up with the answers ourselves" (The National, 2010). Partly in reaction to the impact of the financial crisis on property markets, this decision was also a response to lessons learned over the past several years in the design and construction of a carbon-neutral city. Concentrated solar power (CSP), which uses mirrors to reflect sunshine on to a central collection point, for example, is less effective in Abu Dhabi, where humidity and sand in the air can make the sun's rays less intense than anticipated. New approaches to CSP will have to be developed. The use of geothermal power in Abu Dhabi will also require new thinking, as the far deeper drilling required will be a more costly process than initially foreseen. These unexpected developments point to the need to make educational reform an integral part of any strategy to move from fossilfuel-based economies to renewable energy systems and to the importance of systems thinking, interdisciplinary approaches and continuous feedback throughout a transition process.

98 The Abu Dhabi Economic Vision 2030 was designed based on the advice of development experts from Norway, Ireland, and New Zealand (Abu Dhabi, 2008).

99 As part of the Masdar initiative, Abu Dhabi has also created a US\$50 million development fund that will be used to provide loans to support renewable energy projects in the developing world until 2016.

\subsubsection{The Dutch Energy Transition Approach}

An interesting attempt at working towards an energy transition to a low-carbon economy is the Dutch energy transition approach. It is significant because of its focus on transformative change, its reliance on bottom-up processes, and its enrolment of business and other nonstate actors in the transformation process. It grew out of deliberations between innovation researchers and policymakers in 2000, in which policymakers came to accept that a traditional policy approach based on short-term goals formulated by various ministries (in an uncoordinated way) and cost-effectiveness will not work. They also recognized that fostering radical innovation requires a different approach, one that is more forward-looking, with attention to possibilities and barriers, drawing on ideas for innovative change among market actors and innovative thinkers, with policy aligned to identified transition paths. This new way of thinking has been described as follows:

It is clear that working on fundamental changes to the energy system can only be successful if the government adjusts its policy instrumentarium accordingly. This means that the policy for research and development, the stimulation of demonstration projects, and the (large-scale) market introduction must be brought in line with the selected transition pathways. In addition, the suggestions for new policies put forward by the platforms must be taken seriously. At this point, the government faces a major challenge, because much of the current policy was formulated based on the classic way of thinking that is characterized by a top-down approach and dominated by short-term objectives, implemented by fragmented and individually-operating departments and ministries, on which market influences do not or hardly have any effect (Dietz et al., 2008).

At the heart of the energy transition project are the activities of seven "transition platforms": new gas, green resources, chain efficiency, sustainable electricity supply, sustainable mobility, built environment, and energy-producing greenhouses. These platforms bring together individuals from the private and the public sector, academia, and civil society to identify innovative system configurations in a particular field, to develop a common ambition for an area of energy use or energy conversion, to think up pathways and programs, and to suggest transition experiments. Through these platforms, 31 transition paths have been selected.

The portfolio of transition paths contains technological innovations at different stages of development. The choice is based on technologies in which there is expertise in the Netherlands and an interest from business actors to work on them.

Based on suggestions from the transition platforms, a transition action plan was formulated in 2006 with the following goals:

- reducing $\mathrm{CO}_{2}$ emissions by $50 \%$ by 2050 in a growing economy; - increasing the rate of energy saving from $1.2 \%$ to $1.5-2 \% / y e a r$; 
Table 25.1 | The frontrunners' desk in the Netherlands. Source: Weterings, 2006.

\begin{tabular}{l|l}
\hline \multicolumn{1}{c|}{ Services for innovators } & Services for policymakers \\
\hline Obtain financial support from existing instruments & Make existing instruments more conducive for innovation \\
\hline Contact relevant agencies and government staff & Improve policy coordination between and within ministries \\
\hline Overcome legal problems and problems with permits & Encourage case-sensitive implementation of existing and new policy \\
\hline Widen their network and strengthen the organizational set-up of the innovation trajectory & Encourage policy development in areas of the innovation chain that are not well covered \\
\hline Provide business support and public relations help for successful market introduction & Be of service to businesses in a case-sensitive way \\
\hline
\end{tabular}

- making the energy system progressively more sustainable; and

- creating new business. ${ }^{100}$

The platforms are intended to mobilize the interests of society and of business in innovative change and to promote learning and action. Issues of wider interest (or more strategic nature) are taken care of via a special council called the Regieorgaan Energietransitie Nederland.

The transition approach was consciously set up as a vehicle for coordinated socio-technical change and policy change. Through their involvement in the platforms, businesses are encouraged to work on and assist in the development of low-carbon innovations, including those that are not yet ready for the market. The platforms fulfill an intelligence function based on discussion, specially commissioned studies, and a coordinating function for emerging technology innovation systems. ${ }^{101}$

In addition to the transition platforms, an interesting policy innovation is the "front-runners' desk," created in 2004, which seeks to help innovative companies with problems they encounter, and to help policy to become more innovation friendly. Problems varied from difficulties with obtaining financial support (from government or the private sector), to problems with getting permits. Between January 2004 and March 2006, 69 companies approached the desk to discuss their problems. In 59\% of cases, the problems were solved thanks to the intervention of the desk, in $12 \%$ of the cases the companies could not be helped, and in the remaining cases (29\%), the desk was still dealing with the issue at the time of the evaluation (Weterings, 2006). Table 25.1 provides an overview of the functions of the front-runners' desk for innovators and policymakers.

100 The official goals in 2009 for 2020 were: $2 \%$ rate of energy saving a year, $20 \%$ share for renewable energy, and $30 \%$ reduction in $\mathrm{CO}_{2}$ emissions.

101 As an illustration, in 2009, the platform for sustainable mobility will: (i) make recommendations for the fiscal treatment of clean vehicles; (ii) discuss the action plan on alternative mobility with leasing companies; (iii) examine how natural gas and green gas may pave the way for hydrogen; (iv) evaluate experiences with bus experiments funded in the first tender; ( $v$ ) offer advice on how public transport concessions may be used for innovation; (vi) assist in the implementation of five pilots about smart grids and electric mobility; (vii) launch or stimulate pilots for sustainable biofuels (high blends and biogas) and hydrogen in five cities, in cooperation with Germany and the province of Flanders in Belgium.
The energy transition involves government agencies on different issues and at all levels. Some mechanism of cooperation is thus needed. Special arrangements have been set up for this task in the Netherlands, the most important of which is the Interdepartmental Project directorate Energy transition (IPE). The IPE plays an important role in "taking initiatives," "connecting and strengthening initiatives," "evaluate existing policy and to act upon the policy advice from the Regieorgaan and transition platforms," to "stimulate interdepartmental coordination" and to "make the overall transition approach more coherent" (The Netherlands, 2008). In drawing upon suggestions from the platforms, however, there is a danger of the transition process becoming a closed shop. Options outside the portfolio are at a disadvantage, but are not locked out. New initiatives may emerge outside the platforms through parliament or because certain powerful parties in society are able to secure policy support for it. This happened in the case of battery-powered electric vehicles, for which a coalition of NGOs, businesses (Essent, Better Place), finance (ING, Rabobank), and the Urgenda (a coalition for sustainability action) successfully lobbied ministers and parliament to provide special support to electric vehicles.

On the whole, policy coordination has improved in recent years (200010). For example, battery-powered electric vehicles, hybrid electric vehicles and other low-emission vehicles are subject to special fiscal treatment. There is more cooperation between ministries and among government, business, research, and civil society. There is also more cooperation between previously separate national and regional initiatives.

Various kinds of capabilities are being created in a strategic way for technologies and policy through the Dutch transition approach. Areas for creating capabilities are being identified through the activities of the transition platforms, and they are supported by policy in a provisional manner. The government's ability to act to bring about systemic change has improved, and there is a commitment to transitional change that is absent in many countries. Indeed, the political discussion on low-carbon energy in many countries is narrowly focused on centralized choices of carbon capture and storage (CCS), and natural gas and nuclear power plants. These discussions are also taking place in the Netherlands, but more options can be explored through the energy transition approach. 
The Dutch approach is not without faults. The platforms are dominated by well-known energy companies (the insider-outsider problem). A second problem is that subsidies for energy investment are funded through general taxes, which makes those subsidies vulnerable to cuts. It is better to fund these through energy bills, as is the case in Germany, in order to create an element of continuity in energy transition policy. This takes on particular importance when governments change. Dutch clean energy policies have been characterized by major discontinuities that have hampered energy innovation (Verbong et al., 2008). This is not the fault of the energy transition approach, but the problem has not yet been resolved.

\subsubsection{Moving Towards an Energy Transition}

Oil- and gas-producing and exporting countries have faced considerable difficulty in overcoming the tendency to rely heavily on this one sector, to the detriment of greater economic diversity and flexibility. Significant new thinking and practices have emerged in these countries, although overcoming the challenges of path dependence, sunk costs, and established habits and practices to move towards an energy transition has been particularly difficult.

The broad set of initiatives discussed in this section provides pointers for working with and around habits, practices, and challenges in other environments. The Norwegian government, for example, created the Norwegian Petroleum Fund in 1990. All central government revenues from petroleum operations are deposited in this fund, all of which is invested abroad to provide a buffer between current petroleum revenues and the use of these revenues in the Norwegian economy. The government uses about $4 \%$ of its petroleum revenues annually (Norges Bank, 2004). The Norwegian energy innovation system also includes Enova SF, a public enterprise created in 2002 and owned by the Ministry of Petroleum and Energy. Enova SF advises the ministry on issues related to new renewable energies and energy efficiency, with the goal of reducing energy use. Its funding comes from a levy on the electricity distribution tariffs (Enova, undated; Borup et al., 2008). Brazil, already well along the pathway towards cleaner energy in the transport sector, is planning a development fund using oil revenues. Abu Dhabi's Masdar initiative has grown out of a similar process, and the Arab Gulf states are developing the education and research base needed for an energy transition that will involve more than simply importing technologies and expertise.

The policy dimension has also been important in moving towards energy transitions in these countries. Mexico, having moved away from a focus on building and sustaining capacity in the oil sector, is now on the brink of developing a cleaner energy strategy based on wind and solar power for which capacity development will be necessary. Some capacities have already developed within existing organizations, but policy coordination and new policy measures that provide the incentives and support the use of this new knowledge for innovation are lacking.
The Netherlands has adopted a particularly innovative approach to energy transition thinking and practice that provides pointers for others looking to work with and around existing habits and practices in their own environments. The approach is embodied in the role of energy platforms. These platforms bring together individuals from the private and public sectors, academia, and civil society to identify and make proposals to government about policies for different energy-related initiatives. They are not just "talk shops," but spaces for dialogue that inform the participants of their diverse interests, concerns, and goals. They mobilize and legitimize a process of change and the kinds of support measures that would be needed for movement along consensual pathways. Their proposals feed directly into the policy process.

\subsection{Enhancing Capacity for Effective Participation at the International Level}

A wide variety of new technology, energy, and environment issues are increasingly being dealt with at the international level and across many different venues. They include trade, intellectual property, and antidumping issues at the World Trade Organization (WTO); technology transfer and the future of a multilateral climate framework at meetings of the United Nations Framework Convention on Climate Change (UNFCCC); funding opportunities through the CDM under the Kyoto Protocol; the Global Environment Facility (GEF); and other funds managed by the World Bank. Enhancing the capacity for effective participation in international negotiations has thus become an arena within which substantive knowledge about the subject under negotiation will be needed, as well as the capacity to design projects for and secure access to the many funding sources now available for adaptation to climate change, and new energy technologies and their diffusion. This will require the strengthening of capacities for networking, learning, and innovation ${ }^{102}$ along multiple dimensions.

Developing countries soon faced the rising transaction costs of settling antidumping complaints, which were first signaled in the controversies generated by the difficulties that developing countries encountered in accessing drugs to deal with HIV/Aids and the role of the Agreement on Trade-Related Aspects of Intellectual Property Rights. Like most developing countries, Brazil initially met this new international legal challenge by hiring foreign law firms. Subsequently, a few Brazilian law firms created departments specializing in WTO negotiations, and they signed agreements with government and major law schools in Brazil to create domestic expertise in international trade law. The presence of local lawyers on law school faculties helped to form expert groups that strengthened the capacity development process (Shaffer et al., 2008).

102 For example, UNDP's "Capacity development for policy makers" project seeks to strengthen the national capacity of developing countries to develop policy options for addressing climate change, as inputs to the UNFCCC negotiations. 
Further experiments in capacity development began when Brazil established an advanced WTO mission in Geneva and signed agreements with Brazilian schools of law and of international relations to create a training program in Geneva - the first of its kind in Brazil. This experiment played an important role in strengthening Brazil's capacity to participate in the more informal dispute settlement negotiations in Geneva, where many such disputes were actually resolved (Shaffer et al., 2008). The virtuous cycles of learning and practice further strengthened Brazil's network connections, with some surprisingly positive and unexpected benefits. ${ }^{103}$

\subsubsection{Funding Energy Transitions: A Capacity Development Approach}

The CDM, as a development financing mechanism, marks a new innovation in international environmental law and with it the need for a new set of capacities. The CDM is an emissions offset trading system that allows countries to meet their Kyoto targets by investing in emissions reduction projects in developing countries, where the marginal costs of GHG abatement are expected to be lower than in industrialized countries. It has the added purpose of helping to promote sustainable development and technology transfer to developing countries (Doranova, 2009).

After several years in operation, the results of the CDM are mixed. The mechanism has attracted considerable investment, with more than 4500 projects currently at some stage of development and approval (UNEPRisø, 2011). But there are also a range of problems:

- there are concerns that many of these projects would have happened without the CDM (lack of additionality or environmental integrity);

- few projects promote sustainable development;

- projects are not distributed equally (especially in Africa);

- there are high administrative burdens and transaction costs; and

- there is unequal negotiating power among project participants (see van Asselt and Gupta, 2008).

The CDM has generally not spurred innovation and is not in and of itself poised to foster any type of energy transition in developing countries. There is also no firm evidence that the mechanism has encouraged participating companies in the North to move towards cleaner technology, rather than simply buying time. Many CDM projects are "end-of pipe" control technologies such as HFC-23 control projects, ${ }^{104}$ which favor existing interests in pursuing the cheapest emissions reductions. Path dependence thus remains the driver, not change.

Multilateral climate negotiations are in a state of transition. This is not surprising, considering that they cover not only the respective emission cuts by different groups of countries, but also topics as wide as agriculture, deforestation, technology transfer, intellectual property rights, competitiveness, international transportation, and financial mechanisms to support climate change mitigation in developing countries. This requires a significant amount of capacity development with negotiators. The European Capacity Building Initiative $(E C B I, 2011)$ is an initiative for sustained capacity building in support of international climate change negotiations. The ECBI promotes a more level playing field between government delegations during international climate change negotiations and aims to facilitate mutual understanding and trust, both between European and developing countries and among developing countries.

The most important topic for the foreseeable future in the climate change negotiations is financing and crediting. Moving forward approaches such as the Clean Development Fund, the existing Least Developed Country Fund, and the Special Climate Change Fund, requires specialized and substantive knowledge from all negotiators involved. Currently, most negotiators in the climate talks are career diplomats who lack sufficient knowledge of financial markets, technology development, and scientific fields relevant to climate change to lay the foundational framework for energy transitions. Negotiators too often do not have the capacity to develop a clear overview of the options on the negotiation table, let alone how they might reach strategic targets that are in the common interest.

The capacity to have a broad overview of the climate negotiations and to translate diplomatic decisions into action will be crucial in the next few years. This is especially the case now that the "collective commitment" that emerged in the Copenhagen Accord to provide "new and additional resources [...] approaching US\$30 billion to developing countries for adaptation, technology development and transfer and capacity building in the period 2010-12" (UNFCCC, 2009) has been confirmed at the UN Climate Change Conference in Cancún in December 2010. Developed countries also committed to a goal of jointly mobilizing US $\$ 100$ billion a year by 2020, "in the context of meaningful mitigation actions and transparency on implementation" (UNFCCC, 2009). Such funds must focus on building capacity in developing countries.
103 An analysis of data on over 1300 antidumping investigations initiated by different countries against other WTO members showed that "those countries that are abundant in legal capacity are more likely to challenge $A D$ duties brought against them and less likely to be targeted by AD duties in the first place. These results are especially striking in light of the fact that we control for these countries' market power, which make credible their threat to retaliate" (Busch et al., 2008).
104 The top-two renewable energy projects (after hydropower) are biomass (129) and wind (161) projects. Together, they generated 37,272,397,000 carbon credits (Certified Emission Reductions, or CERs), whereas the 18 HFC (fluoroform) projects in the CDM pipeline as of October 2009, generated 218,637,000 CERs. See UNEPRisø, 2011. 
Even if these funds were to be fully subscribed, there would still remain a vital need for capacity development to enable developing countries to participate effectively in international negotiations concerning the governance and use of these funds and to benefit from the various funding opportunities. There is also a need for the funding itself to support broader innovative capacity in low-carbon technologies in developing countries - not just a series of low-carbon hardware projects (e.g., Ockwell et al., 2009). Past practice has shown that funding mechanisms such as the CDM have had a limited impact on the development and diffusion of new energy technologies. Most developing countries do not have the capacity to design such projects or identify partners and work with them to do so. The CDM recognized this and began, rather late, to emphasize a needs assessment approach, but without the methodology and training that would make local choices possible. The CDM's own methodology, doing baseline studies and attempting to determine additionality, are meaningless in the context of least developed countries, where the capacity to undertake data collection and analysis and to evaluate choices is critical yet largely absent. Only in the past several years have UNEP and the GEF begun a series of workshops to fill the gap, as the case of Bahrain and the role of the Arabian Gulf University in that country illustrate (see Case Study 6, Section 25.11). Of particular interest is the way in which the use of local education and research institutes to train analysts in the developing world strengthens their capacity to support regional networks.

In conclusion, effective participation in the international system is critical for energy transitions. Although currently going through stages of learning, global regimes including the CDM have an important role to play in encouraging and supporting change. This cannot be done solely through financial flows. It must also provide legitimacy for citizen action. An equitable framework for legitimate engagement and negotiation in which stakeholders can participate at a substantive level is part of the global enabling environment that would ultimately enable the system to work for energy transitions.

\subsection{Conclusions}

Bringing cleaner, safe, and affordable energy and energy services to people, moving away from our current dependence on fossil fuels, and reducing the need for energy to the largest possible extent, are key energy challenges for society today in both developed and developing countries. Meeting these challenges will involve major changes in energy supply systems, energy-using technologies, and their associated practices. Improving trajectories based on fossil fuels and building supercritical coal-fired power plants will not enable us to meet these challenges - it will merely lead to problems in the future. Ultimately, we must shift to renewable and green energy sources, electric transport technologies, zero-energy buildings, and more efficient energy supply systems. The focus in this chapter, therefore, has not been on "policies for capacity development," in general, but on the challenges of energy transitions and the capacities and capacity development processes that are needed to overcome them.

As energy transitions will differ across countries, and perhaps even between regions within a country, these conclusions do not attempt to provide a definitive list of what should be done. But the experiences reviewed here do point to a number of principles that might usefully be applied when thinking about capacities and capacity development policies for sustainable energy transitions in a given environment. This takes us one step beyond the classic discussion about what needs to be done, and towards an exploration of ways in which such changes might be brought about in a variety of different contexts. It also opens opportunities for reflection on the multiple benefits that might be generated for livelihoods, learning, innovation, consensus building, and development, through the capacity development process.

\subsubsection{Getting There from Here: First Principles}

Energy transitions are long-term, socially embedded processes that involve changes in production and consumption patterns, knowledge, skills, formal and informal institutions, and the habits and practices of the actors involved. These characteristics have major consequences for the choice of an energy transition pathway today and the capacities that might be needed to move down that pathway successfully in the future. From this perspective, capacity development can no longer be seen as a simple aggregation of individual skills and competences or the introduction of a new "technology." In the course of an energy transition, moreover, capacities at the actor and systems levels, and the policies for capacity development themselves, will inevitably change. This will require feedback and the capacity for flexible adaptation over time. How might we deal with the uncertainties and complexities generated by such a process?

\subsubsection{Principle 1: Understanding the Challenges}

All change processes inevitably face challenges that emerge from established habits, practices, norms, and interests, or what we have called "informal institutions and path dependency." These can slow both the development and the diffusion of new energy technologies. In conjunction with the "lock-in" effects of earlier investment in physical plants, supplier linkages, infrastructure and skills, and efforts to move towards energy efficiency improvements are also slowed.

Understanding these informal institutions and learning to work with and around them in a given context are important first steps in an energy transition process. This principle was illustrated in a wide variety of cases that include efforts to improve energy end-use efficiency in transport (Section 25.4.1) and buildings (Section 25.4.3), the introduction of new energy technologies and their accompanying practices in the case of smart grids (Section 25.4.2) and wind turbines (Section 25.5.1), and the 
diffusion of solar home systems (Section 25.5.2) and cookstoves. What emerged from these studies is the need for dialogue (Section 25.5) of many sorts and at many levels in dealing with the challenges of energy transitions.

\subsubsection{Principle 2: Dialogues Make a Difference}

Dialogues may not "solve" these problems, but they do open channels for innovative ways to deal with them. Moreover, they open channels that traditional awareness-raising programs, based on public meetings, conferences, one-off consultations, and focus groups, cannot. For dialogues to work, confidence-building measures that recognize the legitimacy of local concerns, interests, and needs is a first step in gaining broad societal support for an energy transition. And this is the case whether it concerns renewable energies, lighting services, improved cookstoves, or personal mobility in the public transport system.

Dialogues must begin early in the process of conceptualization to be effective. This is when the identification of needs and problems and the range of options available and preferences for how to deal with them are first discussed. Dialogue should not be limited to the usual stakeholders, nor should solutions be reduced to a few predetermined options. An open mind should be kept vis-à-vis nonconventional solutions. This applies to both broad policy directives and the development of programs and projects at the local level. It is at this point in the process that a framework for domestic consensus building must be developed by involving the wider community in discussions about key issues and choices, as well as their consequences. One such approach consists of creating spaces for dialogue about transition pathways, processes, and policies that bring together members of the public and private sectors, academics, and civil society in what the Dutch have called transition platforms (Section 25.8.2).

Identifying relevant stakeholders and building the capacities needed to engage meaningfully in this new practice are essential in initiating and sustaining energy transition processes. Not all stakeholders will have the same view of a problem and possible solutions. In a dialogue, it is understood that the solution to barriers may not lie in support policies for the technology but in finding the appropriate technology configuration, which will require coalition building and stakeholder learning. This opens opportunities to reconsider the proposed solution, a process that may result in its rejection or major adaptation. "Not in my backyard" resistance may be turned into constructive dialogue focused on the question: if not this, then what else?

\subsubsection{Principle 3: Dialogue Processes Have Wide Applicability in Energy Transitions}

Dialogues will be needed throughout the lifetime of a program or project in an energy transition. To make dialogues meaningful, mechanisms for feedback and flexibility will have to be built into programs and projects - the former to legitimize the use of "negative" feedback as a positive incentive for change, and the latter to create space for adaptation to take place as energy transitions evolve.

Going beyond the project level, the emergence of decentralized and distributed processes, energy-related practices, and new technologies have raised the importance of local actors in decision-making processes. Examples include wind power in Germany, the Netherlands, and the United Kingdom, agriculture-based renewables in Brazil and Mali (Section 25.6.1) and micro hydro in China, Bhutan, Nepal, and Rwanda (Section 25.6.2). In this context, dialogue can become a useful bridging mechanism for consensus building across national and local levels.

Although the notion of dialogues has been in circulation for some time in the capacity development literature, the practice of designing projects through a dialogue has not been systematically applied (Section 25.3.1). Long-standing discussion on the need for developing country ownership of donor-funded projects can also benefit from this engagement in the dialogue process. The success of such an approach, however, depends critically on the extent to which those in partner countries have access to the knowledge and information they require to develop positions of their own. It also depends upon the extent to which experts from donor agencies have learned to engage in meaningful dialogue processes.

For least developed and many developing countries, the capacities to articulate their positions in international negotiations are also an issue. The experience of Brazil in international negotiations (Section 25.9) and the development of programs such as those at the Arabian Gulf University (Section 25.9 and Case Study 6, Section 25.11) suggest ways to meet this capacity development need. Indeed, UNDP, IDRC (Section 25.3.1) and ODI (Section 25.7.3), among others, have developed tools for this purpose.

\subsubsection{Making Choices about Energy Transition Pathways}

Access to knowledge and information - and the capacity to use such inputs - are critical in making choices about energy transitions, whether at the level of individual actors, communities, or national governments. Most developed and emerging economies have created national agencies for this purpose. These agencies monitor international developments and regularly undertake national surveys that provide comparative information for making choices among alternatives in both the short and the longer term. With access to a wide array of information on local and international conditions, and the capacity to use such data, these countries are developing methodologies that will enable them to move from static cost comparisons to analyses of factors that might affect longerterm costs and savings (Section 25.3.2). This longer-term perspective opens up opportunities for building flexibility into strategies for energy transitions and the necessary policies for capacity development. 
Many developing countries, however, lack access to continuous flows of knowledge and information on new and improved energy technologies, the policies and practices of other governments, or enterprise strategies. But these countries' governments also face the challenge of collecting local and national data on the state of education, innovation, industry, energy use, and efficiency. Surveys and studies undertaken by UNESCO, UNIDO, and New Partnership for Africa's Development (NEPAD) attest to this. ${ }^{105}$ Strengthening the capacities of governments, universities, NGOs, and other organizations in data collection and analysis can widen the range of choice of new energy technologies to meet local needs and expectations.

\subsubsection{Principle 4: Accessing Knowledge and Information}

Problem solving can be accelerated by developing channels for access to knowledge and information. These channels consequently encourage the more rapid diffusion of new energy technologies. The beneficiaries would be manifold, going beyond local governments, research bodies, and the banking and business sectors to include agricultural extension services, energy users, and intermediaries such as urban transport and utility companies, architects, and builders. National reference centers in Brazil (Section 25.7.2) and front-runner desks in the Netherlands (Section 25.8.2) are two examples of how this concept can be adapted to different contexts.

To encourage a more diversified set of criteria for rewards, such as research grants and promotions, policies will need to be put in place that stimulate and support linkages between research and users - whether in the business, health, government, NGO, or other sectors (Section 25.7.2). Research funding will also need to be made available for this purpose. This can take a number of forms. In Brazil, national reference centers are attached to universities and are supported by university research. Two quite different approaches linking R\&D to its potential users are, first, CT-Energy, a fund created in Brazil to support "public interest research," including energy $R \& D$ and energy efficiency, and, second, the integrated approach to $R \& D$, energy industries, and investment in the Masdar initiative (see Case Study 5, Section 25.11).

\subsubsection{Principle 5: Create Opportunities for Interdisciplinarity and Systems Thinking}

The higher education system is crucial for sustaining an energy transition, yet current practices will need to change if it is to play this role. The long-term and uncertain nature of energy transition processes requires flexibility that standard discipline-based educational and training

105 The lack of up-to-date statistical information in the surveys published by UN Agencies show how difficult it has been to collect comparable data at regular intervals from local ministries. The launch of innovation surveys by NEPAD has also faced a lack of trained personal and funding. programs do not often provide. This at least suggests there is more need for interdisciplinarity in graduate, postgraduate, continuing education, and training programs. In many countries, this will require policy changes at the national and university levels to create this flexibility now and thus strengthen the capacity for adaptive curricula changes as the relative importance of issues, technologies, and challenges change over time.

Interdisciplinarity impacts the speed with which new energy technologies are developed and diffused in disciplines where established practices mediate between the demand for and acceptance of these technologies. Examples include architecture, engineering, housing and construction, new materials, transport, urban planning (Section 25.4.3), and the biosciences (Section 25.6.1). Targeting these disciplines will enable university programs to offer a wider view of the issues and options that are currently available and to study and assess those that are on the horizon. For developing countries, interdisciplinarity could provide evidence-based research as an input into planning and policymaking processes across a wide spectrum of actors in civil society, the business sector, and government.

Managing energy transitions is another area in which universities could play an important role. They could create opportunities to update policymakers on the range of available options and strengthen the contribution of scientists and social scientists in decision-making processes. Both the rapid turnover in personnel at the middle and senior advisory and policy levels in developing countries, and the need for mobility to widen perspectives in the industrialized world, make continuous education for energy transitions imperative. Interdisciplinary masters-level programs designed to bring together scientists, and policymakers have a role to play here.

\subsubsection{Principle 6: Use Knowledge Networks to Solve Problems during Energy Transitions}

Open innovation practices and networking in industrialized countries are helping to speed up the pace of problem solving in a growing number of sectors. Users, especially companies, but also government agencies and community organizations, are becoming increasingly aware of its possibilities (see Case Study 3, Section 25.11). The core insight of this approach is the ability to use the world outside an organization to generate internally useful knowledge in a purposeful manner. This involves the development of networks and the capacities needed to use them.

Developing countries are moving in this direction now as well. In particular, they are strengthening their domestic research capacity (Section 25.7.3) and problem solving (Section 25.7.1), and they are facilitating adaptive changes in the course of energy transitions and supporting the process of making choices about energy pathways. It was a critical factor in boosting productivity and reducing costs in the development of ethanol from sugarcane in Brazil (Section 25.6.1). In Mali, with the 
support of the local member of the AREED network, research has supported the growing of jatropha in a multi-cropping environment and the use of jatropha oil for power and electricity generation (Section 25.6.1). The UNEP-funded REED network, of which AREED is a member, has supported renewable energy enterprise development in Senegal (Section 25.5.2) and its GNESD network (Section 25.7.2). This network comprises centers of excellence in industrialized, emerging, and developing economies, undertakes joint energy policy-related research, and provides a space for knowledge sharing on the links between sustainable energy and other development and environmental priorities, as well as technology and policy options.

In the field of new energy technologies, United Nations University Geothermal Training Programme has designed its training program to deal with the problem of brain drain by strengthening capacities for local research, exploration, and the development and production of geothermal energy in East Africa. Participants in the six-month workshop in Iceland had jobs in this field in East Africa to which they would return. Bringing policymakers and practitioners from the region together in local workshops supported network building among these countries (Section 25.7.3).

\subsubsection{Policies and Practices in Making and Sustaining Energy Transitions}

The long-term, socially embedded nature of energy transition processes gives rise to various challenges. The choices made in selecting energy transition pathways are also inextricably linked to broader development issues and goals. These, too, must become visible as part of a dialogue process, and the tradeoffs must be made explicit. The case studies reviewed in this chapter make clear that in laying the foundation for an energy transition, it is necessary to work from a longer-term, systems perspective.

\subsubsection{Principle 7: Energy Efficiency is a First Step towards an Energy Transition}

Energy efficiency improvements can potentially bring about changes in existing habits and practices of energy use, but they do not in and of themselves constitute energy transitions. They are only one step on a path that might lead to a more transformative change. In designing energy efficiency programs, it is important to take a longer-term perspective that builds in a strategy for developing the steps to follow.

Urban public transportation provides a good example of how this might be done. Energy efficiency improvements in this sector are driven mainly by the need to reduce costs and increase fuel efficiency, especially where fuel is imported, and to address transport access issues. For instance, bus rapid transit (BRTs) systems - of which there are currently
47 around the world, including 16 in Latin America, several in Asia, and one in sub-Saharan Africa (Section 25.4.1) - provide relatively cheap and frequent bus services that widen access to employment opportunities. In some cases, they have also been designed to lure drivers away from their automobiles, thus reducing traffic congestion in urban areas, contributing to changes in current habits and practices, and reducing overall GHG emissions.

But there is a need to go beyond these objectives and develop a strategy that replaces fossil fuels with renewable energy. Examples of this can be found in programs such as the European Regions and Municipalities Partnership for Hydrogen and Fuel Cells, and in the creation of a private sector firm in Tanzania that produces biodiesel from used cooking oil, which it sells to the minibus (matatu) sector (Section 25.4.1).

\subsubsection{Principle 8: Adopting a Multi-Goal Perspective in Energy Transition Strategies Can Generate Multiple Benefits}

As the transport sector illustrates, an extensive array of multiple benefits can be envisaged as part of an energy transition process. Support for the development of biofuels in developing countries and their use in urban and rural areas is one way to create a continuous movement towards an energy transition over the long term. It also offers income-generating opportunities for rural smallholders who intercrop biofuel crops with food crops, as the examples of Garalo in Mali and the Brazilian Amazon region illustrate (Section 25.6.1). Adopting a multigoal perspective starts with an analysis of local resource availability and the early identification of linkages and support structures that will be needed to build local markets for biofuels, and cleaner energy technologies such as cookstoves and multifunctional energy platforms. At the same time, such a perspective can help to identify alternatives to existing energy pathways. For this to take place, a multi-goal perspective must be consciously built into policies, programs, and financing mechanisms from the outset.

In both industrialized and developing countries, SMEs continue to be major drivers of innovation processes, as well as contributors to livelihoods and employment creation. Opening space and creating the support structures for the establishment of innovative SMEs in the provision of energy services has played a role in stimulating market growth and the diffusion of new energy technologies in such diverse areas as solar home systems, renewable energies, and offgrid energy access.

In creating small-scale energy solutions, knowledge of the local market is critical but needs to be complemented by networks and local organizations that help to strengthen business skills and the ability to adapt technologies to local needs, as the AREED examples show (Section 25.5). This requires users to have some domain knowledge 
and technical skills, as well as the habits and practices that support learning and innovation. Financing for SMEs to develop such capabilities is scarce in developing countries. New international support programs that might strengthen capabilities to meet the challenges of development and climate change were envisaged in Copenhagen and in Cancun, at the $16^{\text {th }}$ meeting of the Conference of the Parties, a decision was adopted to establish a Technology Mechanism comprised of a Technology Executive Committee and the Climate Technology Centre and Network (UNFCCC, 2011).

How these new organizations will operate still needs to be defined. Ensuring that developing countries have the capacities to participate meaningfully in future negotiations on programs and practices under the Technology Mechanism will be critical to their success and sustainability. As to funding, the European Parliament acknowledges that this will be a challenge but believes it to be feasible. Members of the European Parliament's "climate parliament" have formally proposed that at least $5 \%$ of the EU budget should be devoted to ensuring a rapid transition from fossil fuels to wind, solar, and other renewables in the European Union and a further one billion euro/year be used to support renewable energy in developing countries. Such funds could support local NGOs, domestic foundations, R\&D, grant-making councils, and business support structures in developing countries, and take this process of building rural and peri-urban energy solutions into a broader program of market building and SME upgrading.

\subsubsection{Principle 9: Consciously Pursue Market-Building Strategies as a Driver of Diffusion}

The development of a conscious strategy of market building in energy-related projects and programs is also important in driving the widespread diffusion of new energy technologies in developing countries. The diffusion of solar home systems in Kenya, Sri Lanka, and Bangladesh (Section 25.5.2) and micro-hydro in China, Bhutan, and Nepal, illustrate some of the challenges and successes of bottom-up processes that take a market-building approach (Section 25.6.2 and Case Study 3, Section 25.11). The absence of such a strategy and its impact on diffusion is also clear, notably in the traditional approach to improved cookstoves. The latter relies on stoves designed abroad with expensive materials and that are imported, as opposed to stoves with longer local value chains, opportunities for local repair and manufacture, and thus with lower prices (Section 25.5.3). Similarly, the early experience in the diffusion of multifunctional energy platforms lacked a built-in feedback and adaptive learning strategy that limited market development and slowed the diffusion of these platforms (Section 25.5.3 and Case Study 2, Section 25.11). This is now changing, as the case of Garalo in Mali (Section 25.6.1) demonstrates. The provision of business services and coaching to start-ups and SMEs would stimulate the diffusion of clean and more efficient energy technologies at the same time as it opened opportunities for a wide range of benefits.

\subsubsection{Principle 10: Governments are Critical Actors in Energy Transition Processes}

As the above principles illustrate, a policy aimed at fostering energy transitions will need to involve a range of government bodies at various administrative levels in the analyzing of problems and the designing and implementing of policies. No government ministry can be expected to have all of the required instruments in its "arsenal." Adopting a systems approach and a multi-goal perspective will require dialogues across ministries and the creation of inter-ministerial teams for policy integration and coordination. Capacities for dialogue and policy coordination must therefore exist or be created.

Designing for flexibility over the course of an energy transition will require access to the knowledge needed to create a portfolio of options that allow for different development possibilities. The portfolio should build on existing capacities and the interests, concerns, and needs of local actors and national actors alike. Developing countries might begin this process by identifying those capacities that are needed across many renewable energy technologies and support universities in the development of interdisciplinary programs around each knowledge nexus. This would create the flexibility to move between different technologies as conditions change.

Another task for strategic decision makers is to develop the analytical capacity to create and manage a shifting portfolio of renewable options as technological frontiers are breached, costs decline, and needs change. This includes the ability to undertake comparative assessments of the impacts of different choices and combinations of choices, as well as how these change over time. These impacts could include energy efficiency, consumer habits and practices of energy use, GHGs and other emissions, job losses and gains, and inducements offered to move towards an energy transition. Linkages to local knowledge centers and participation in wider networks will be essential if governments are to play these roles.

Government, therefore, will be one of the key actors in the transition process at local, national, and international levels. Developing and keeping a focus on transformative change, however, cannot succeed in the absence of broad-based support, continuous dialogue, and a long-term, systems-based approach to change.

\subsection{Case Studies}

\subsubsection{Case Study 1: Path Dependence and Lock-in: Decentralized Energy in the United Kingdom}

Efforts to increase the contribution from decentralized energy in the United Kingdom have been underway for over 10 years, ${ }^{106}$ driven mainly

106 These efforts date back to the report of the government-industry Embedded Generation Working Group, Report into Network Access Issues. A Consultation Document (DTI, 2001). 
by government targets to expand the use of renewable energy (including small-scale installations) - but also by a desire to explore more fully the scope for district heating, smart distribution grids, and more active participation by individuals and communities in the United Kingdom's low carbon transition (HM Government, 2009). Progress with many forms of decentralized energy has been slow. One of the reasons for this is that the existing system is highly centralized, and the United Kingdom has no recent tradition of decentralized electricity production (Foresight, 2008). This means that local institutions that understand local needs, such as local authorities, play a relatively minor role in decisions on energy investments and strategies. Another barrier is local opposition, particularly to proposals for wind farms from which many communities feel they have little to gain (Toke et al., 2008). In addition, there are economic and financial barriers. Small-scale renewable and low-carbon energy technologies tend to have high capital costs, and can in some cases face additional economic barriers such as the costs of connections to the grid.

The regulation of the electricity system provides a good illustration of the barriers to decentralization - and also how recent reforms are attempting to tackle them. Technical challenges arise because significant increases in decentralized electricity generation will have a particularly strong impact on the existing electricity grid, which was not designed for that purpose. Furthermore, decentralized generation is not just about connecting new plants to the system, but also about innovation and transformation of the system. Decentralization is part of a more general move to a more complex electricity system in the United Kingdom, which includes smart meters in homes, more sophisticated supply-demand balancing facilitated by smart grids, and the possible diffusion of plug-in electric vehicles (DECC, 2009).

Associated regulatory challenges arise because a more decentralized electricity system requires distribution network operators to play a more active role in managing their networks - and therefore need the appropriate skills and incentives to do so. The technical and regulatory impacts of decentralized generation will vary according to whether the approach taken is a piecemeal connection or a transformation of the system (Sauter and Bauknecht, 2009). In the former case, each generator is appraised with reference to the current system and is connected as a "one off." In the latter case, innovative solutions are needed for the development of generation and network infrastructure, and must work in conjunction with demand-side measures. The United Kingdom's pricebased approach to regulation, for example, allows network companies to increase their charges by the retail price index minus an efficiency factor - a formula known as RPI-X. While it has been argued that this should act as a driver of innovation, it only does so if the aim of the innovation is to increase the efficiency of current network operations. As a result, innovations that would facilitate significant changes to the architecture and operation of networks have not been encouraged.

Some tentative moves to encourage innovation were introduced in 2005, but the impacts were limited (Woodman, 2006), largely because the innovative capacity within network companies started from a very low base, and the incentives were too weak and limited. It is only recently (in April 2010) that the regulator, the Office of Gas and Electricity Markets (Ofgem) has introduced significant new incentives for innovation in the form of a Low Carbon Networks Fund (Ofgem, 2010). This is designed to provide a much stronger rationale for distribution companies to move in the direction of smarter grids that could not only include decentralized generators, but also encompass the early rollout of electric vehicles and integrate the demand side through smart meters - something that the government supports (e.g., DECC, 2009). However, it remains to be seen what impact the new Ofgem fund will have, and whether it will be enough to overcome historical barriers to decentralized energy systems.

\subsubsection{Case Study 2: A Bottom-up Approach for Micro- Hydro in Bhutan}

The development of a hydropower industry is recognized as the primary driving force for economic development in the Kingdom of Bhutan. The Power System Master Plan (PSMP, 2004) identified technically and economically feasible and potential hydropower sites that could provide a total of 23,760 MW of electricity. The current installed generating capacity is $1505 \mathrm{MW} .{ }^{107}$

Bhutan's rural electrification efforts are guided by "Bhutan 2020," a policy document that set a target of providing electricity to $50 \%$ of the rural population by 2012 , and to all households by 2020 . The policy also seeks to transform the role of the state from that of a "provider" to an "enabler." Bhutan's clear policy directives and its Electricity Act 2001, which provided for free licenses up to $500 \mathrm{~kW}$, are helping to stimulate development of micro-hydropower.

The high cost of extending the grid, however, has made it difficult to connect a large percentage of the rural population to the national power grid. Based on past rural electrification projects, it is estimated that electrifying one rural household costs about US\$1800. This needs to be financed by the government, and on-grid rural consumers receive substantial operational subsidies. ${ }^{108}$

In the past, the Bhutan Power Corporation owned, managed, operated, and maintained the country's micro-hydropower plants. However, due to the corporation's lack of financial viability, it has been reluctant to take over the management of the new micro-hydros being built. Thus, when the Chendebji micro-hydro plant was commissioned in October 2005, an alternative model involving the community had to be developed. The community-based management model now being piloted in

107 This includes the recently commissioned Tala hydropower project.

108 The average rural consumer utilizes less than $50 \mathrm{kWh} /$ month and falls in the lowest tariff category of US $\$ 0.013 / \mathrm{kWh}$. The estimated cost of supplying electricity to rural households is about US\$0.10/kWh. 
Chendebji is expected to be refined and the lessons learned applied in future projects.

In particular, the development of micro-hydropower should be coupled with the creation of income-generating opportunities that will enhance the economic self-reliance of rural communities. Further, by integrating micro-hydropower with the grid at higher feed-in tariffs, the sale of surplus power could improve load management and displace the need for government subsidies. Finally, training programs are needed to maintain the skills of local plant operators, and education campaigns are necessary to raise consumers' awareness of the need for energy conservation.

\subsubsection{Case Study 3: How Open Innovation Systems Speed}

Problem Solving: InnoCentive

Most of the work on distributed innovation systems has focused on software development. In a recent study, a team of researchers looked at the value of openness in scientific problem solving in the life sciences (Lakhani et al., 2007). The study considered a diversity of disciplines, several of which are relevant in the development of biofuels and other renewable energy sources.

Unlike the open source software approach, the InnoCentive network was not a spontaneous development but an offshoot of a multinational pharmaceutical firm, Eli Lilly. Its creation recognized both the explosion of knowledge and the combinatorial nature of knowledge bases in the technologies that emerged in the last quarter of the $20^{\text {th }}$ century.

InnoCentive describes itself as an "open innovation community of smart, creative people, who provide solutions to tough problems" (InnoCentive, 2011). Membership of InnoCentive is open to anyone who is attracted both by the challenge of solving problems and by the financial rewards that are attached. The notion that this is a community along the lines of the open source software community is misleading, however. InnoCentive's problem solvers rarely interact among themselves or with the seekers. Another difference lies in the "openness" of the knowledge produced by solvers, who must sign an agreement upon joining InnoCentive under which all rights to the knowledge they generate belong to the seeker.

Despite the absence of a free flow of knowledge and open access to and use of the knowledge generated by solvers - both of which are arguably among the factors that enable open innovation systems to speed the pace of innovation and diffusion - InnoCentive has served to accelerate problem solving for seekers who are willing to share some information with solvers. One study, for example, illustrates the efficacy of this approach in the case of " 166 discrete scientific problems from the research laboratories of 26 firms from 10 different countries between June 2001 and January 2005" (Lakhani et al., 2007). Firms came from a variety of industries, including agrochemicals, biotechnology, chemicals, and pharmaceuticals, and most had attempted to solve the problem within their own laboratories. Out of 166 problems, 49 (29.5\%) were solved using this approach (Lakhani et al., 2007).

The outreach that such an approach permits is interesting for problem solving. "On average, 240 (sd: 195, range: 19-1058) individuals examined each detailed problem statement and 10 (sd: 14, range: 0-103) individuals submitted solutions for evaluation" (Lakhani et al., 2007). More recent data provide a higher rate of problems solved. Of the "(a) round 900 challenges that have been posted so far by 150 firms [...] (m)ore than 400 have been solved"(The Economist, 2009). The range of seekers and problems has already extended to the renewable energy sector (Bent, 2009).

\subsubsection{Case Study 4: Creating a Policy Framework for Innovation and Technology Transfer in South Africa}

The South African white paper on science and technology (DST, 1996) created a National System of Innovation based framework, for key enabling policies and strategies that would inform the strategic development of science and technology in post-apartheid South Africa. In 2002, the national R\&D strategy, implemented by the Department of Science and Technology, aimed to improve the impact of the white paper by identifying interventions needed to address systemic weaknesses. One of these involved improving the protection and management of intellectual property from publicly financed research as a way to "bridge the innovation chasm."

New legislation aiming to address this issue has recently been passed. It prescribes in some detail the policies, processes, and structures that recipients of public $R \& D$ funding will have to institute in managing their intellectual property and provides for the establishment of a National Intellectual Property Management Office and Intellectual Property Fund to assist in financing the costs of obtaining intellectual property protection. The question of whether the legislation has struck the right balance between creating an enabling environment and regulating relevant activities continues to generate debate. This is of particular importance in the South African context, where more than half of R\&D expenditure comes from industry. The focus of the legislation on publicly funded research could therefore potentially limit the overall impact of these interventions.

With regard to local university-industry linkages, for example, until now, the ownership of intellectual property arising out of collaborative research or industry-sponsored research at universities has been a matter of negotiation. Under the new legislation, the circumstances under which a company may own intellectual property have been significantly reduced. There is concern that this might act as a deterrent to companies sponsoring research at, or collaborating with, universities (Wolson, 2007). 
The R\&D strategy also recommended that a core agency be set up to stimulate technological innovation by aligning, coordinating, and providing a single point of strategic direction for a range of existing and anticipated innovation support instruments. In the first instance, this will involve consolidating several existing agencies and institutions, mainly from within the Department of Science and Technology, under the umbrella of the new Technology Innovation Agency. The new policy instruments aimed at promoting innovation and the transfer and commercialization of technology bode well for a supportive environment. It is hoped that they are implemented in a flexible, enabling, and responsive manner so as to successfully cultivate the anticipated improvements in the systems.

\subsubsection{Case Study 5: The Masdar Initiative}

Abu Dhabi has taken a bold step towards creating a knowledge-based economy. The Masdar initiative, driven by the Abu Dhabi Future Energy Company, is designed to be a global cooperative platform for engagement in the search for solutions to pressing issues such as energy security, climate change, and the development of human expertise in sustainability. If successful, it will also serve to position Abu Dhabi as a world-class R\&D hub for new energy technologies and drive the commercialization and adoption of these and other technologies in sustainable energy, carbon management, and water conservation. In parallel with "Vision 2030," Masdar will also assist economic diversification and the development of a knowledge-based economy, while enhancing Abu Dhabi's record of environmental stewardship (see Masdar, 2011).

Masdar has five business units. Its Carbon Management Unit is developing greenhouse gas emission reduction projects, creating value by trading carbon Certified Emission Reduction certificates under the CDM of the Kyoto Protocol. The unit also develops sustainable technologies, including large-scale projects that generate sizable carbon emission reductions, focusing on CCS. This unit presumes the sustainability of the CDM and the global carbon market beyond 2012. Among its projects are a partnership with Bahrain's National Oil and Gas Authority to reduce carbon emissions derived from energy efficiency projects in the Bahraini oil industry and the development of a national carbon capture network to reduce Abu Dhabi's carbon footprint. The first phase of the network will capture around 6.5 million tonnes of $\mathrm{CO}_{2}$ from power plants and industrial facilities for injection into oil reservoirs for enhanced oil recovery. Natural gas will be processed to hydrogen and $\mathrm{CO}_{2}$, with the former being used for power generation and the latter re-injected into oil fields.

The Industries Unit invests globally and locally to establish a portfolio of production assets to provide Masdar access to technology and markets for the renewable energy value chain. The unit's current flagship investment is Masdar PV, which was created in April 2008 with the goal of becoming a top-three global thin-film PV manufacturer. A US\$600 million phase-one investment will fund the construction of plants in Germany and Abu Dhabi with a combined annual output of 210 MW.
The Masdar Institute of Science and Technology, developed in cooperation with the Massachusetts Institute of Technology, offers masters- and doctoral-level degree programs focused on the science and engineering of advanced energy and sustainable technologies. The aim is to develop a pool of highly skilled scientists, engineers, managers, and technicians capable of accelerating the development of technology in the region and globally. The first class of 92 students, of which $13 \%$ are UAE nationals, ${ }^{109}$ started in September 2009. A faculty of 20 academics from 11 countries, eight of whom are from Arab origins, has been recruited from internationally renowned universities.

Masdar's property development unit is currently constructing the carbon-neutral Masdar City I, soon to become home to 40,000 residents as well as research centers and companies with expertise in clean technology. The International Renewable Energy Agency is also located here, though it is uncertain whether much research will actually be conducted at its headquarters.

The utility assets and management unit aims to secure for Masdar a leading position in future energy markets by building a renewable energy portfolio through investments in companies with promising technology. The unit is positioned as a renewable energy power project developer, in bridging the gap between equipment manufacturers that lack project development capital and local utilities that lack the renewable energy economics, knowledge, and know-how. The current focus is on CSP, PV, wind, and waste-to-energy systems.

Within this framework, Masdar recently connected a 10 MW PV plant to the electricity grid, which will reduce Abu Dhabi's carbon footprint by 15,000 tonnes/year and will supply all the energy needs of the Masdar Institute of Science Technology. The plant, consisting of 87,777 panels $(50 \%$ thin film and $50 \%$ crystalline silicon) is projected to generate $17,500 \mathrm{MWh}$ of clean energy each year. A thin-film plant was expected to begin production in late 2010. Other new projects include the construction and operation of a 500 MW hydrogen-fired power plant ${ }^{110}$ and a 100 MW CSP plant that will use parabolic trough technology. This is planned to be the first of many CSP plants in Abu Dhabi that will feed green power into the grid.

\subsubsection{Case Study 6: Strengthening Effective Participation at the International Level: The Arabian Gulf University}

The Arabian Gulf University (AGU) was established in Bahrain in 1979 and as a regional university was the first of its kind. With the founding of the Gulf Cooperation Council (GCC) in 1981, AGU became a regional

109 The remaining students came from 22 countries, including Algeria, Egypt, Eritrea, Germany, the Netherlands, Iceland, India, Mexico, Morocco, Nigeria, Pakistan, Palestine, Taiwan, Turkey, the United States, and the United Kingdom.

110 The project is a joint venture between BP, Rio Tinto, and Hydrogen Energy, a UK-based company that produces low-carbon hydrogen for electricity generation. 
institution of the GCC with the objective of contributing to regional integration and development in the region and strengthening regional efforts in human resources development. It has since become a center for building research and training capacities on energy and the environment in the GCC countries and strengthening their participation on such issues at the international level.

AGU's unique teaching program is based on a multidisciplinary, integrated studies approach that emphasizes problem-based learning through case studies. To ensure flexibility in responding to the emerging development needs of the region, the AGU has adopted a flexible structure based on programs rather than rigid departments, focusing on technology and the environment. The latter was further strengthened by the creation of the Sheikh Zayed Al Nahyan Academic Chair of Environmental Sciences in 1998, which aims to enhance research and capacities in resource management and environmental issues. Two major milestones have been the launch of the environmental management program at AGU in 2004 and the creation of the Zayed seminar series. The seminars are particularly important as a networking mechanism across the region which, IPCC models predict, will become considerably hotter and drier over the century. Gelil (2010) observes, "If the Arab countries have failed, for decades, to join hands on most fronts, the climate change problem might be a 'golden opportunity' to start."

Five seminars have now been held. The first laid the basis for the Environmental Management Program at AGU. The others examined the potential of alternative energy in the GCC, sustainable cities, and the issues of climate change, energy, water, and food security in the Arab region. The seminars were attended by 400 participants from the GCC, of whom $57 \%$ were from the academic community, $23 \%$ from government agencies, $15 \%$ from the private sector, and the remaining $5 \%$ from NGOs, the media, etc. Although the seminars could play an important role in knowledge production and sharing, the low level of participation by governments and policymakers from the region thus far limits opportunities for joint problem solving and policy coordination.

The AGU has begun to gain credibility and name recognition that is enabling it to help strengthen the capacity of Bahrain and other Arab Gulf countries to participate in international energy negotiations, and to benefit from financial and technical assistance programs provided by GEF and other agencies. The AGU has assisted the government of Bahrain to develop its initial national communication to the UNFCCC in 2005. It subsequently was invited to lead two of the research teams that prepared the Kingdom of Bahrain's second national communication. The studies provided assessments of the vulnerability of biodiversity and natural ecosystems to climate change and of mitigation measures. In addition, the project was designed to strengthen Bahrain's human, institutional, scientific, technical, and informational capacities. Moreover, it was designed to enhance its ability to respond to the challenges of climate change and meet its obligations, as a Non-Annex I Party, towards UNFCCC, and therefore each proposed activity of the project included an element of capacity development. Staff from Bahrain's Environmental Agency participated in the research projects, managed the process, and participated in training throughout the project. At the end of the project, the staff of the agency will establish a unit to address all issues related to climate change.

The AGU is also working as a collaborating center of UNEP in the preparation of the Global Environment Outlook (GEO). AGU faculty members have contributed to the West Asia chapter in the series of GEO reports, the latest of which was GEO-4, published in 2007 (UNEP, 2007). The holder of the Zayed Academic Chair has also been a member of the team of international experts led by the International Institute for Sustainable Development, which developed the GEO Integrated Environmental Assessment training manual used by UNEP to build national and regional capacity to undertake these assessments and prepare GEO national reports. The manual has been used in training activities in a number of Arab countries, including Egypt, Jordan, Yemen, and Qatar (UNEP and IISD, 2008). 


\section{References}

Abu Dhabi, 2008: Abu Dhabi Economic Vision 2030. The Government of Abu Dhabi, Abu Dhabi, United Arab Emirates.

ACCESS SARL, 2010: Electrification Rural a Base de Biocarburant le Pourghere dans la commune rural de Garalo dans le Sud du Mali. September 28, 2010, Bamako, Mali.

AEPC and UNDP, 2009: Successful Delivery of Modern Energy Services to the Poor in Rural Areas: Lessons from Nepal. Working Draft, United Nations Development Programme (UNDP) and Alternative Promotion Center (AEPC), Nepal.

Agbemabiese, L., 2008: Renewable energy enterprise development. In Renewable Energy for Rural Areas in Africa: The Enterprise Development Approach. A. BrewHammond and F. Kemausuor (eds.), Kwame Nkrumah University of Science and Technology (KNUST), Ghana, pp.6-14.

AGECC, 2010: Energy for a Sustainable Future. The UN Secretary-General's Advisory Group on Energy and Climate Change (AGECC), Summary Report and Recommendations, United Nations, New York.

Accra Agenda for Action, 2008: Endorsement Statement. 3rd High Level Forum on Aid Effectiveness, Accra, Ghana.

Agterbosch, S. and S. Breukers, 2009: Socio-political embedding of onshore wind power in the Netherlands and North Rhine-Westphalia. Technology Analysis \& Strategic Management, 20(5): 633-48.

Ahmed, A., 2008: Expats make up 99\% of private sector staff in UAE. gulfnews.com. April 7, 2008. gulfnews.com/news/gulf/uae/employment/expats-make-up-99-ofprivate-sector-staff-in-uae (accessed 30 May 2010).

ARC, 2011: StoveTec. Aprovecho Research Center (ARC). www.aprovecho.org/lab/ stovetec-story (accessed May 30, 2011).

AREED, undated : AREED II. African Rural Energy Enterprise Development (AREED). www.areed.org (accessed May 30, 2010).

Ashden, 2006: Rahimafrooz Renewable Energy, Bangladesh: Manufacturing and Installing Solar Home Systems. The Ashden Awards for Sustainable Energy, London, UK www.ashdenawards.org/winners/rahimafrooz (accessed May 30, 2011).

Ashden, 2009: 2009 Ashden Awards Case Study: The Solar Energy Foundation. The Ashden Awards for Sustainable Energy, London, UK. www.ashdenawards.org/ blog/solar-energy-foundation-bbc (accessed May 30, 2010).

Balagopal, B., P. Paranikas and J. Rose, 2010: What's Next for Alternative Energy? Boston Consulting Group (BCG), Boston, MA, USA.

Ballarin, P., 2002: Petrobras: Estratégia e Esforço Tecnológico. Petróleo \& Gás Brasil, Vol. 3, pp. 5-6.

Barnes, D., R. Van der Plas, K. Openshaw and K. R. Smith, 1994: What Makes People Cook with Improved Biomass Stoves? A Comparative International Review of Stove Programs. Technical Paper No. 242, The World Bank, Washington, DC, USA.

Baser, H. and P. Morgan, 2008: Capacity, Change and Performance: Study Report. Discussion Paper No. 59B, European Centre for Development Policy Management (ECDPM), Maastricht, The Netherlands.

Bell, M., 1984: "Learning" and the accumulation of industrial technological capacity in developing countries. In Technological Capability in the Third World. M. Fransman and K. King (eds.), Macmillan, Basingstoke, UK, pp.187-209.

Bell, M., 2009: Innovation Capabilities and Directions of Development. STEPS Working Paper 33, Social, Technological and Environmental Pathways to Sustainability (STEPS) Centre, Brighton.
Bell, M. and K. Pavitt, 1997: Technological accumulation and industrial growth: Contrasts between developed and developing countries. In Technology, Globalisation and Economic Performance. D. Archibugi and J. Michie (eds.), Cambridge University Press, Cambridge, UK, pp.83-137.

Bensch, G., J. Kluve and J. Peters, 2010: Rural Electrification in Rwanda: An Impact Assessment Using Matching Techniques. Ruhr Economic Papers No. 231, Rheinish-Westfälisches Institut für Wirtshaftsfortschung (RWI), Essen, Germany.

Bent, Mark, 2009: How InnoCentive accelerates our $R \& D$. InnoCentive. wn.com/ SunNight_Solar_CEO_How_InnoCentive_accelerates_our_R\&D (accessed May 30, 2010).

Bergman, N. and C. Jardine, 2009: Power from the People:Domestic Microgeneration and the Low Carbon Buildings Programme. ECI Research Report No. 34, Oxford Environmental Change Institute (ECI), University of Oxford, UK.

Borja-Díaz, M., O. Jaramillo-Salgado and F. Mimiaga-Sosa, 2005: Primer Documento del Proyecto Eoloeléctrico del Corredor del Istmo de Tehuantepec. Government of the State of Oaxaca, Mexico.

Borup, M., P. D. Anderson, S. Jacobsson and A. Midtune, 2008: Nordic Energy Innovation System Patterns of Need and Cooperation. Nordic Energy Research, Copenhagen, Denmark.

Bouille, D. and S. McDade, 2002: Capacity development. In Energy for Sustainable Development: A Policy Agenda. T. B. Johansson and J. Goldemberg (eds.), United Nations Development Programme (UNDP), New York, NY, USA, pp.173-205.

Boyle, G., J. Kirton, R. Lof and T. Nayler, 2009: Transitioning from the CDM to a Clean Development Fund. Carbon and Climate Law Review, 1: 14-22.

BRASIL, 1996: Industrial Property Law. Lei n. 9.279, May 14, 1996. www.planalto. gov.br/ccivil_03/Leis/L9279.htm (accessed July 25, 2009).

BRASIL, 2004: On the Incentives for Innovation and Scientific and Technological Research and Other Subjects. Lei n. 10.973, December 2, 2004. www.planalto.gov.br/ccivil_03/_ato2004-2006/2004/Lei/L10.973.htm (accessed July 25, 2009).

BRASIL, 2007: Plano de Ação de Ciência, Tecnologia e Inovação para o Desenvolvimento Nacional 2007-2010. www.inovacao.unicamp.br/report/integras/index.php?cod=197 (accessed July 25, 2009).

Brehm, D., 2009: Cement's basic molecular structure finally decoded. MIT News, September 14, 2009.

Breukers, S. and M. Wolsink, 2008: Wind power implementation in changing institutional landscapes: An international comparison. Energy Policy, 35(5): 2737-2750.

Brew-Hammond, A. and A. Crole-Rees, 2004: Reducing Rural Poverty through Increased Access to Energy Services: A Review of the Multifunctional Platform Project in Mali. United Nations Development Programme (UNDP), New York, NY, USA.

Brew-Hammond, A. and F. Kemausuor (eds.), 2008: Renewable Energy for Rural Areas in Africa: The Enterprise Development Approach. Kwame Nkrumah University of Science and Technology (KNUST), Kumasi, Ghana.

Brew-Hammond, A., L. Darkwah, G. Obeng and F. Kemausour, 2008: Renewable Energy Technology, Capacity and R\&D in Africa. Background paper for the International Conference on Renewable Energy in Africa, organized by the Government of Senegal, the African Union, BMZ and UNIDO, 16-18 April 2008, Dakar, Senegal.

Broydo Vestel, L., 2010: Q and A: The renewable energy czar. Green: A Blog about Energy and the Environment. New York Times, December 9, 2010. 
Burrell, T., 2008: Garalo Bagani Yelen, a Jatropha-fuelled rural electrification for 10,000 people in the Commune of Garalo. Mali Folk Centre (MFC) Nyetaa, Mali.

Busch, M. L., E. Reinhardt and G. Shaffer, 2008: Does Legal Capacity Matter? Explaining Dispute Initiation and Antidumping Actions in the WTO. Series Issue Paper No. 4, ICTSD Project on Dispute Settlement, International Centre for Trade and Sustainable Development (ICTSD), Geneva, Switzerland.

Butler, R. A., 2010: Brazil launches major push for sustainable palm oil in the Amazon. mongabay.com, (accessed May 7, 2010).

C40 São Paulo Summit, 2011: Velib - A new Paris love affair. C40 São Paulo Summit. www.c40saopaulosummit.com/site/conteudo/index.php?in_ secao=36\&lang=3\&in_conteudo $=44$ (accessed May 30, 2011).

Caniels, M. and H. Romijn, 2010: The Jatropha Biofuels Sector in Tanzania 2004-9: Evolution Towards Sustainability? Working Paper 10.04, Einhoven Centre for Innovation Studies (ECIS), The Netherlands, forthcoming in Research Policy, 2011.

City of Johannesburg, 2011: New York transport experts to ride on Rea Vaya. City of Johannesburg, South Africa. Press release, February 22, 2011. www.joburg. org.za/index.php?option=com_content\&view=article\&id=6267\&catid=209\&lt emid=114 (accessed February 24, 2011).

Chesbrough, H., 2006: Open Innovation: Researching a New Paradigm, Oxford University Press, Oxford, UK.

Coelho, S. T., O. C. da Silva, S. M. S. G. Velazquez, M. B. C. A. Monteiro and C. E. G. Silotto, 2003: Energy from Vegetable Oil in Diesel Generators: Results of a Test Unit at Amazon Region. Brazilian Reference Center on Biomass (CENBIO), Electrochemical and Energy Institute, University of São Paulo, Brazil.

Coelho, S. T., O. C. da Silva, A. F. L. Andrade and F. de Godoy, 2005: Palm Oil as Fuel to Conventional Diesel Engines in the Amazon Region Isolated Communities, Brazilian Reference Center on Biomass (CENBIO), Electrochemical and Energy Institute, University of São Paulo, Brazil.

Colaneri, K., 2010: Kearny Student, Hoboken developer receive Governor's environmental awards. The Jersey Journal, December 20, 2010.

Coutinho, L. N., 2001: Protegendo as invenções: a visão de pesquisadores brasileiros sobre facilidades e dificuldades do caminho entre a bancada e o INPI. Masters Diss., Centro Federal de Educacão Celso Suckow da Fonseca, Rio de Janeiro, Brazil.

Cruz, C. H. B. and L. Mello, 2006: Boosting Innovation Performance in Brazil. OECD Working Paper 532, Economics Department, Organisation for Economic Co-operation and Development (OECD), Paris, France.

DAC, 1991: Principles for Evaluation of Development Assistance. Development Assistance Committee (DAC), Organisation for Economic Co-operation and Development (OECD), Paris, France.

DAC, 2006: The Challenge of Capacity Development: Working towards Good Practice. DAC Guidelines and Reference Series. Development Assistance Committee (DAC), Organisation for Economic Co-operation and Development (OECD), Paris, France.

Dantas, E. and M. Bell, 2009: Latecomer firms and the emergence and development of knowledge networks: The case of Petrobras in Brazil. Research Policy, 38(5): 829-844.

David, P., 1985: Clio and the economics of QWERTY. American Economics Review, 75(2): 332-337.

Davidson, 0. and Y. Sokona, 2001: Energy and sustainable development: Key issues for Africa. In Proceedings of the African High-level Regional Meeting on Energy and Sustainable Development. N. Wamukonya (ed.), 1-3 January 2001, United
Nations Development Programme (UNDP) Collaborating Centre on Energy Development, Risø National Laboratory, Roskilde, Denmark, pp.1-19.

DECC, 2009: Smarter Grids: The Opportunity. UK Department of Energy and Climate Change (DECC), London, UK.

DECC, 2010a: Annual Energy Statement. DECC Departmental Memorandum. UK Department of Energy and Climate Change (DECC), London, UK.

DECC, 2010b: Huhne ends local authority power struggle. UK Department of Energy and Climate Change (DECC). Press release, August 9, 2010, London, UK.

Dechezlepretre, A., M. Glachant, I. Hascic, N. Johnstone and Y. Meniere, 2009: Invention and Transfer of Climate Change Mitigation Technologies on a Global Scale: A Study Drawing on Patent Data. Final Report, Centre d'Economie Industrielle (CERNA) Mines Paris Tech, Paris, France.

Dietz, F., H. Brouwer and R. Weterings, 2008: Energy transition experiments in the Netherlands. In Managing the Transition towards Renewable Energy: Theory and Practice from Local, Regional and Macro Perspectives. J. van den Bergh and F. Bruinsma (eds.), Edward Elgar, Cheltenham, UK, pp. 217-244.

Dogbevi, E. K., 2009a: Update: Any lessons for Ghana in India's jatropha failure? Ghana Business News, 23 May 23, 2009. ghanabusinessnews.com/2009/05/23 (accessed May 30, 2010).

Dogbevi, 2009b: Another major Jatropha project suffers setback. Ghana Business News, July 28, 2009. www.ghanabusinessnews.com/2009/07/28 (accessed May 30, 2010).

Doranova, A., 2009: Technology Transfer and Learning under the Kyoto Regime. Diss., United Nations University, Maastricht Economic and Social Research Training Center on Innovation and Technology (UNU-MERIT), Maastricht, The Netherlands.

Drame, A., 2008: The AREED experience in Senegal. In Renewable Energy for Rural Areas in Africa: The Enterprise Development Approach. A. Brew-Hammond and F. Kemausuor (eds.), Kwame Nkrumah University of Science and Technology (KNUST), Kumasi, Ghana.

DST, 1996: Preparing for the 215t Century. White Paper on Science and Technology, Department of Arts, Culture, Science and Technology (DST), Government of South Africa, Pretoria, South Africa.

DST, 2006/2007: National Survey of Research and Experimental Development. Department of Arts, Culture, Science and Technology (DST), Government of South Africa, Pretoria, South Africa.

DST, 2007: South African Innovation Survey 2005: Highlights. Department of Arts, Culture, Science and Technology (DST), Government of South Africa, Pretoria, South Africa.

DTI, 2001: Report into Network Access Issues: A Consultation Document. Embedded Generation Working Group, Department of Trade and Industry (DTI), London, UK.

DTI, 2007: Meeting the Energy Challenge. Report CM 7124. Department of Trade and Industry (DTI), UK.

Duffy, J., 2010: World Bank pressured on clean energy. International Herald Tribune, October 11, 2010, pp.11-12.

Earl, S., F. Carden and T. Smutylo, 2001: Outcome Mapping: Building Learning and Reflection into Development Programs. International Development Research Centre (IDRC), Ottawa, Canada.

ECBI, 2011: The European Capacity Building Initiative. European Capacity Building Initiative (ECBI). www.eurocapacity.org (accessed May 30, 2011).

ECOWAS, 2006: White Paper for a Regional Policy on Access to Energy Services for Populations in Rural and Peri-Urban Areas for Poverty Reduction in Line with Achieving the MDGs in Member States. Economic Community of West African 
States (ECOWAS), Twenty Ninth Summit of the Authority of Heads of State and Government, January 12, 2006, Niamey, Niger.

Edquist, C., 1997: Systems of innovation approaches: Their emergence and characteristics. In Systems of Innovation: Technologies, Institutions and Organisations. C. Edquist (ed.), Pinter, London, UK.

EnergyAccess, 2010: Toyola Case Study. EnergyAccess. energyaccess.wikispaces. com/Toyola+-+Case+Study (accessed August 5, 2011).

Enova SF, undated: Funding, Scope and Objectives. Enova SF, Royal Norwegian Ministry of Petroleum and Energy, Trondheim, Norway. www.enova.no/sitepageview.aspx?sitePagelD=1001 (accessed May 30, 2010).

Envirofit, 2010: Envirofit. www.envirofit.org (accessed May 30, 2010).

EPA, 2008: Multifunction Energy Platform (MFP) Pilot, Columbia University Earth Institute and Engineers without Borders. United States Environmental Protection Agency (EPA), October 28, 2010, Washington, DC, USA.

EPA, 2010a: Final Report: Multifunction Energy Platform (MFP) Pilot. United States Environmental Protection Agency (EPA), Washington, DC.

EPA, 2010b: MFP and Jatropha Program, Description. Columbia University, May 26, 2010, New York, NY, USA.

ERC, 2007: Electricity from Solar Home Systems in South Africa, Case Study 2. Energy Research Centre, University of Cape Town, South Africa.

Ernst, D., L. Mytelka and T. Ganiatsos, 1998: Technological capabilities in the context of export-led growth: A conceptual framework. In Technological Capabilities and Export Success. D. Ernst, T. Ganiatsos and L. Mytelka (eds.), Routledge, London, UK, pp.5-45.

ESMAP, 2005a: Advancing Bioenergy for Sustainable Development: Guidelines for Policymakers and Investors. Report 300/05, prepared for United Nations Development Programme (UNDP) and World Bank Energy Sector Management Assistance Program (ESMAP), Washington, DC.

ESMAP, 2005b: Potential for Biofuels for Transport in Developing Countries, Joint United Nations Development Programme (UNDP)/World Bank Energy Sector Management Assistance Program (ESMAP), Washington, DC, USA.

ESMAP, 2008: Accelerating Clean Energy Technology Research: Development and Deployment Lessons from Non-Energy Sectors. Working Paper 138, P. Avalo and J. Coony (eds.), World Bank Energy Sector Management Assistance Program (ESMAP), Washington, DC, USA.

ESMAP, 2009: Good Practices in City Energy Efficiency, Bogota, Colombia: Bus Rapid Transit for Urban Transport. World Bank Energy Sector Management Assistance Program (ESMAP), Washington, DC, USA.

ESMAP, 2010: Improved Cookstoves and Better Health in Bangladesh: Lessons from Household Energy and Sanitation Programs. Final Report, World Bank Energy Sector Management Assistance Program (ESMAP), Washington, DC, USA.

Feller, J., B. Fitzgerald, S. Hissam and K. Lakhani, 2005: Perspectives on Free and Open Source Software. MIT Press, Cambridge, MA, USA.

Forbes, N. and D. Wield, 2002: From Followers to Leaders: Managing Technology and Innovation in Newly Industrializing Countries. Routledge, London, UK.

Foresight, 2008: Powering Our Lives: Sustainable Energy Management and the Built Environment. Government Office for Science, London, UK.

Fouquet, R. and P. J. G. Pearson, 1998: A thousand years of energy use in the United Kingdom. The Energy Journal, 19(4): 1-41.

Freeman, C. and C. Perez, 1988: Structural crises of adjustment: Business cycles and investment behavior. In Technical Change and Economic Theory. G. Dosi, C. Freeman, R. Nelson, G. Silverberg and L. Soete (eds.), Pinter, London, UK, pp. 38-66.
Fridleifsson, l., 2006: UNU-GTP Capacity Building and Central America. Presented at the Workshop for Decision Makers on Geothermal Projects in Central America, November 26-December 2, 2006, organized by United Nations University Geothermal Training Programme (UNU-GTP) and LaGeo in San Salvador, El Salvador.

Fukuda-Parr, S., C. Lopes and K. Malik (eds.), 2002: Capacity for Development: New Solutions to Old Problems. Earthscan, London, and United Nations Development Programme (UNDP), New York, NY, USA.

GE, 2010: Brazil energy milestone: GE, Petrobras using sugarcane-based ethanol to produce electricity. General Electric (GE), press release, January 19, 2010, Rio de Janeiro, Brazil.

Geels, F. W., 2002: Technological transitions as evolutionary reconfiguration processes: A multi-level perspective and a case-study, Research Policy, 31(-): 1257-1274.

Geels, F. W., 2004: From sectoral systems of innovation to socio-technical systems: Insights about dynamics and change from sociology and institutional theory. Research Policy, 33(8-9): 897-920.

Geels, F. W., 2005: Technological Transitions: A Co-Evolutionary and Socio-Technical Analysis. Edward Elgar, Cheltenham, UK.

Geels, F. W. and R. Kemp, forthcoming: The transition perspective as a new perspective for road mobility study. In Automobility in Transition? A Socio-Technical Analysis of Sustainable Transport. F. W. Geels, R. Kemp, G. Dudley and G. Lyons (eds.), Routledge, London, UK.

Gelil, I. A, 2010: Towards a science-led climate policy in the Arab region. Nature Middle East, June 9, 2010. www.nature.com/nmiddleeast/2010/100609/full/ nmiddleeast.2010.160.html (accessed May 30, 2011).

Georgsson, L., 2008: Geothermal Energy in the World. United Nations University Geothermal Training Programme (UNU-GTA) and Orkustofnun, Uganda Short Course, November 11, 2008, Uganda.

Gibbs, A., 1997: Focus groups. Social Research Update 19, University of Surrey, UK.

Gibbons, M., C. Limoges, H. Nowotny, S. Schwartzman, P. Scott and M. Trow, 1994: The New Production of Knowledge: The Dynamics of Science and Research in Contemporary Societies. Sage, London, UK.

GNESD, 2007: Renewable Energy Technologies and Poverty Alleviation: Overcoming Barriers and Unlocking Potentials. Global Network on Energy for Sustainable Development (GNESD), Roskilde, Denmark.

GNESD, 2009: What is GNESD? Steering Committee 2008-2009, Global Network on Energy for Sustainable Development (GNESD). www.gnesd.org (accessed May $30,2010)$.

Goertz, L., 2006: Mali Multi-functional Platform Project, Evaluation and Diagnostic Report. Engineers without Borders (EWB) Canada and the Mali Multi-functional Platform Staff, Toronto.

Goldemberg, J., T. B. Johansson, A. K. N. Reddy and R. H. Williams, 1985: Basic needs and much more with one kilowatt per capita. Ambio, 14(24): 190-200.

Gomes, R., 2009: Market solutions to combat indoor air pollution: Shell Foundation and Envirofit International. In Cookstoves and Markets: Experiences, Successes and Opportunities. K. Rai and J. McDonald (eds.), Global Village Energy Partnership, London, pp.7-9.

Grameen Shakti, 2011: Energy for Development: The Grameen Shakti Model. Proceedings of the Global Social Business Summit, Vienna, Austria.

Grubler, A., 2004: Transitions in Energy Use. In Encyclopedia of Energy. C. J. Cleveland (ed.), Elsevier; Amsterdam, pp. 163-177. 
GTZ, 2009: Target Market Analysis Kenya's Solar Energy Market. Federal Ministry of Economics and Technology and Deutsche Gesellschaft für Technicsche Zusammenarbeit (GTZ) GmbH, Eschborn, Germany.

GTZ (GIZ), 2010: Energising Development Partnership. EnDev Fact Sheet, Deutsche Gesellschaft für Technicsche Zusammenarbeit (GTZ) GmbH, Eschborn, Germany.

Guajardo, G., 2007: Lecciones sobre cambio tecnológico e institucional en la investigación y desarrollo del petróleo en México. Agenda para el desarrollo. Política Energética, Vol. 8. J. L. Calva (ed.), UNAM-Porrúa, México DF, Mexico, pp.138-155.

Guetali SADC, 2009: Marine algae biofuel launched in the Eastern Cape. Guetali South African Development Community (SADC), March 23, 2009. guetalisadc. blogspot.com/2009/03/marine-algae-biofuel-pilot-project.html (accessed May 30, 2010).

GVEP, 2009: Cookstoves and Markets: Experiences, Successes and Opportunities. K. Rai and J. McDonald (eds.), Global Village Energy Partnership (GVEP), London, UK.

Hall, P. and R. Taylor, 1996: Political science and the three institutionalisms. Political Studies, 44: 936-957.

Hamlin, T. and A. Fikre-Marium, 2004: The African Rift Geothermal Energy Development Facility (ARGeo). Presentation to the UNEP and KfW Renewable Energy Conference, Bonn, German

Hankins, M., 2011: A solar strategy for Africa: International players set to expand key market. Renewable Energy World, January 4, 2011. www.renewableenergyworld.com/rea/news/print/article/2011/01/a-solar-strategy-for-africa (accessed May 30, 2011).

Harhoff, D., B. Hall, G. von Graevenitz, K. Hoisl and S. Wagner, 2007: The Strategic Use of Patents and its Implications for Enterprise and Competition Policies. EU Final Report No. ENTR/05/82, European Union (EU), Munich, Germany

Healey, P., 1998: Building institutional capacity through collaborative approaches to urban planning. Environment and Planning, A30: 1531-1546.

Heher, T., 2005: Implications of international technology transfer benchmarks for developing countries. International Journal of Technology Management and Sustainable Development, 4(3): 207-225.

Heisenberg, W., 1962: Physics and Philosophy: The Revolution in Modern Science. Harper and Row, New York, USA.

HM Government, 2009 : The UK Low Carbon Transition Plan: National Strategy for Climate and Energy. Stationery Office, London, UK.

Ho, M.-W., 2010: Eradicating Rural Poverty with Renewable Energies. ISIS Report, 24/11, Institute of Science in Society (ISIS), London, UK.

Höök, M., R. Hirsch and K. Aleklett, 2009: Giant oil field decline rates and their influence on world oil production. Energy Policy, 37(6): 2262-2272.

Hukkinen, J., 1999: Institutions in Environmental Management: Constructing Mental Models and Sustainability. Routledge, London, UK.

Huntley, M. E. and D. G. Redalje, 2006: $\mathrm{CO}_{2}$ mitigation and renewable oil from photosynthetic microbes: A new appraisal. Mitigation and Adaptation Strategies for Global Change, 12: 573-608.

IDRC, 2008: Research Matters - Knowledge Translation: Bridging the 'Know-do' Gap. International Development Research Centre (IDRC), Ottawa, and the Swiss Agency for Development and Cooperation, Canada and Switzerland.

IFC, 2009: FAQ - Tata Mundra Project. International Finance Corporation (IFC). www.ifc.org/ifcext/southasia.nsf/Content/TataMundra_FAQ (accessed May $30,2011)$.
IIE, 2005/2006: Sexto Informe de Labores. Instituto de Investigaciones Eléctricas (IIE), Morelos, Mexico.

InnoCentive, 2011: InnoCentive. www.innocentive.com (accessed May 30, 2011).

IOI, 2011: Global Initiative for Open Innovation Launched to Promote Patent System Transparency. Initiative for Open Innovation (IOI). Press release, July 13, 2009, Geneva, Switzerland. www.openinnovation.org/daisy/ioi/home.html (accessed May 30, 2011).

Jacobson, A., 2004: Connective Power: Solar and Social Change in Kenya. Diss., Energy and Resources Group, University of California, Berkeley, USA.

Jacobsson, S. and A. Bergek, 2004: Transforming the energy sector: The evolution of technological systems in renewable energy technology. Industrial and Corporate Change, 13(5): 815-849.

Jannuzzi, G. de M., 2005: Power sector reforms in Brazil and its impacts on energy efficiency and research and development activities. Energy Policy, 33(13): 1753-7162.

Katz, J., 1983: Technological change in the Latin American metalworking industries: Results from a programme of case studies. CEPAL Review, 19: 85-143.

Katz, J., 1985: Domestic technological innovations and dynamic comparative advantages: Further reflections on a comparative case-study programme. International Technology Transfer Concepts, Measures, and Comparisons. N. Rosenberg and C. Frischtak (eds.), Praeger, New York, USA, pp.127-166.

Katz, J., 2004; Market-oriented reforms, globalization and the recent transformation of Latin American innovation systems. Oxford Development Studies, 32(3): 375-388.

Kemp, R., 1994: Technology and the transition to environmental sustainability: The problem of technological regime shifts. Futures, 26(10): 1023-1046.

Kim, L., 1997: Imitation to Innovation: The Dynamics of Korea's Technological Learning. Harvard Business School Press, Boston, MA, USA.

Kim, L., 2003: Foreign direct investment, technology development and competitiveness: Issues and evidence. In Competitiveness, FDI and Technological Activity in East Asia. S. Lall and S. Urata (eds.), Edward Elgar, Cheltenham, UK, pp.12-82.

Kim, L., 2004: The multifaceted evolution of Korean technological capabilities and its implications for contemporary policy. Oxford Development Studies, 32(3): 342-363.

Kiron, V., W. Phromkunthong, M. Huntely, I. Archibald, and G. de Scheemaker, 2010: Marine Microalgae: A green alternative protein source in aquatic feeds. European Aquaculture Meeting (September 2010), Porto, Portugal.

Kishore, V. V. N. and P. V. Ramana, 2002: Improved cookstoves in rural India: How improved are they? A critique of the perceived benefits from the National Programme on Improved Chulhas (NPIC). Energy, 27: 470-463.

KITE, 2004: Technical Feasibility of Jatropha Oil and Biodiesel as Fuel for Rural MFPs. $2^{\text {nd }}$ Draft Report, Prepared by A. Brew- Hammond, J. Robinson, D. Derzu and C. Ciarra, Kumasi Institute of Technology and Environment, Ghana.

Kline, R. and T. J. Pinch, 1996: Taking the black box off its wheels: The social construction of the automobile in rural America. Technology and Culture, 37: 776-795.

Kline, S. J. and N. Rosenberg, 1986: An Overview of Innovation in the Positive Sum Strategy. R. Landau and N. Rosenberg (eds.), National Academies Press, Washington, DC, USA.

Krugmann, H., 1988: Improved Cookstove Programs: Boon or Boondoggle? International Development Research Centre (IRDC), Ottawa, Canada, pp. 22-23.

Lahorgue, M., M. Santos and J. Mello, 2005: Economic Development Mission in Brazilian Universities. Triple Helix 2005 Conference, May 17-20, 2005, Turin, Italy. 
Lakhani, K. R., L. B. Jeppesen, P. A. Lohse and J. A. Panetta, 2007: The Value of Openness in Scientific Problem Solving. Working Paper 07-050, Harvard Business School, Boston, MA, USA.

Lakhani, K. R. and J. A. Pannetta, 2007: The principles of distributed innovation. Innovations, 2(3): 97-112.

Lall, S., 1992: Technological capabilities and industrialization. World Development, 20(2): 165-186.

Landman, M., 2010: LEED Platinum Certified Buildings. M. Landman Communications and Consulting, San Francisco, CA, USA. www.mlandman.com/gbuildinginfo/ leedplatinum.shtml (accessed May 20, 2011).

Lewis, W. A., 1950: The industrialization of the British West Indies. Caribbean Economic Review, May.

Lindau, L., D. Hidalgo and D. Facchini, 2010: Curitiba, the cradle of Bus Rapid Transit. Built Environment, 36(3): 274-22.

Looi, M.-K., 2009: Platform for research - African Institutions Initiative. Wellcome Trust, London, July 3, 2009. www.wellcome.ac.uk/news/2009/features/ wtx055738.htm (accessed May 30, 2010).

Lovallo, D. and O. Sibony, 2010: The Case for Behavioral Strategy. McKinsey Quarterly, March. www.mckinseyquarterly.com/The_case_for_behavioral_strategy_2551 (accessed May 30, 2011).

Lundvall, B.-A., 1992: National Systems of Innovation: Towards a Theory of Innovation and Interactive Learning. Pinter Publishers, London, UK.

Lusthaus, C., M.-H. Adrien and M. Perstinger, 1999: Capacity Development: Definitions, Issues and Implications for Planning, Monitoring and Evaluation. Occasional Paper No. 23, Montreal, Canada.

Mafuta Sasa, 2011: Mafuta Sasa Biodiesel Limited. Mafuta Sasa Biodiesel Limited, Dar es Salaam, Tanzania. www.mafutasasa.com/about-tanzania (accessed May 30, 2011).

Mali Biocarburant, 2010: Company Profile: Mali Biocarburant, Bamako, Mali. www.malibiocarburant.com/website $\% 20$ example $\% 20-\% 20$ copie/Mali_ Biocarburant_SA/MBSA/MBSA_files/Depliant\%20MBSA.pdf (accessed May 30, 2010).

Martinot, E. and S. Birner, 2005: Market transformation for energy-efficient products: lessons from programs in developing countries, Energy Policy, 33(14): 1765-1779.

Martinot, E., A. Cabraal and S. Mathur, 2001: World Bank/GEF solar home system projects: Experiences and lessons learned 199-000. Renewable and Sustainable Energy Reviews, 5: 39-57.

Masdar, 2011: Masdar Initiative: About Us. Masdar: A Mubadala Company. www. masdar.ae/en/Menu/Index.aspx?MenulD=42\&mnu=Pri, (accessed May 30, 2011).

McDonough, M., 2008: Mass Wall Building: An Achievable Approach to Green, High Performance and Net Zero Energy Buildings, White Paper, Hoboken Brownstone Co., Hoboken, NJ.

McKinsey and Company, 2010: A Portfolio of Power-Trains for Europe: A Factbased Analysis. The Role of Battery Electric Vehicles, Plug-in Hybrids and Fuel Cell Electric Vehicles. McKinsey and Company, London, UK.

Mehlomakulu, B., 2008: Hydrogen and fuel-cell technology issues for South Africa: The emerging debate. In Making Choices About Hydrogen. Transport Issues for Developing Countries. L. K. Mytelka and G. Boyle (eds.), United Nations University (UNU) Press, Tokyo and International Development Research Centre (IRDC), Ottawa, Canada, pp.324-345.
Microhydropower.net, 2011: Microhydropower Discussion Group. Wim Jonker Klunne, moderator. www.microhydropower.net (accessed May 30, 2011).

Moreira, J. R. and A. D. Poole, 1993: Hydropower and its constraints. In Renewable Energy: Sources for Fuels and Electricity. T. B. Johansson, H. Kelly, A. K. N. Reddy and R. H. Williams (eds.), Island Press, Washington, DC, USA, pp. 73-120.

Mowery, D. (ed.), 1988: International Collaborative Ventures in U.S. Manufacturing, Ballinger, Cambridge, MA, USA.

Muchie, M., P. Gammeltoft and B.-A. Lundvall (eds.), 2003: Putting Africa First: The Making of African Innovation Systems. Aalborg University Press, Denmark.

Mutizwa-Mangiza, N. 2009: Why urban planning systems must change. Urban World, 1(4):16-21.

Mwakilasa, M., 2008: Mafuta Sasa Biodiesel Limited. Bid Network. www.bidnetwork.org/page/144465/en (accessed May 30, 2011).

Mytelka, L. K., 1985: Stimulating effective technology transfer: The case of textiles in Africa. In International Technology Transfer Concepts, Measures, and Comparisons. N. Rosenberg and C. Frischtak (eds.), Praeger, New York, pp.77-126.

Mytelka, L. K., 1986: The Transfer of Technology: Myth or Reality? In The European Community's Development Policy: The Strategies Ahead. C. Cosgrove and J. Jamar (eds.), De Tempel, Bruges, pp. 243-28l.

Mytelka, L. K., 1989: The unfulfilled promise of African industrialization. African Studies Review. 32(3): 77-137.

Mytelka, L. K., 2000: Local systems of innovation in a globalized world economy. Industry and Innovation, 7(1)15-32.

Mytelka, L. K., 2001: Mergers, acquisitions and inter-firm technology agreements in the global learning economy. In The Globalising Learning Economy. D. Archibugi and B.-A. Lundvall (eds.), Oxford University Press, Oxford, UK, pp. 127-144.

Mytelka, L. K., 2004: Catching up in new wave technologies. Oxford Development Studies, 32(3): 389-405.

Mytelka, L. K., 2008: Hydrogen fuel cells and alternatives in the transport sector: A framework for analysis. In Making Choices About Hydrogen Transport Issues for Developing Countries. L. Mytelka and G. Boyle (eds.), United Nations University Press, Tokyo, Japan, and International Development Research Centre (IDRC), Ottawa, Canada, pp.5-38.

Nelson, R. (ed.), 1993: National Innovation Systems: A Comparative Analysis. Oxford University Press, Oxford, UK.

Nelson, R., 2004: The challenge of building an effective innovation system for catchup. Oxford Development Studies, 32(3): 365-374.

Nepal, 2007: Energy and Poverty in Nepal: Challenges and the Way Forward. Regional Energy Programme for Poverty Reduction, United Nations Development Programme (UNDP) Regional Centre, Bangkok, Thailand.

Norges Bank, 2004: The Long-term Investment Strategy of the Norwegian Petroleum Fund. Address by Governor Svein Gjedrem to the Argentium Conference, September 30, 2004.

North, D. C., 1994: Institutional change: A framework of analysis. Economic History, 9412001, EconWPA.

OECD, 1992: Technology and the Economy: The Key Relationships. TEP Report, Organisation for Economic Co-operation and Development (OECD), Paris, France.

OECD, 2005/2008: The Paris Declaration on Aid Effectiveness (2005) and the Accra Agenda for Action (2008). Organisation for Economic Co-operation and Development (OECD), Paris, France. 
OECD, 2009: The Bioeconomy to 2030: Designing a Policy Agenda. Organisation for Economic Co-Operation and Development (OECD), Paris, France.

Ockwell, D., J. Watson, A. Verbeken, A. Mallett and G. MacKerron, 2009: A Blueprint for Post-2012 Technology Transfer to Developing Countries. Policy Briefing No.5, Sussex Energy Group, University of Sussex, Sussex, UK.

Ofgem, 2010: Low Carbon Networks Fund Governance. Document V.3. Office of the Gas and Electricity Markets (Ofgem), London, UK.

Oh. S.-H., 2009: Seoul's bid to be the world's greenest city. Urban World, 1(4): 5-7.

Perez, C., 1988: New technologies and development. In Small Countries Facing the Technological Revolution. C. Freeman and B.-A. Lundvall (eds.), Pinter, London, UK, pp. 85-97.

Petrobras, 2011: Petrobras joins consortium to accelerate adoption of green fuels. Newsnet, February 16, 2011. www.newenergyworldnetwork.com (accessed May 30, 2011).

Pietrobelli, C. and R. Rabellotti (eds.), 2006: Upgrading to Compete: SMEs, Clusters and Value Chains in Latin America. Harvard University Press, Cambridge, MA, USA.

Pigaht, M. and R. van der Plas, 2009: Innovative private micro-hydro power development in Rwanda. Energy Policy, 37(11): 4753-4760.

Planting, S., 2006: A place in the sun. Financial Mail, November 3, 2006. free.financialmail.co.za/innovations/06/1103/cinn.htm_fin_mail_3_nov_2006.aplace in the sun sasha_planting (accessed May 30, 2011).

Portal do Ministério da Sciência e Technologia, 2002: Livro Branco de Ciencia, Technologia e Inovacao. Portal do Ministério da Sciência e Technologia, Brazil. acessibilidade.mct.gov.br/index.php/content/view/18765.html (accessed May 30, 2011).

Pouris, A., 2008: Science-Industry Relations and the SA Innovation Chasm: Searching for Lost Technologies. Paper prepared for the Department of Trade and Industry, South Africa.

Prebisch, R., 1959: The role of commercial policies in underdeveloped countries. American Economic Review, Papers and Proceedings, 49: 251-73.

REN21, 2008: Renewables 2007: Global Status Report. Renewable Energy Policy Network for the $21^{\text {st }}$ Century (REN21) Secretariat and Worldwatch Institute, Washington, DC, USA.

REN21, 2009: Chinese Renewables Status Report. Background Paper, Renewable Energy Policy Network for the $21^{\text {st }}$ Century (REN21), Paris, France.

Renn, 0., 1999: A model for analytic-deliberative process in risk management. Environmental Science and Technology, 33: 3049-3055.

Reuters, 2009: SA's thin film solar tech at commercial stage. Mail \& Guardian (South Africa), October 13, 2009.

Right Livelihood Award, 2011: The Right Livelihood Award. www.rightlivelihood. org/grameen_shakti.html (accessed May 30, 2011).

Rijssenbeek, W. and I. Togola, 2007: Jatropha Village Power in Garalo, Mali: A New Dimension for People, Planet and Profit Actions. Mali Folk Centre (MFC) Nyetta, Mali.

Rip, A. and R. Kemp, 1996: Towards a Theory of Socio-technical Change. Mimeo University of Twente, Enschede, the Netherlands.

Rip, A. and R. Kemp, 1998: Technological change. In Human Choice and Climate Change: An International Assessment. S. Rayner and E. L. Malone (eds.), Vol. 2, Batelle Press, Washington, DC, USA, pp. 327-400.

Rosenberg, N. and C. Frischtak, 1985: International Technology Transfer: Concepts, Measures, and Comparisons. Praeger, New York, USA.
Saenz, T., 2008: The path to innovation: The Cuban experience. International Journal of Technology Management and Sustainable Development, 7(3): 205-221.

Sandén, B. and C. Azar, 2005: Near-term technology policies for long-term climate targets: Economy-wide versus technology-specific approaches. Energy Policy, 33: 1551-1576.

Sauter, R. and D. Bauknecht, 2009: Distributed generation: Transforming the electricity network. In Energy for the Future: A New Agenda. I. Scrase and G. MacKerron (eds.), Palgrave Macmillan, Basingstoke, UK.

Science Commons, 2011: Patent licenses. Science Commons. sciencecommons.org/ projects/patent-licenses (accessed May 30, 2011).

SENER, 2002: Programa de Investigación y Desarrollo del Sector Energía 2002-2006. Secretaría de Energía de Mexico (SENER), Mexico.

SENER, 2006: Renewable Energies for Mexico's Development. Secretaría de Energía de Mexico (SENER) and Gesellschaft für Internationale Zusammenarbeit (GTZ), Mexico.

SENER, 2007: Diagnóstico de la Situación de Pemex. Secretaría de Energía de Mexico (SENER) and Pemex, Mexico.

Scharpf, F., 1997: Games Real Actors Play: Actor-Centered Institutionalism in Policy Research. Westview Press, Boulder, CO.

Shaffer, G., M. R. Sanchez and B. Rosenberg, 2008: The trials of winning at the WTO: What lies behind Brazil's success. Cornell International Law Journal, 41(2): 383-501.

Sibanda, M., 2009: Intellectual property, commercialization and institutional arrangements at South African publicly financed research institutions. In The Economics of Intellectual Property in South Africa. World Intellectual Property Organization, Geneva, pp. 113-145.

Sinha, K. C., 2003: Sustainability and urban public transportation. Journal of Transportation Engineering, 129(4): 331-341.

Sinja, J., J. Karugia, M. Waithaka, D. Miano, I. Baltenweck, S. Franzel, R. Nyiakal and D. Romney, 2004: Adoption of fodder legumes technology through farmer-to-farmer extension approach. Uganda Journal of Agricultural Sciences, 9: 222-226.

Smil, V. 1994: Energy in World History. Westview Press, Boulder, CO, USA.

Stern, N., 2006: The Economics of Climate Change. The Stern Review, Government of the United Kingdom, His Majesties Treasury, London, UK.

Stewart, F., 1984: Facilitating indigenous technical change in third world countries. In Technological Capability in the Third World. M. Fransman and K. King (eds.), Macmillan, Basingstoke, UK, pp. 81-94.

Storper, M., 1998: Industrial policy for latecomers: Products, conventions and learning. In Latecomers in the Global Economy. M. Storper, T. Thomadakis and L. Tsipouri (eds.), Routledge, London, UK, pp.13-39.

Stoves, 2011: Improved Biomass Cooking Stoves. Global Alliance for Clean Cookstoves. Leslie Cordes, moderator. www.bioenergylists.org (accessed May 30, 2011).

Taweekul, K., J. Caldwell, R. Yamada and A. Fujimoto, 2009: Assessment of the impact of a farmer-to-farmer learning and innovation scaling out process on technology adaptation, farm income and diversification in Northeast Thailand. International Journal of Technology Management and Sustainable Development, 8(2): 129-144.

Taylor, M. G. and D. Collins, 2006: Novel Cements: Low Energy, Low Carbon Cements. British Cement Association (BCA), Fact Sheet 12, May 25, 2006. 
Teece, D., 1988: Technological change and the nature of the firm. In Technical Change and Economic Theory. G. Dosi, C. Freeman, R. Nelson, G. Silverberg and L. Soete (eds.), Pinter, London, UK, pp.256-281.

Teixeira da Sousa, P., E. Dall'Ogllio, M. Sato, J. Marta, A. Brito and C. Spindola, 2008: The ethanol and biodiesel programmes in Brazil. In Making Choices About Hydrogen Transport Issues for Developing Countries. L. Mytelka and G. Boyle (eds.), United Nations University (UNU) Press, Tokyo, Japan, and International Development Research Centre (IDRC), Ottawa, Canada, pp.118-140.

The Economist, 2009: InnoCentive: A market for ideas. The Economist, September 17, 2009. www.economist.com/node/14460185 (accessed May 30, 2011).

The National, 2010: Masdar's vision remains unchanged. The National, October 12, 2010.

The Netherlands, 2008: Instellingsbe sluit Regieorgaan Energietransitie. No.WJZ8015552, February 22, 2008, Regieorgaan-energietransitie-nederland, Minister van Economische Zaken, The Netherlands.

Toke, D., S. Breukers and M. Wolsink, 2008: Wind power deployment outcomes: How can we account for the differences? Renewable and Sustainable Energy Reviews, 12: 1129-1147.

Torres-Montoya, M., 2007: Innovative Public-Private Sector Cooperation in Urban Transport in India. Paper 08-117, World Bank, Washington, DC, USA.

Tripathy, U., P. S. Sandhu and D. C. Prakash, 2008: Turnaround Success Story of Urban Public Transport Undertaking - BMTC. Bangalore Metropolitan Transport Corporation (BMTC), Bangalore, India.

UN AGECC, 2010: Energy for a Sustainable Future: Summary Report and Recommendations. Secretary-General's Advisory Group on Energy and Climate Change (AGECC), United Nations (UN), April 28, 2010, New York, USA.

UNDP, 2004: Reducing Rural Poverty through Increased Access to Energy Services: A Review of the Multifunctional Platform Project in Mali. United Nations Development Programme (UNDP), Bamako, Mali.

UNDP, 2007: Energy and Poverty in Nepal: Challenges and the Way Forward. Regional Energy Programme for Poverty Reduction, United Nations Development Programme (UNDP) Regional Centre, Bangkok, Thailand.

UNDP, 2008a: Capacity Development Practice Note. United Nations Development Programme (UNDP), New York, USA.

UNDP, 2008b: Successfully Implementing, Replicating and Scaling up Rural Energy Programmes: Costs and Financing. Powerpoint presentation, United Nations Development Programme (UNDP), New York, USA.

UNDP, 2009a: Capacity Development: A UNDP Primer. United Nations Development Programme (UNDP), New York, USA.

UNDP, 2009d: Towards Sustainable Production and Use of Resources: Assessing Biofuels. United Nations Development Programme (UNDP), New York, USA.

UNDP, 2010: Le Burkina Faso poursuit sa lute contre la pauvrete. Centre de Press, November 15, 2009.

UNDP, undated: MFP Approach in West Africa Results and Potentials for expanding Access to Modern Energy Services in Burkina Faso, Ghana, Mali and Senegal. United Nations Development Programme (UNDP), New York, USA.

UNDP, GEF, 2008: Promotion of Wind Energy: Lessons Learned from International Experience and UNDP-GEF Projects. United Nations Development Programme (UNDP), New York, USA.

UNDP and UNOPS, 2008: Evaluation of the Ghana Multi-Functional Platform Pilot Project. Evaluation Team: E. Morris, R. King and J. Winiecki. United Nations Development Program (UNDP), New York, USA.
UNEP, 2007: Global Environment Outlook: Environment for Development (GEO4). United Nations Environment Programme (UNEP), Nairobi, Kenya, and New York, USA.

UNEP, 2008: Hot Prospect-Geothermal Electricity set for Rift Valley Lift-Off in 2009. United Nations Environment Programme (UNEP), press release, December 2008. UNEP, 2009: Towards Sustainable Production and Use of Resources: Assessing Biofuels. International Panel for Sustainable Resource Management, United Nations Environment Programme (UNEP), Paris, France.

UNEP Risø Centre, 2011: CDM/JI Pipeline Analysis and Database. United Nations Environment Programme (UNEP) Risø Centre, Roskilde, Denmark. cdmpipeline. org (accessed May 30, 2011).

UNEP and IISD, 2008: Integrated Environmental Assessment Training Manual, 2008. United Nations Environment Programme (UNEP) and International Institute for Sustainable Development (IISD), Winnipeg, Canada.

UNFCCC, 2009: Copenhagen Accord. Report No. FCCC/CP/2009/L.7, United Nations Framework and Convention on Climate Change (UNFCCC), Conference of the Parties, December 7-18, 2009, Copenhagen, Denmark.

UNFCCC, 2011: Report of the Conference of the Parties on Its Sixteenth Session and Addendum Part Two: Action Taken by the Conference of the Parties at Its Sixteenth Session, Contents Decisions adopted by the Conference of the Parties. UNFCCC/CP/2010/7/Add. 1, United Nations Framework and Convention on Climate Change (UNFCCC), November 29-December 10, Cancun, Mexico.

UNIDO, forthcoming: Industrial Development Report. United Nations Industrial Development Organization (UNIDO), New York, USA.

Unruh, G. C., 2000: Understanding carbon lock-in. Energy Policy, 28: 817-830.

UNU, 2010: United Nations University Geothermal Training Programme. United Nations University (UNU). www.unugtp.is (accessed December 12, 2010).

van Asselt, H. and J. Gupta, 2008: Stretching too Far? Developing Countries and the Role of the Flexibility Mechanisms beyond Kyoto. Paper presented to the Conference on Climate Law in Developing Countries Post-2012: North and South Perspectives, September 28, 2008, University of Ottawa, Canada.

van de Vleuten, F., N. Stam and R. van der Plas, 2007: Putting solar home systems into perspective: What lessons are relevant? Energy Policy, 33(3): 1439-1451.

Verbong, G. P. J., F. W. Geels and R. P. J. M. Raven, 2008: Multi-niche analysis of dynamics and policies in Dutch renewable energy innovation journeys (1970-2006): Hype-cycles, closed networks and technology-focused learning. Technology Analysis and Strategic Management, 20(5): 55-73.

WBCSD, 2009: The Cement Sustainability Initiative. World Business Council for Sustainable Development (WBCSD), Geneva, Switzerland.

WBG, 2003: Note to the Informal Board Briefing on Infrastructure. World Bank Group (WBG), February 13, 2003.

Wellcome Trust, 2009: African institutions lead international consortia in $\mathrm{f} 30$ million initiative. Wellcome Trust, press release, July 2, 2009, London, UK.

Westphal, L., L. Kim and C. J. Dahlman, 1985: Reflections on the Republic of Korea's acquisition of technological capability. In N. Rosenberg and C. Frischtak (eds.), International Technology Transfer Concepts, Measures, and Comparisons. Praeger, New York, UK, pp.167-221.

Weterings, R., 2006: Quick scan koplopersloket. Een evaluatie van werkwijze, output en effecten, Competentie Centrum Transities, The Netherlands. 
Wolson, R., 2007: The role of technology transfer offices in building the South African biotechnology sector: An assessment of policies, practices and impact. Journal of Technology Transfer, 32: 343-365.

Wolson, R., 2008: The Evolving Policy Landscape for Technology Transfer from Public Research Organisations in South Africa. Masters Diss., University of Cape Town, South Africa.

Woodman, B., 2006: Ofgem, Innovation and Distributed Generation: Recent Initiatives. BIEE/ UK ERC Academic Conference, September 20-22, 2006, Oxford, UK.

World Bank, 2008: Designing Sustainable Off-Grid Rural Electrification Projects: Principles and Practices. Operational Guidance for World Bank Group Staff, The Energy and Mining Sector Board, Washington, DC, USA.

World Bank, 2009: Energy Strategy Approach Paper. World Bank, Washington, DC, USA.
World Bank and IMF, 2004: Global Monitoring Report: Policies and Actions for Achieving the Millennium Development Goals and Related Outcomes. World Bank and International Monetary Fund (IMF), Washington, DC, USA.

WRI, 2010: Climate Analysis Indicators Tool (CAIT). World Resources Institute (WRI), Washington, DC, USA.

Wroughton, L., 2008:World Bank approves funds for Indian coal-fired plant. Reuters, 8 April 2008.

Young, J., 2008: Impact of research on policy and practice. Capacity.org, 35: 4.

Zhao, J. and X. Zhu, 2004: Private Participation in Small Hydropower Development in China - Comparison with International Communities. UNHYDRO, Beijing.

Zhou, S., X. Zhang and J. Liu, 2009: The trend of small hydropower development in China. Renewable Energy, 34: 1078-1083. 